\title{
UNDERGRADUATE PHYSICS COURSE INNOVATIONS AND THEIR IMPACT ON STUDENT LEARNING
}

by

\author{
HEIDI LOUISE IVERSON
}

B.S., University of California Davis, 2001

M.A., Washington University in St. Louis, 2004

\author{
A thesis submitted to the \\ Faculty of the Graduate School of the \\ University of Colorado in partial fulfillment \\ of the requirement for the degree of \\ Doctor of Philosophy \\ School of Education
}

2011 
This thesis entitled:

Undergraduate Physics Course Innovations and their Impact on Student Learning written by Heidi L. Iverson

has been approved for the School of Education

Dr. Erin Furtak

Dr. Derek Briggs

Dr. Noah Finkelstein

Dr. Valerie Otero

Dr. Maria Ruiz-Primo

The final copy of this thesis has been examined by the signatories, and we Find that both the content and the form meet acceptable presentation standards Of scholarly work in the above mentioned discipline. 
Iverson, Heidi L. (Ph.D., Education)

Undergraduate Physics Course Innovations and their Impact on Student Learning

Thesis directed by Dr. Erin Furtak

\begin{abstract}
Over the last several decades, the efficacy of the traditional lecture-based instructional model for undergraduate physics courses has been challenged. As a result, a large number of reform-oriented instructional innovations have been developed, enacted, and studied in undergraduate physics courses around the globe - all with the intended purpose of improving student learning. This thesis satisfies the need for a comprehensive synthesis of the effectiveness of these course innovations by analyzing: (1) the types of innovations that have been enacted, (2) the impact of these innovations on student learning, and (3) the common features of effective innovations. An exhaustive literature search for studies published after 1990 on undergraduate physics course innovations yielded 432 articles which were then coded with respect to the characteristics of the innovations used as well as the methodological characteristics of the studies. These codes facilitated a descriptive analysis which characterized the features of the pool of studies. These studies were then meta-analyzed in order to evaluate the effect of innovations on student learning. Finally, a case-study analysis was conducted in order to identify the critical characteristics of effective innovations. Results indicate that most innovations focus on introductory mechanics and use some combination of conceptually oriented tasks, collaborative learning, and technology. The overall effect of course innovations has been positive, but with the caveat that a large number of studies suffer from poor methodological designs and potential threats to validity. In addition, over half of the studies had to be eliminated from the metaanalysis because they did not report the data necessary for an effect size to be calculated. Despite these limitations the results of the meta-analysis indicated that there was one innovation which had particularly high effect sizes - Workshop/Studio Physics - an innovation which involves an integrated classroom environment in which there is minimal or no lectures and class time focuses on collaborative student activities involving the use of technology.
\end{abstract}




\section{ACKNOWLEDGMENTS}

I am very grateful for the encouragement and guidance of my advisor, Erin Furtak, who helped me put my thoughts down on paper from the first letter to the last word. Additionally, this work would not have been possible without the guidance, work, and support of Ayita Ruiz-Primo, Derek Briggs, Bud Talbot, and Lorrie Shepard. I would also like to thank Rachel Prosser, Jon Smith, Mike Ross, Kara Gray, Lauren Kost, Deb Morrison, Sue Hopewell, Kristen Pozzoboni, and Mark Lewis for the day-to-day conversations that shaped this work and helped me get past the stumbling blocks. I would also like to thank my friends and family for their encouragement and support - particularly Roger Kroog for his strength, my brother Alex for his humor, and my sister Kelsey for her compassion. Most importantly I would like to thank my wonderful parents, Stan and Louise Iverson. They have been my inspiration for lifelong learning through their own endless curiosity about the natural world and passion for education. 
TABLE OF CONTENTS

Page

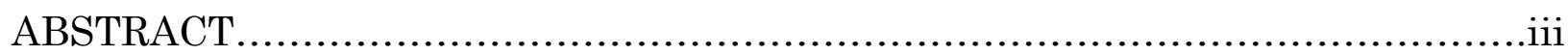

ACKNOWLEDGEMENTS ..............................................................

LIST OF TABLES ................................................................. vii

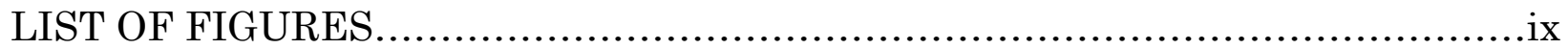

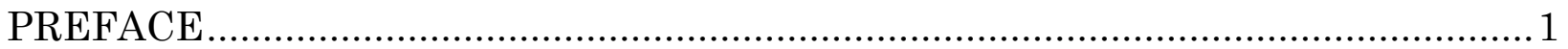

\section{CHAPTER}

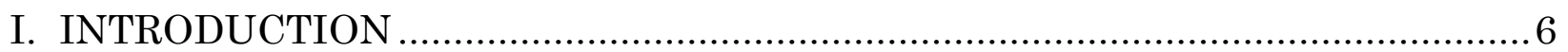

Traditional Instruction and the Impetus for Reform .................................. 6

Characteristics of Reform-Oriented Changes ............................................... 10

The Need for Synthesis ............................................................................ 11

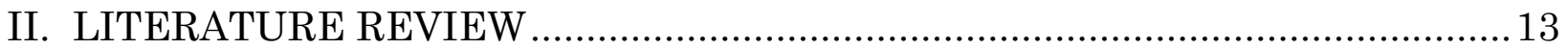

History of Reform in Undergraduate Physics Education ................................ 13

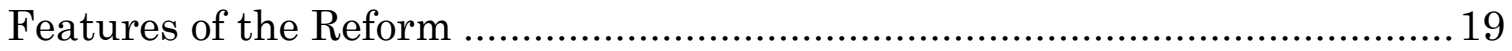

Studies Investigating Student Understanding...................................20

The Development and Implementation of Assessment Instruments ....22

The Development and Evaluation of Curricular and Instructional

Innovations............................................................24

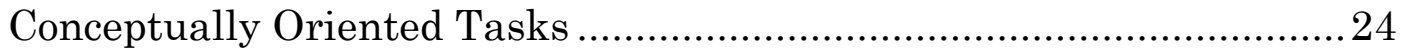

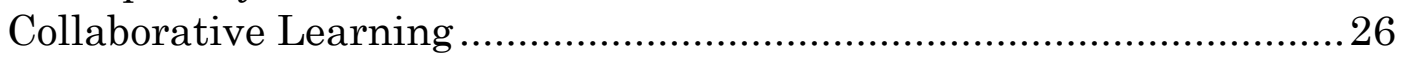

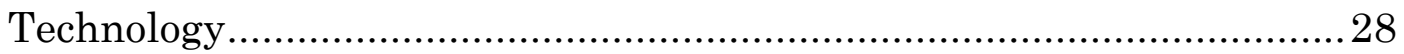

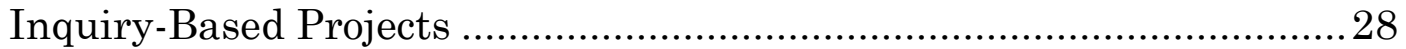

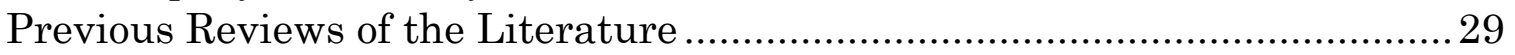

Qualitative Summaries of the Research ................................................ 30

Quantitative Summaries of the Research............................................. 32

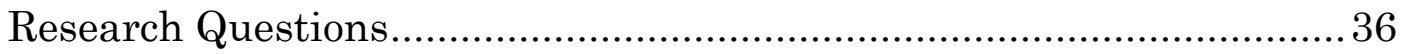

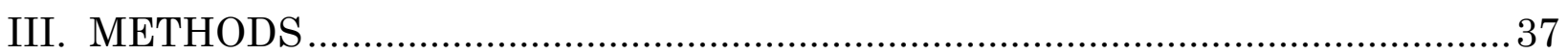

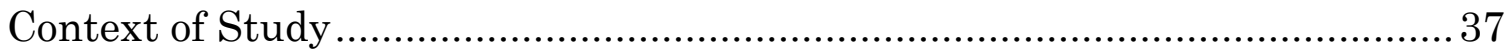

Document Collection Procedures................................................................... 38

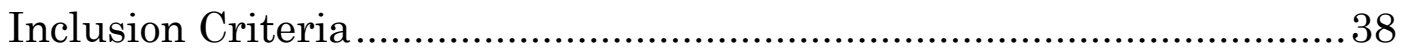

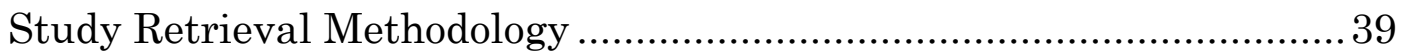

Phase 1 - Word of Mouth Searches .............................................. 42

Phase 2 - Journal Searches and Keyword Validation ................... 44

Phase 3 - Coding Studies by Type............................................... 49

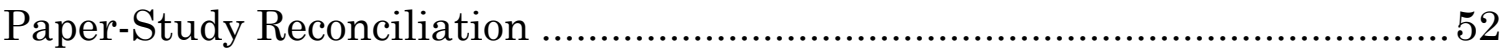

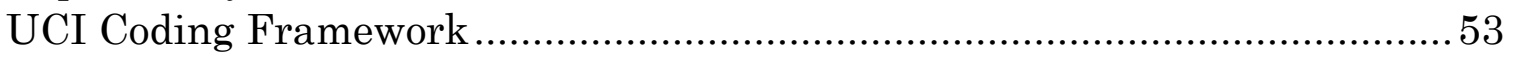

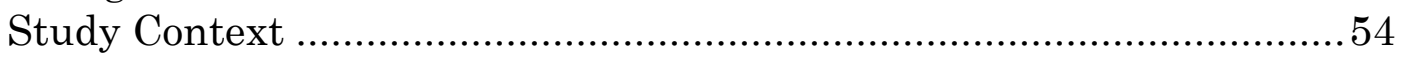




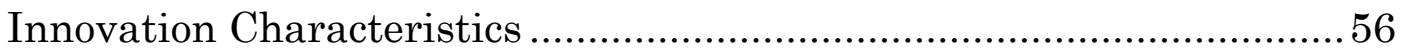

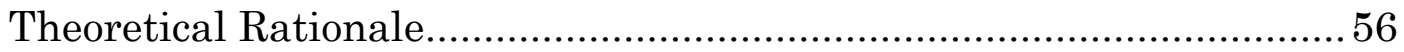

Innovation Type - General Categories .............................................. 56

Conceptually Oriented Tasks.....................................................56

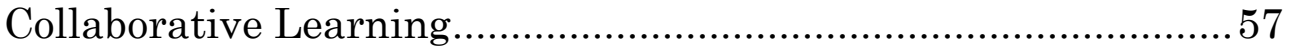

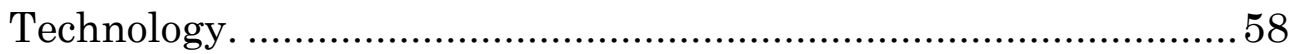

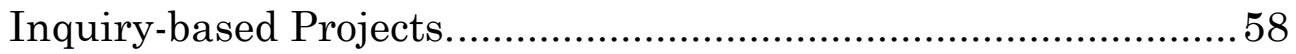

Innovation Type - Known Instructional Innovations .................... 58

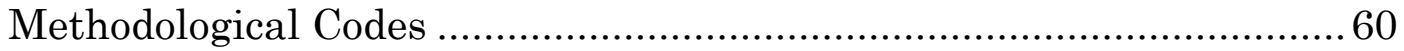

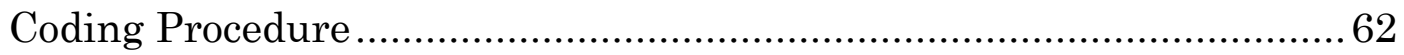

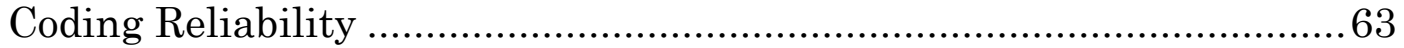

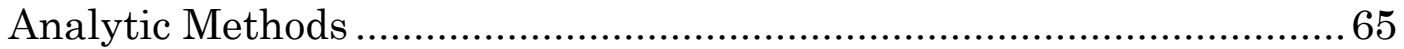

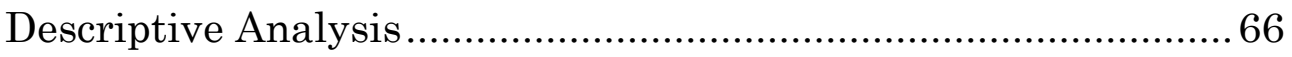

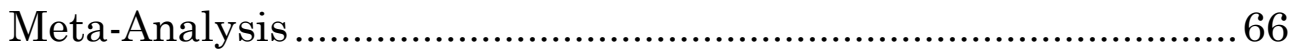

Effect Size Calculation and Estimation................................67

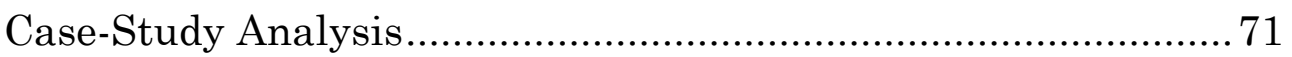

Data Sources ...................................................................... 71

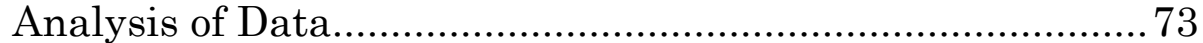

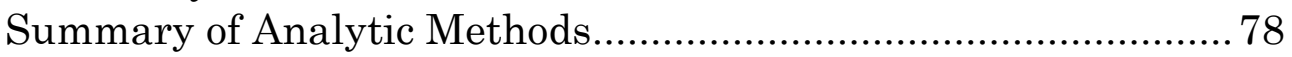

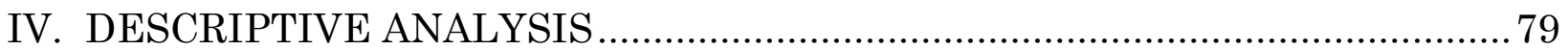

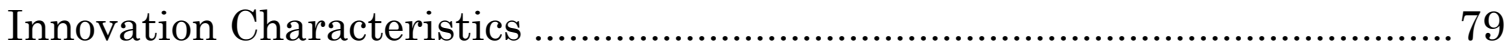

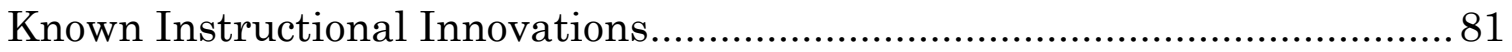

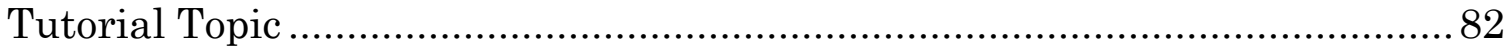

Theoretical and Empirical Basis for Innovation............................................ 84

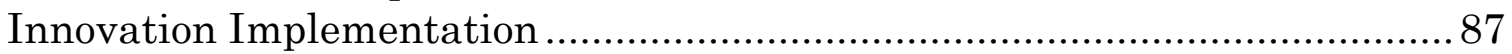

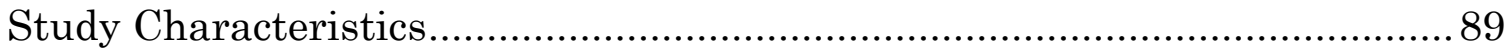

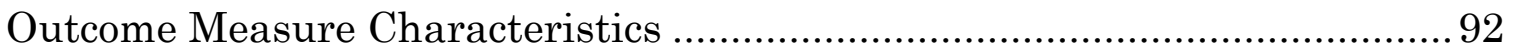

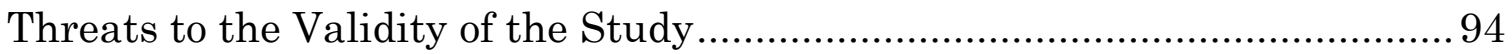

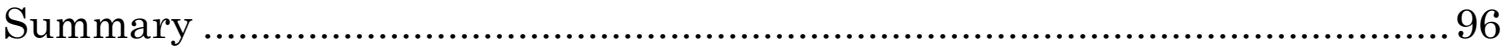

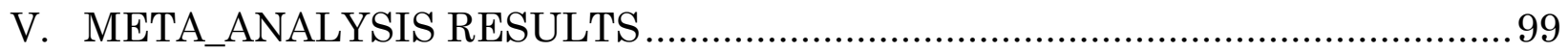

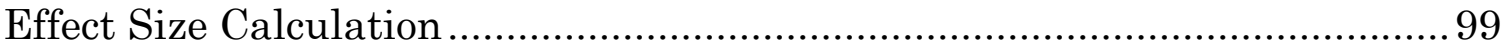

Effect Size Descriptive Statistics.................................................................. 100

Comparison of Results to Previous Quantitative Analysis .................. 102

Variability of Effect Size Distribution ............................................... 102

Accounting for Effect Size Variability ........................................................... 106

Analysis of Methodological Characteristics ........................................107

Study Design Implementation ......................................................... 107

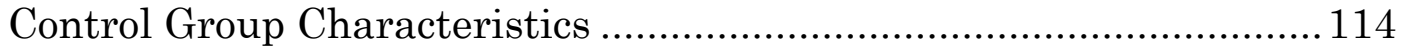

Outcome Measure Characteristics ....................................................115

Summary of Methodological Characteristics ......................................118

Analysis of Innovation Characteristics ...............................................119

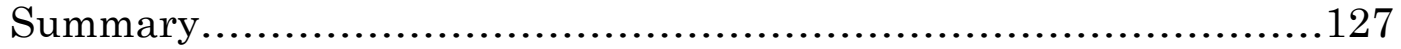


VI. CASE STUDY OF WORKSHOP/STUDIO PHYSICS .....................................129

Overview of Workshop/Studio Physics .......................................................130

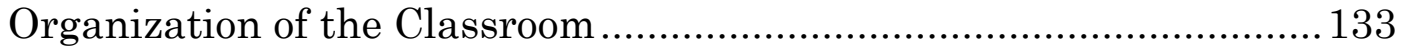

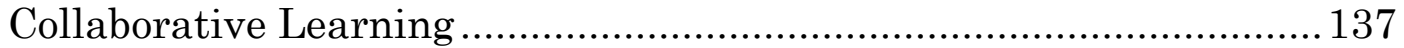

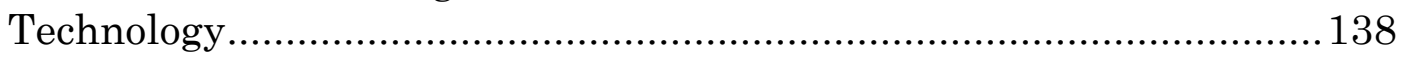

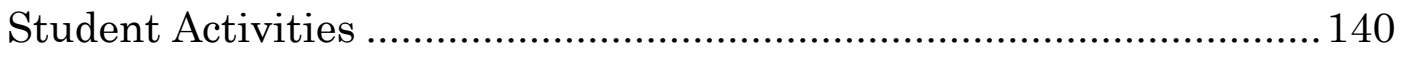

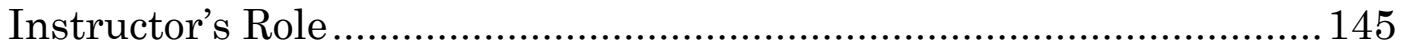

Summary of Critical Characteristics ................................................... 150

Confirming and Disconfirming Evidentiary Analysis ................................. 157

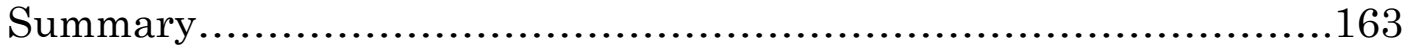

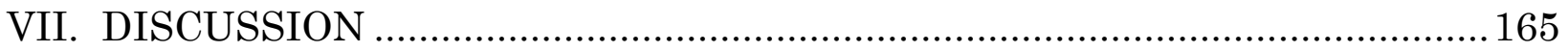

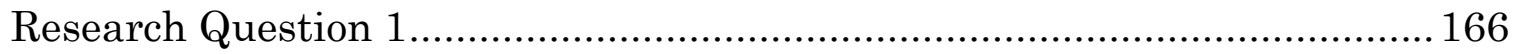

Limitations and Future Work............................................167

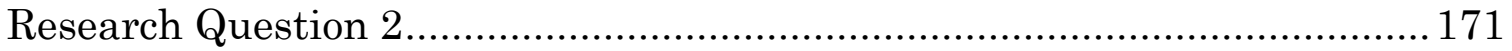

Limitations and Future Work..........................................172

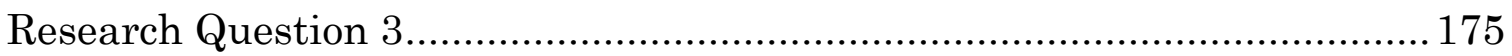

Integrated Classroom Environment................................................176

Research-Based Activities ................................................................ 180

Student Work in Structured Groups................................................... 182

Students Use Technology to Collect Data............................................ 183

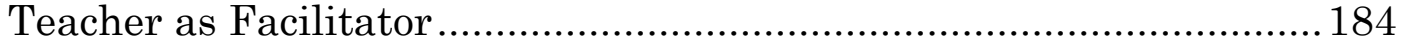

Overall Holistic Impact of Workshop/Studio Physics............................187

Limitations of Case Studv .......................................................... 188

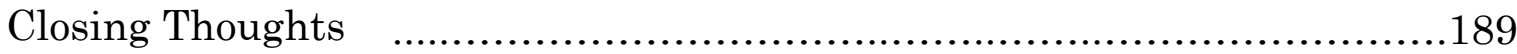

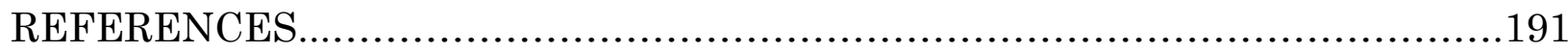

\section{APPENDIX}

A. Letter to Key Researchers....................................................211

B. Reference List of Comparative Studies.........................................212

C. UCI Coding Framework....................................................2220

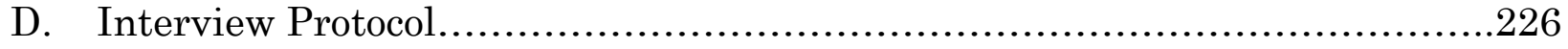

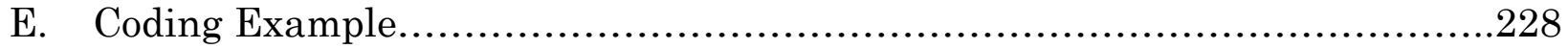


viii

平年

至

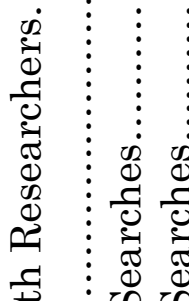

吾

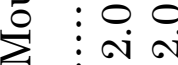

फ

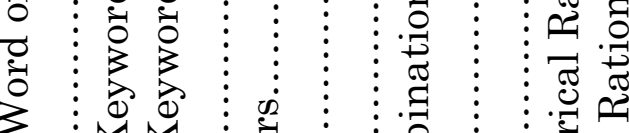

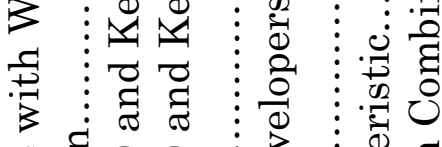

ه

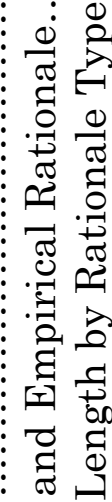

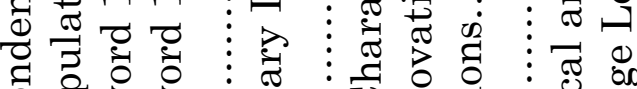

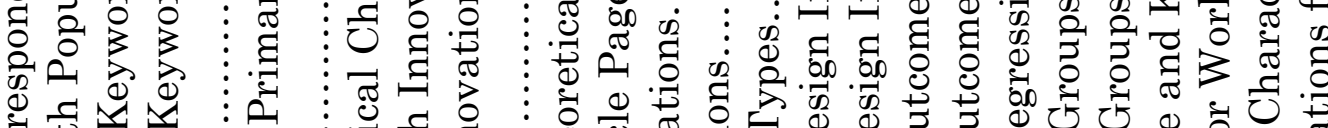

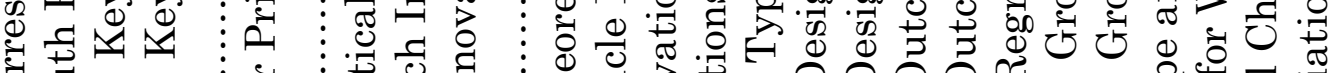

궁ㅇㅇ

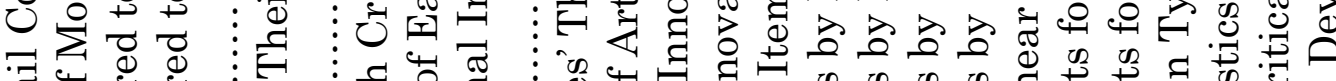
సี घ त्ञ

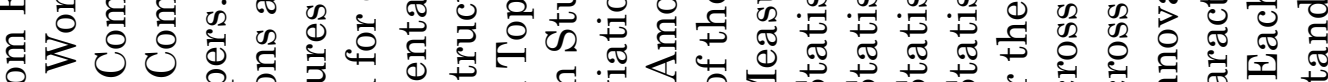
0 थ

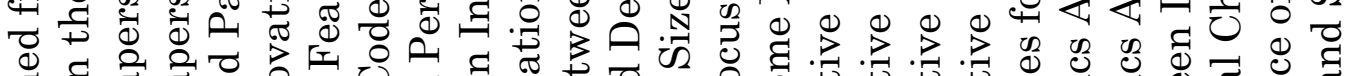
छ. .

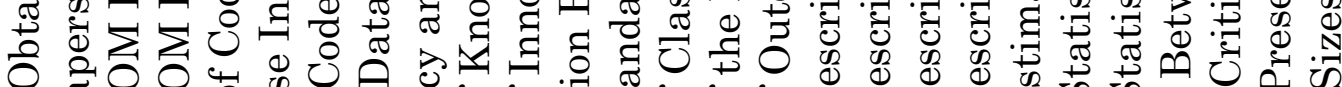

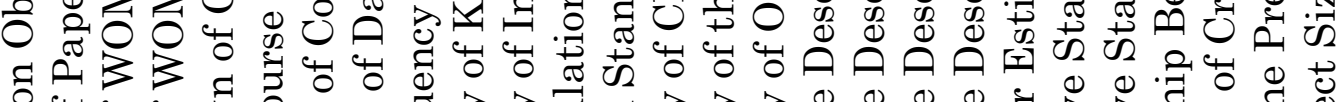
. 땡 फ

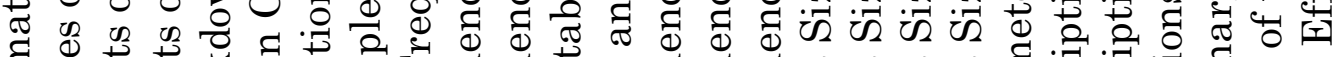

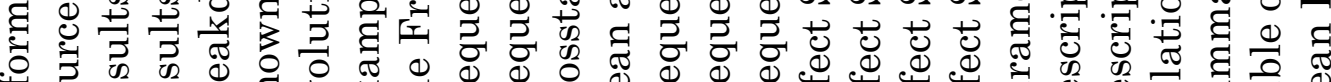

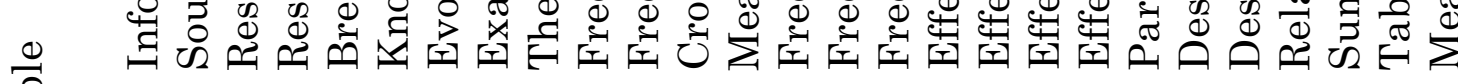
Е 


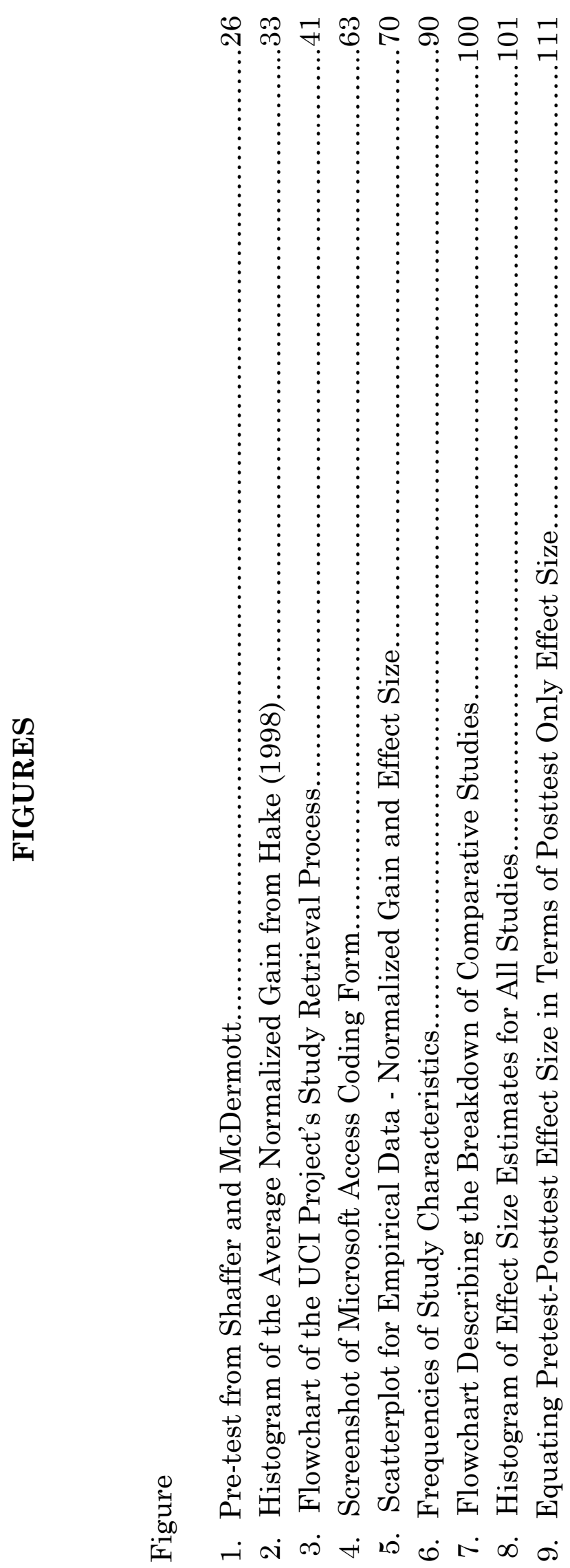




\section{PREFACE}

Consider a day in the life of Sofia, a typical undergraduate physics student. Sofia arrives early to class and finds a seat near the back of an expansive lecture hall. She is surrounded by 250 of her classmates who are all awaiting the arrival of the professor. With the exception of a few murmurs, Sofia and her classmates are sitting in silence. She pulls out her notebook and pencil while others around her are glued to their laptops. Some students have even placed an audio recorder on their desk - preparing to capture any information that they cannot catch through note taking.

Suddenly the professor arrives in haste at the front of the lecture hall. Class begins with several logistical pieces of information from the professor - instructions for the upcoming midterm and subsequent study sessions. Then the lecture commences in the form of a Powerpoint presentation. The professor assures the students that much of the presentation will be repetitive from the reading. As the presentation proceeds the professor clicks though each slide and describes the information. The only voice heard in the room is the professor's. The only exception is the occasionally audible huff of a student in the front row asking the professor to go back to the previous slide so that they can finish copying it all down. As the lecture continues, the fervor of note taking subsides. Sofia glances around and notices that while some students are still paying attention to the lecture most are either checking their email, doodling aimlessly in the margins of their paper, or drifting into a light sleep. As the end of the 50 minute class nears, students begin to 
pack up and a few stand up and leave the class from the back of the room. Eventually the professor ends the class.

The next day Sofia arrives at her assigned recitation session with 30 of her classmates in a much smaller room. Her graduate student instructor arrives and proceeds to work a few problems on the board. Next Sofia and her classmates are instructed to try a few practice problems independently, similar to the ones that were just solved by the graduate student instructor. After about fifteen minutes the graduate instructor tells the students that they may stay and ask questions or they may leave early.

Later that week Sofia arrives at her laboratory session which is taught by a different graduate student. In this 2 -hour class Sofia works with a group of three other students out of a laboratory workbook. After about a half-hour she seems to be a little behind the rest of her group members at answering the workbook questions and in frustration she is compelled to copy their answers instead of ask questions. She feels guilty for asking questions and slowing her group down because she knows that as soon as the work is done they can all leave. In haste, Sofia answers the questions in her lab notebook without feeling the need to understand them. She and her classmates seem only to be worried about making sure the equipment is functioning and that some data, any data, can be collected. Week after week Sofia's experience is the same: lecture, recitation, laboratory, repeat.

Now consider a day in the life of a different undergraduate student, Elinor. On her way to class Elinor walks past the large lecture hall and instead enters a 
smaller classroom where she finds her group members sitting around a large round table. The room is noisy with students getting settled - unzipping backpacks to retrieve notebooks and talking with classmates. The instructor and graduate assistants are circulating around the room answering questions and orienting groups to the activity. Elinor's group members are already getting started on a laboratory activity that has been handed out. The task involves estimating the friction between a book and the table. Her classmates are discussing different methods and debating which equipment may be needed to solve the problem. Elinor shares her idea with the group which is to estimate the initial velocity of the push and then measure the distance it takes for the book to stop. The simplicity of Elinor's idea is well accepted by the group so they begin to discuss how factors will be controlled and estimated in the experiment.

After the activity each group is asked to share their method and results with the other groups in a whole-class discussion. After hearing another groups' presentation Elinor realizes that they have measured static rather than kinetic friction and she brings this to the attention of her other group members. The instructor then asks Elinor to share her ideas with the class and this sparks discussion about the difference between static and kinetic friction.

After a while the instructor suggests that the class move on to the next activity. Elinor is again working with her group on a problem in which they are to estimate how far a bowling ball travels down a lane before it stops skidding and is only rolling. The group discusses how to approach this difficult problem for several 
minutes until the instructor joins in and listens to the conversation. After a few minutes the instructor suggests that the group look at a web-based simulation in order to get a firmer grasp on the problem at hand. Elinor works on the problem a while longer with her group until a graduate student walks over and mentions that class is about to end so they need to logout of the computers and pack up. Elinor glances at her watch in disbelief as she realizes how quickly three hours has passed.

These two vignettes illustrate the starkly different experiences of students in two different kinds of physics courses: one traditional, and one reformed. In the first vignette, Sofia's experience is mainly passive: she takes notes, copies problems, and fills in notebooks. Her experience is typical of many undergraduate students, including myself. However, for an increasing number of students, like Elinor, undergraduate physics education is wholly different. In these reformed courses, student experiences are intended to be more interactive, engaging, and more effective. But have they been more effective in helping students learn?

This dissertation will reveal that indeed they have. Students in reformoriented physics courses, like Elinor, are likely to have an average of $3 / 4$ of a standard deviation higher mean test score than students in traditional classes, like Sofia. This impact is substantially larger than many previous reform-based educational interventions. Clearly, the reforms occurring in many undergraduate physics classrooms are having a tremendous positive impact on student learning. In this thesis I will describe in further detail the types of reforms that have been 
developed and implemented, their impact on student learning, and attempt to describe the features of more and less effective reform-oriented courses. 


\section{CHAPTER I}

\section{INTRODUCTION}

\section{Traditional Instruction and the Impetus for Reform}

The look and feel of undergraduate physics education is undergoing a transformation. As is the case with most efforts to improve education, reform in undergraduate physics education has been the result of dissatisfaction with the traditional model of instruction. While the word "traditional" often just means "what came before," in this case the term is used to describe a very specific style of instruction. The traditional model of physics instruction involves a single professor lecturing to a group of hundreds of students who participate in class in a predominantly passive manner (Austin \& Gilbert, 1973; Heron \& Meltzer, 2005; Reif, 1974).

While this type of instruction is referred to as "traditional", it represents a model of instruction that persists today (DeHaan, 2005). As King (1994) states: "Much of what happens in today's college classrooms is based on the outdated transmission model of teaching and learning: the professor lectures and the students take notes, read the text, memorize the material, and regurgitate it later on an exam" (p. 15). The teacher plays the "central instructional role" and information is passed through "direct oral communication" (Reif, 1974, p. 539). Lillian McDermott (1992) characterizes traditional instruction as follows: 
In recalling how they were inspired by their own experience with introductory physics, many instructors tend to think of students as younger versions of themselves. In actual fact, such a description fits only a very small minority. Most physics instructors are conscientious and have a strong commitment to their subject. They are eager to transmit their knowledge and their enthusiasm to students. . . To save students the trouble of having to go through the same struggles they have experienced, physics instructors often teach from the top down, from the general to the particular. . Very little inductive thinking is involved; the reasoning is almost entirely deductive; the student is not actively engaged in the process of abstraction and generalization (p. 303-304).

In this model students attend lectures in which they listen, take notes, and occasionally ask questions of the professor. Their role in the classroom could be characterized as silent participant. Professors prepare and deliver lectures without much consideration for the individuals in attendance among the rows and rows of seats located behind them in the lecture hall. Instead, their role is to deliver information without much regard for the students who may, or may not, be present in class.

The efficacy of this traditional model of undergraduate physics education has been challenged in the last several decades by empirical research. For example, research has shown that students' common sense ideas about physics concepts persist even after years of traditional instruction (e.g. Clement, 1982; Cohen, Eylon, 
\& Ganiel, 1983; Halloun \& Hestenes, 1985b; McCloskey, Caramazza, \& Green, 1980; McDermott, 1984; Reif, 1986; Trowbridge, \& McDermott, 1980), and that students' knowledge consists mainly of declarative factual information rather than deep conceptual understanding (Arons, 1973, 1974).

One explanation for the pervasive underperformance of students in traditional college physics classes, according to Reif (1974), is that the model is based on outdated assumptions about student learning. Furthermore, Reif argues that it is an artifact of a time when the faculty-student ratio was much smaller, and students could receive the individualized instruction necessary for success. David Hestenes (1979) brought to the attention of the physics education community that there had been a major shift in the field of psychology which had yet to be reflected in instructional practices (Hestenes, 1979); namely, the epistemological shift from behaviorism, epitomized by the work of B.F. Skinner, to cognitive psychology, characterized by the work of Jean Piaget. These advances in cognitive psychology suggested that educational strategies are most effective when focused on the construction, rather than the acquisition, of knowledge (Bransford, Brown, \& Cocking, 2000).

An additional motivator for reform was a national "call to action" from the Carnegie Commission on Higher Education in 1972 (Reif, 1974, The Carnegie Commission on Higher Education, 1972). The Commission's report focused on the need for an "educational revolution" in undergraduate science education. The report called for a shift in the educational norms of colleges and universities; moving away 
from the view that education is just a list of degree requirements and contact-hours, toward an increased focus on educational endeavors with the same amount of energy, investment, and rigor as any other mission of the university. This involved encouraging faculty members to develop, implement, and evaluate innovative approaches to college teaching. It also required a shift in the general perception that educational endeavors do not attract first-rate talent, and are not highly regarded or valued at the university.

Professional scientists were also a motivational factor for the reform.

Scientists began to raise questions about the preparation students were receiving at the university. The growing need for professionals to be able to think and work in an interdisciplinary manner, take advantage of innovative technologies, and work collaboratively called into question whether the traditional model of instruction was instilling these qualities in students (Hestenes, 1979; Reif, 1974).

In summary, the major motivational factors for change in undergraduate physics education included the pervasive underperformance of students under traditional instruction combined with the advances occurring in the field of cognitive psychology, a national "call to action" for change at the undergraduate level, and a major shift within the industry of science. The next section describes these changes. 


\section{Characteristics of Reform-Oriented Changes}

In an attempt to improve upon the education of undergraduate physics students, universities across the globe have developed, implemented, and evaluated a large number of reform-oriented instructional and curricular changes, impacting hundreds of thousands of students. These changes work to engage students in the learning process and help them take a more active role in their own learning. They are characterized by a "student-centered approach, as opposed to the teachercentered approach" (Hestenes, 1979, p. 242, emphasis in original) to education, as well as their "aims to get the student actively engaged in working with the subject matter, rather than passively hearing about it" (p. 242). The changes involve moving away from lecturing as the main or central instructional strategy, shifting the focus from the professor (instructor) towards the student, and supporting shared collaboration. The major premise underlying course changes is that they have been developed with the intention of better facilitating student learning (Ruiz-Primo, Briggs, \& Shepard, 2006).

In this thesis, the term innovation will be used to describe the range of reform-oriented instructional and curricular changes that have occurred in undergraduate physics education. This term not only encompasses diverse types of instructional strategies, but it is used within the undergraduate physics education research community and is not associated with any specific strategy. 


\section{The Need for Synthesis}

Over the last several decades, the National Science Foundation (NSF) has provided support for course innovations through various divisions of its Directorate for Education and Human Resources with the hope that these transformations would help to improve the science human resources in the country (Suter \& Narayanan, 2006). As a result of this funding and the growing interests of the undergraduate physics education research community, a great deal of empirical research has accumulated particularly after an increase in NSF funding in 1991 (Heron \& Meltzer, 2005; McDermott \& Redish, 1999; Suter \& Narayanan, 2006).

Despite this boom in research studies on undergraduate physics course innovations, no systematic attempts have been made to describe the differential effects of these innovations, and the characteristics of more and less effective innovations. Although there have been several published summaries of the undergraduate physics education research innovations, these approaches have either been primarily qualitative in nature (making no attempt to synthesize effect estimates across studies, e.g. Dancy \& Henderson, 2007; McDermott \& Redish, 1999) or they have not attempted to differentiate between different types of innovations (Beichner, Saul, Abbott, Morse, Deardorff, Allain, Bonham, Dancy, and Risley, 2007; Crouch, Watkins, Fagen, \& Mazur, 2007; Crouch \& Mazur, 2001; Fagen, Crouch, \& Mazur, 2002; Hake, 1998). The issue is that the broad diversity of instructional changes is likely mirrored by the high degree of variability in their effect on student learning (Hake, 1998).Therefore a systematic synthesis of research 
studies on course innovations is needed in order to build a theory of what works in undergraduate physics education.

This thesis satisfies the need for a rigorous quantitative synthesis of the vast amount of instructional innovations that have been developed, enacted, and evaluated, and investigates the effect of these innovations on student learning. To conduct this synthesis, the research described in this synthesis began with an exhaustive search of the research literature for papers that evaluated an instructional innovation, followed by an analysis of these papers through three approaches. First, the range of undergraduate physics course innovations that have been implemented and evaluated were characterized through a descriptive analysis. This involved frequency counts of the different characteristics of course innovations as well as the methodological features of the evaluation of these innovations. Second, a meta-analytic approach was used to investigate the effect that these innovations have had on student learning. In this approach, similar innovations were grouped together in order to understand which characteristics of innovations seem to be more, or less, effective at impacting student learning. Lastly, a case study analysis was used to investigate the critical features of highly effective innovations. This research provides a synthesis of what has been done, what has been effective, and characterizes some aspects of effective innovations which have been enacted and evaluated in undergraduate physics education. 


\section{CHAPTER II}

\section{LITERATURE REVIEW}

To place the studies explored in this thesis in context, this chapter will provide an overview of the history of the reforms in physics education. The sections that follow include an overview of the reform, including the motivation for the reform and specific features of the reform, as well as a discussion of previous syntheses of this research.

\section{History of Reform in Undergraduate Physics Education}

The history of educational reforms at the elementary and secondary levels has been well documented. Scholars of the history of science education (e.g. Atkin \& Black, 2003; Bybee, 1997; DeBoer, 1991; Rudolph, 2002) have characterized the cycles of reform that have dominated public education in America since the nineteenth century - for example: the Progressive era at the turn of the twentieth century, the post-Sputnik science education reform that accompanied the Cold War, and the standards movement that accompanied the publication of $A$ Nation at Risk (National Commission on Excellence in Education, 1983).

While science education at the elementary and secondary levels has undergone several cycles of reform, science education at the postsecondary level has remained relatively unchanged during this period of time. Even amidst the postSputnik period of significant educational reform, in which university professors 
played a significant role (Bybee, 1997; DeBoer, 1991; Rudolph, 2002), undergraduate physics instruction continued largely unaffected (McDermott, 1991). This is not to say that there weren't small-scale reform-oriented initiatives, orchestrated by singular individuals, which had taken place over this period of time. For example, in 1903, Robert Millikan was motivated by his dissatisfaction with "traditional" physics instruction and developed a more holistic approach to his course (Laws, 1997; Redish, 1999), which he describes in the following quote:

I had become thoroughly disillusioned by the ineffectiveness of the large general lecture courses of which I had seen so much of in Europe and also in Columbia, and felt that a collegiate course in which laboratory problems and assigned quiz problems carried the thread of the course could be made to yield much better training, at least in physics...I started with the idea of making the whole course self-contained...I abolished the general lectures...This general method of teaching...has been followed in all the courses with which I have been in any way connected since. (Laws, 1997, p.

One of his overarching goals was "teaching introductory physics courses without lectures" (quoted in Laws, 1997, p. 14).

Disillusion with large impersonal physics lecture classes is also reflected in the work of several other authors. For example, Fred Keller developed a method of individualized instruction for physics students in the 1960s which was popularized and replicated at universities well into the 1970s. In this approach, students 
worked at their own pace through the text and study guides and needed to demonstrate mastery of the material via unit exams before moving on to the next unit (Austin \& Gilbert, 1973; Green, 1971; Keller, 1968). This style of instruction was based on the argument that students in large lecture classes are forced to learn the material at a pace that may not suit them, and that individualized or "selfpaced study" (Green, 1971, p. 765) is a more favorable approach to instruction. David Hestenes touted the benefits of a Personalized System of Instruction (PSI), like that developed by Keller (1968), stating: "The strength of PSI is its studentcentered approach, as opposed to the teacher-centered approach" (1979, p. 242).

While there were a number of other reform-oriented instructional approaches during the 1960s and 1970s, these two examples represent the minority that involved an overhaul of the total instructional model. In contrast, the large majority of reform-oriented instructional approaches during this time centered on changes that were interesting to the instructor and fit within the overall lecture centered instructional model (Green, 1971). For example, these early reform-oriented instructional approaches typically included:

an early apparatus to demonstrate conservation of angular momentum, a cheaply producible accelerometer, a beautiful film showing example of geometrical symmetry, a way to draw Lissajous figures with sand, and, on the theoretical side, a simpler way to derive a difficult result. (Green, 1971, p. 764-765) 
However, as Green (1971) summarizes, these reform-oriented instructional approaches neglected to take into account - or prioritize - the needs and interests of the students. In contrast, the reform-oriented instructional approaches developed by Robert Millikan and Fred Keller place an emphasis on moving away from the lecture as the primary instructional strategy. Thus, their work marks a distinct shift in the history of reform in undergraduate physics education.

The shift that occurred among reform efforts in the 1960s and 1970s is illustrative of the advances that were taking place in the field of cognitive psychology, predominantly as a result of the work of Jean Piaget. The influence of Piagetian theory on undergraduate physics education research can be traced back to a workshop at the American Association of Physics Teachers in 1975 (Hestenes, 1979). This workshop illuminated several key ideas within Piagetian theory regarding how students learn: namely, that students must be provided with sufficient time to "grapple mentally" with the material "without being told the answer" and "be allowed to put their ideas together for themselves" (Fuller, Karplus, Lawson, 1977, p. 28). The work of Piaget provided a theoretical basis for the incipient reform-oriented instructional approaches being developed in undergraduate physics education, i.e. a basis for why instructional approaches that focus more on the student and move away from lecturing as the primary instructional strategy are more effective.

In addition to theoretical advances, empirical evidence was fueling the fire for reform as well. A large number of research studies in the 1980s began to investigate 
student understanding of physics concepts in an in-depth manner, predominantly due to the influence of cognitive psychology on education (see Trowbridge \& McDermott, 1980). These studies were typified by a general model: (1) the researchers developed and implemented a series of conceptual questions on a specific topic in physics, (2) a sample of students with various amounts of education in physics were selected, (3) student responses were gathered through both written and verbal response via an interview, and (4) responses were analyzed and usually revealed that a high percentage of students, regardless of the number of years they had studied traditional physics, were not able to convey understanding of presumably "simple and fundamental" concepts (See Clement, 1982; Cohen, Eylon, \& Ganiel, 1983; Halloun \& Hestenes, 1985a\&b; McClosky, Caramazza, \& Green, 1980; McDermott, 1984; Reif, 1986; Trowbridge \& McDermott, 1980). These studies ended with recommendations for how this information might be incorporated into educational practice, such as areas that instructors may do well to spend more time on or at least acknowledge that their assumptions about what students know and can do in these areas may not be accurate. These studies provided evidence that students' understanding of physics consisted mainly of factual information rather than deep conceptual knowledge, and that students' misunderstanding of the subject persisted even after many years of traditional instruction.

Clearly, traditional physics instruction had been allowing students to succeed without a deep understanding of the subject. As Arnold Arons described, 
purely verbal presentation - lecturing at large groups of students who passively expect to absorb ideas that actually demand intense deductive and inductive mental activity coupled with personal observation and experience leaves virtually nothing permanent or significant in the student mind (p. 771).

This dissatisfaction with traditional instruction paved the way for instructors and researchers to begin to consider alternative methods of instruction; that is, reformoriented instructional approaches.

At nearly the same time that instructors and researchers in physics departments at colleges and universities began to consider alternative instructional methods, various high-level committees and funding agencies began to consider their role in this reform effort as well. Changes in the social demands of professional scientists began to raise questions about the preparation students were receiving at the university. The growing need for professionals to be able to think and work in an interdisciplinary manner, take advantage of innovative technologies, and work collaboratively called into question whether the traditional model of instruction was instilling these qualities in students (Hestenes, 1979; Reif, 1974; see also DeHaan, 2005 for a modern take on this argument). The Carnegie Commission on Higher Education published a report in 1972 on the need for an "educational revolution" in undergraduate science education (The Carnegie Commission on Higher Education, 1972). This report called for a shift in the way education had been viewed collectively by institutions of higher education: from 
"reasonable adequacy" to "excellence" and "innovative leadership" (Reif, 1974, p. 537; see also Hestenes, 1979). In addition the National Science Foundation (NSF) began in 1991 to increase support for research projects that sought to reconceptualize the delivery of undergraduate science instruction (Suter \& Narayanan, 2006). This funding from the NSF, the National Science Resource Center, the National Science Teachers Association, and the National Institutes of Health, among others, paved the way for the subsequent boom in research on the development and enactment of reform-oriented instructional approaches (DeHaan, 2005).

\section{Features of the Reform}

The reform efforts that have taken place in undergraduate physics education have been broad and diverse, with research groups located at colleges and universities worldwide (Beichner, 2009). In their Resource Letter on Physics Education Research, McDermott \& Redish (1999) identified three themes among these reforms: (1) investigations into the nature of student understanding, (2) the development and implementation of assessment instruments, and (3) the development and evaluation of reform-oriented instructional approaches, which are referred to here as innovations. These categories are not mutually exclusive; many involve two of more of these themes. In the following sections, each of the themes will be described in more detail 
Studies Investigating Student Understanding

Lillian McDermott and her research group at the University of Washington were among the first physicists to conduct research into the nature of student understanding. This research focused on the identification of conceptual difficulties, often called "misconceptions" or "naïve conceptions," that students have within a specific content area. In these studies, carefully designed questions and situations are presented to students which "elicit" any underlying ideas and assumptions which may be hindering the learning process (Ambrose, Shaffer, Steinberg, McDermott, 1999; Heron, Loverude, Shaffer, \& McDermott, 2003; McDermott \& Shaffer, 1992; Trowbridge \& McDermott, 1980; Vokos, Shaffer, Ambrose, McDermott, 2000; Wosilait, Heron, Shaffer, McDermott, 1999).

Research investigating student understanding has since come to include a variety of conceptual domains of physics. For example, Goldberg \& Anderson (1989) investigated student understanding of the concept of negative velocity, Fredette \& Lochhead (1980) looked at students' responses to the task of connecting a battery, bulb, and wire such that the bulb lights, Wittmann, Steinberg, \& Redish (1999) investigated student understanding of mechanical waves, and Johnson, Crawford, \& Fletcher (1989) investigated student understanding of quantum mechanics.

Other studies on student understanding included work on students' problemsolving abilities. Chi, Feltovich, and Glaser (1981) investigated differences in the way that experts and novices approach solving physics problems. This work showed 
that novices focus on the surface features of a problem when attempting to solve it rather than the underlying physics concepts involves. For example, when shown two problems involving an inclined plane, one in which the solution involves Newton's Law and another that involves energy, the novice classified both as "an inclined plane problem" while the expert classified them based on the underlying concepts involved. Heller \& Hollabaugh (1992) showed that novices tend to dive right into the problem without much thought for the underlying concepts. Instead, novices tend to work on finding and manipulating equations, plugging in variables, and when they arrive at a numerical solution of any kind they are satisfied and do not check to see that their answer makes sense or consider alternative solutions. Other work on the difference between experts' and novices' problem-solving abilities and strategies includes the work of Hardiman, Dufresne, \& Mestre (1989), and Larkin \& Reif (1979).

Additional research has investigated students' attitudes and beliefs about learning physics. Hammer (1989) performed a case-study analysis of two students who had very different perceptions of what it meant to learn physics. One student's perceptions were consistent with the traditional learning style of the class, while the other student's perceptions were not, and eventually this student adopted a belief consistent with "what everybody else" was doing in order to succeed in the class (Hammer, 1989, p. 668). In later work, Hammer (1994) developed a framework based on extensive student interviews that classified students' beliefs in one of two ways on three different dimensions. The framework consisted of: 
1. Beliefs about the structure of physics knowledge as

a. a collection of isolated pieces or,

b. a single coherent system.

2. Beliefs about the content of physics knowledge as

a. formulas or,

b. concepts that underlie the formulas.

3. Beliefs about learning physics, whether it means

a. receiving information or,

b. involves an active process of reconstructing one's understanding (Hammer, 1994, 151).

More recent work on students' attitudes and beliefs focuses on the assessment of these variables. This work is described in the next section.

The Development and Implementation of Assessment Instruments

The development and use of innovative assessment instruments have driven aspects of the reform in undergraduate physics education. One of the most wellknown and influential reform-oriented assessments is the Force Concept Inventory (FCI), developed by Hestenes, Wells, and Swakhammer (1992) and based on dissertation research by Halloun (Halloun \& Hestenes, 1985a, b). This multiplechoice assessment was informed by students' ideas about Newtonian mechanics (Beichner, 2009). The tasks on the FCI include predicting the motion of a cannonball when fired off a cliff, and identifying the forces acting on a book lying on 
a table. Despite appearances, however, college students under traditional instruction have historically performed poorly on the assessment even after instruction. One of the more famous examples of this phenomenon is recounted in Eric Mazur's book Peer Instruction (Mazur, 1999), in which his Harvard physics students were able to successfully answer what he believed to be computationally difficult physics problems and yet were not able to correctly answer the conceptual, and seeming simplistic, questions on the FCI.

Other multiple-choice assessments targeted at students' conceptual knowledge within the broad topic of mechanics include the Mechanics Baseline Test (MBT) (Hestenes \& Wells, 1992), the Test of Understanding Graphs in Kinematics (TUG-K) (Beichner, 1994), and the Force and Motion Conceptual Evaluation (FMCE) (Thornton \& Sokoloff, 1998). Other assessments of note include the Brief Electricity and Magnetism Assessment (BEMA) (Ding, Chabay, Sherwood, \& Beichner, 2006), and the Quantum Mechanics Conceptual Survey (QMCS) (McKagan, Perkins, \& Wieman, 2010). The use of these well-known assessments has highlighted the deficiencies of traditional instruction on student learning. Assessments have also been developed that investigate other aspects of student understanding besides cognition. For example, several assessments have been developed for the purpose of evaluating students' attitudes and beliefs about learning physics. Of note are the Epistemological Beliefs Assessment for Physical Sciences (EBAPS) (Elby, Frederiksen, Schwarz, \& White, 1997), the Maryland Physics Expectations Survey (MPEX) (Redish, Steinberg, \& Saul, 1997), the Views 
About Science Survey (VASS) (Halloun \&Hestenes, 1996), and the Colorado

Learning Attitudes Science Survey (CLASS) (Adams, Perkins, Podolefsky, Dubson, Finkelstein, \& Wieman, 2006).

The Development and Evaluation of Curricular and Instructional Innovations

The largest category of research involves the development, and often the evaluation, of a curricular and/or instructional innovation targeted at improving the effectiveness of undergraduate physics education. The development of these innovations is often based on previous research on student understanding and/or the types of reform-based assessments described in sections above. Studies on the use of innovations represent the body of work that is of interest in this thesis.

There are four main types of innovations that have emerged through the work of this thesis: those which involve conceptually oriented-tasks, collaborative learning, technology, and inquiry-based projects. These different innovation types are used either alone or, more commonly, in combination with each other. The sections below will describe these four categories in greater detail.

\section{Conceptually Oriented Tasks}

Innovations using conceptually oriented tasks involve questions, activities, problems, and laboratory exercises that focus on the conceptual aspects of physics, rather than the computational and mathematical representations of physics. Conceptually oriented tasks are often designed to elicit students' deep conceptual 
understanding about a key physics topic. Many of these tasks are designed to identify any common "misconceptions" or misapplied ideas that the students may be relying on (Beichner, 2009). Conceptually oriented tasks also include activities that center on a real-world problem which serves as a platform for students to engage with physics content in a way that may be more meaningful to them. While these tasks may involve some computational components, the focus of the activity is on understanding the central concept in which a mathematical representation may be applicable. The role of problem-solving in conceptually oriented tasks involves helping students with problem solving strategies such as problem representation and the identification of physics principles which are central to solving the problem.

Conceptually oriented tasks are typified in the literature by Tutorials (e.g. McDermott, Shaffer, \& Somers, 1994) which were developed by Lillian McDermott and researchers at the University of Washington. In Tutorial activities, students work on conceptual problems which have been developed based on common student misconceptions. Students are often prompted to express their initial ideas, discuss them with peers, and revise them accordingly. This procedure is often summarized as: elicit, confront, resolve. In these activities students' ideas are often elicited through a pre-test, and then their ideas are confronted and resolved through a tutorial activity involving some discrepant event.

An example tutorial activity comes from Shaffer and McDermott (1992). In the activity students are given a pre-test on the brightness of light bulbs connected in parallel versus those in series. Figure 1 shows the pre-test task. 

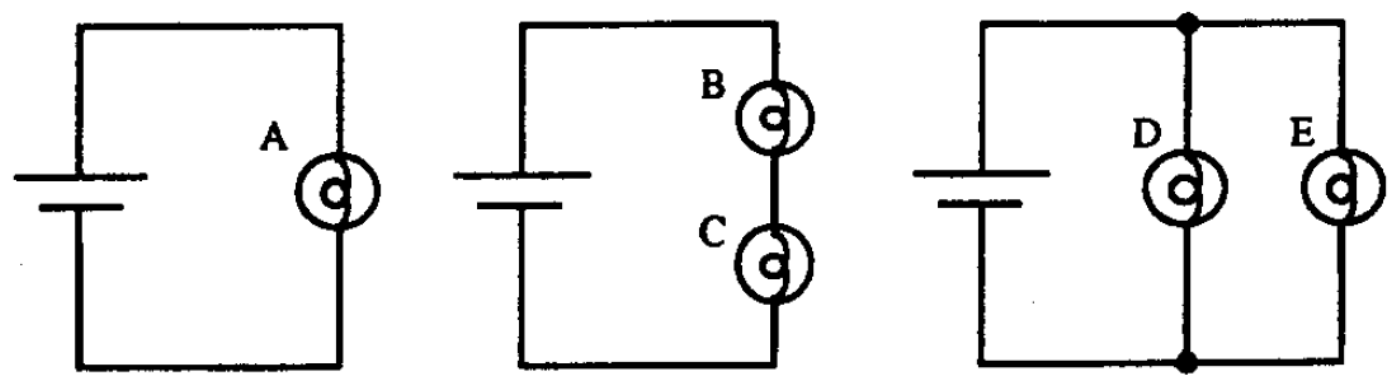

Figure 1. Pre-test from Shaffer and McDermott (1992, p. 1005). Students are asked to rank by brightness the five identical bulbs in the circuits shown and to explain their reasoning. They are told to assume that the batteries are ideal. The correct response is $\mathrm{A}=\mathrm{D}=\mathrm{E}>\mathrm{B}=\mathrm{C}$.

Some students may predict that bulb $\mathrm{C}$ will not be as bright as bulb B. This represents a misapplied idea among introductory students; namely, that some of the current from the battery is "used up" by the first bulb such that the second bulb will not be as bright. Other students may predict that bulb A will be brighter than bulbs $\mathrm{D}$ and $\mathrm{E}$. This represents a misapplied idea that the current through a battery is constant and does not depend on the configuration of the circuit. Next, student "misconceptions" are confronted when they are given the materials to test their predictions and discuss with classmates.

\section{Collaborative Learning}

Innovations which use collaborative learning involve activities where students are required or encouraged to engage with their classmates regarding course work. Some of the purposes of collaborative learning include allowing students to express, explore, and defend their ideas in a low-stakes environment 
(Heller, Keith, \& Anderson, 1992; Lenaerts, Wieme, \& Zele, 2003), allowing students to reason through their own ideas in order to integrate their prior knowledge with new information (Singh, 2005), and helping students to stay alert during class time (Crouch \& Mazur, 2001; Mazur, 1999). Collaborative learning may involve students working as a team to gather, interpret, and analyze data in a laboratory activity. In other situations collaborative learning involves discussion among two or more students in which ideas are shared along with explanations, interpretations, and solutions, among other things.

An example of an instructional innovation involving collaborative learning is Cooperative Group Problem Solving (e.g. Heller, Keith, \& Anderson, 1992). This innovation involves students working in groups on a complicated problem. The groups have been carefully designed in order to "optimize" the functionality of the group (p. 640). For example Heller, Keith, and Anderson (1992) report that groups of three students which are heterogeneous with respect to ability and gender are the most effective. In addition, the specification and adoption of roles by each group member keep the groups functioning effectively.

An additional example of collaborative learning is Peer Instruction (Mazur, 1999). In this innovation students are provided with a conceptual problem and asked to first answer it on their own. Once students have an answer they are polled for their response and the instructor tallies the results through the use of electronic clickers or by counting or estimating frequencies with a show of hands. Then 
students are instructed to discuss their answers with one or two students seated around them. After this discussion student responses are polled and tallied again.

\section{Technology}

Innovations using technology involve 3 -D visualizations of phenomena such as small-scale visualizations of electromagnetic interactions (see Dori, Hult, Breslow, Belcher, 2007), large-scale models of the universe (see Hansen, Barnett, MaKinster, \& Keating, 2004), and complex mechanistic systems (Hung \& Jonassen, 2006). Other uses of technology include simulations where students are allowed to manipulate systems to answer questions and explore physics phenomena (see Finkelstein, Adams, Keller, Kohl, Perkins, Podolefsky, Reid, \& LeMaster, 2005). Additional uses of technology include the use of clickers, which were described above (Mazur, 1999). Lastly, technology can be used to provide feedback to students. One approach to this is through the use of clickers (Mazur, 1999) and another is with online homework programs (Bonham, Deardorff, \& Beichner, 2003) which assess student work immediately and provide feedback and hints, as well as allow instructors to easily collect student data and respond with feedback or instructional changes.

\section{Inquiry-Based Projects}

Inquiry-based projects involve activities which span the course of several class days (Bransford, Brown, \& Cocking, 2000). They provide students with an 
opportunity to engage in a research project which may include the development of a procedure or plan, collection of data, and/or analysis. Some inquiry-based activities require that the student is responsible for developing each part of the research, or alternatively some inquiry-based projects provide some of the aspects of the research (for example the procedure) for the students. Similar to problem-solving activities, this type of innovation involves an overarching problem to be solved which takes the form of an on-going project.

One approach to inquiry-based projects in undergraduate physics education research is the Investigative Science Learning Environment (ISLE; Etkina, Murthy, \& Zou, 2006). Using complex real-world problems as the basis for collaborative, investigative activities, ISLE generally presents a problem with little or no formal instruction and students are expected to devise an investigative procedure, collect any necessary data, and perform any analysis needed to solve the problem.

\section{Previous Reviews of the Literature}

The large body of literature on course innovations in undergraduate physics education naturally gives rise to questions about the effect these various innovations have on student learning, and whether or not these innovations are in fact better than traditional approaches to undergraduate physics education. Previous authors have synthesized the body of undergraduate course innovations in terms of the qualitative differences between studies, or in terms of the quantitative differences in their effectiveness. While this research has illuminated some key 
findings, the methods in which they have been carried out have not allowed for the effect of different innovations to be compared. This information is central to the task of understanding what has been done, what has been effective, and what future innovations should look like in order to best serve the needs of students.

Qualitative Summaries of the Research

Several researchers have approached summarizing the body of empirical research studies by forming sub-groups of innovations. For example, in their Resource Letter in the American Journal of Physics, Lillian McDermott and Joe Redish (1999) provide descriptions of empirical research studies with respect to the content area in which they were conducted: mechanics, electricity and magnetism, light and optics, properties of matter, waves and sound, and modern physics.

Other qualitative syntheses of the literature involve grouping studies according to more specific aspects of the innovation. For example, Melissa Dancy and Charles Henderson (2007) developed a framework for evaluating the degree to which classroom activities were more or less "interactive" for students. They evaluated several common undergraduate physics education research innovations with respect to their framework and provided a narrative synthesis of how these common undergraduate physics education research innovations compared to each other across different criteria within their framework.

Lastly, the National Study of Education in Undergraduate Science (NSEUS) performed a qualitative synthesis of the "extent and effort" of reform-oriented 
science coursework at the undergraduate level, with particular interest in papers on reform designed and implemented for pre-service teachers (Sunal, Sunal, Sundberg, Mason, Lardy, \& Zollman, 2008, p. 1). Their analysis consisted of 23 articles, books, and reports published between 1999 and 2006. However none of the published reports on the NSEUS webpage (http://nseus.org/) describe the process by which papers were included or excluded from the analysis. The authors did describe how each report was reviewed and how common facets were identified across studies. These facets included studies which: (a) support or facilitate the enactment of reform-oriented instruction, (b) have characteristics of reform-oriented instruction, or (c) indicate the effect or impact of reform-oriented instruction (Sunal et al., 2008) ${ }^{1}$. The authors reported that, "undergraduate science content achievement correlated positively with participation in courses having greater focus on [reformoriented instruction]" (p. 7, Sunal et al., 2008). However, this statement is not supported by a quantitative summary of the results of these studies; rather it represents a more general summary of similar statements contained within these studies. Do to the lack of quantitative data, these analyses do not allow for the analysis of the impact that course innovations have on student learning. In summary, previous qualitative reviews of the undergraduate physics education research literature have been conducted by several authors. These syntheses were performed for the purpose of describing the range of innovations being implemented. While the approaches to some of the qualitative syntheses have

\footnotetext{
1 This synopsis is a simplified version of the results of the NSEUS study and represents an accurate,
} yet more abstract, version of the Sunal, et al. (2008) findings. 
been informative, the lack of quantitative outcome measures used in these syntheses does not allow for comparisons to be made across studies.

Quantitative Summaries of the Research

Other approaches to summarizing the research literature have been quantitative in nature where research studies are grouped and compared based on measures of their effect on student learning. An often-cited synthesis paper on undergraduate physics education research reform efforts is Richard Hake's report on the effect of classes that use "interactive-engagement" techniques versus traditional teaching methods (Hake, 1998). In this paper, Hake defined "interactive engagement" courses as those which were

"designed at least in part to promote conceptual understanding through interactive engagement of students in heads-on (always) and hands-on (usually) activities which yield immediate feedback through discussion with peers and/or instructors" (Hake, 1998, p. 65).

He further defined "traditional" courses as those which rely "primarily on passivestudent lectures, recipe labs, and algorithmic-problem exams" (Hake, 1998, p. 65). In this research report, student learning outcomes for over six thousand students in 62 different introductory high-school, college, and university physics courses were combined and averaged. Student outcomes, as measured with two popular conceptual inventories (the FCI and the FMCE) in a pre- and post-test design, were collected for all classes. 
In this paper, Hake used the average normalized gain to calculate the effect of the courses. This metric, which is frequently used to report effects in undergraduate physics education research, is often referred to as the "Hake factor". The average normalized gain is the ratio of the average actual gain in test score to the maximum possible gain. This relationship is shown below:

$$
<g>=\frac{\left(<S_{f}>-<S_{i}>\right)}{\left(M A X-<S_{i}>\right)},
$$

where $\left\langle S_{f}>\right.$ and $<S_{i}>$ are the average post-test score and pre-test scores, and $M A X$ is the total possible score.

In this study, the average normalized gains for both IE and traditional courses were combined and averaged. The reported average normalized gains were 0.23 (SD 0.04) for traditional, and 0.48 (SD 0.14) for IE courses. This data is represented in Figure 2 (from Hake, 1998, p. 66).

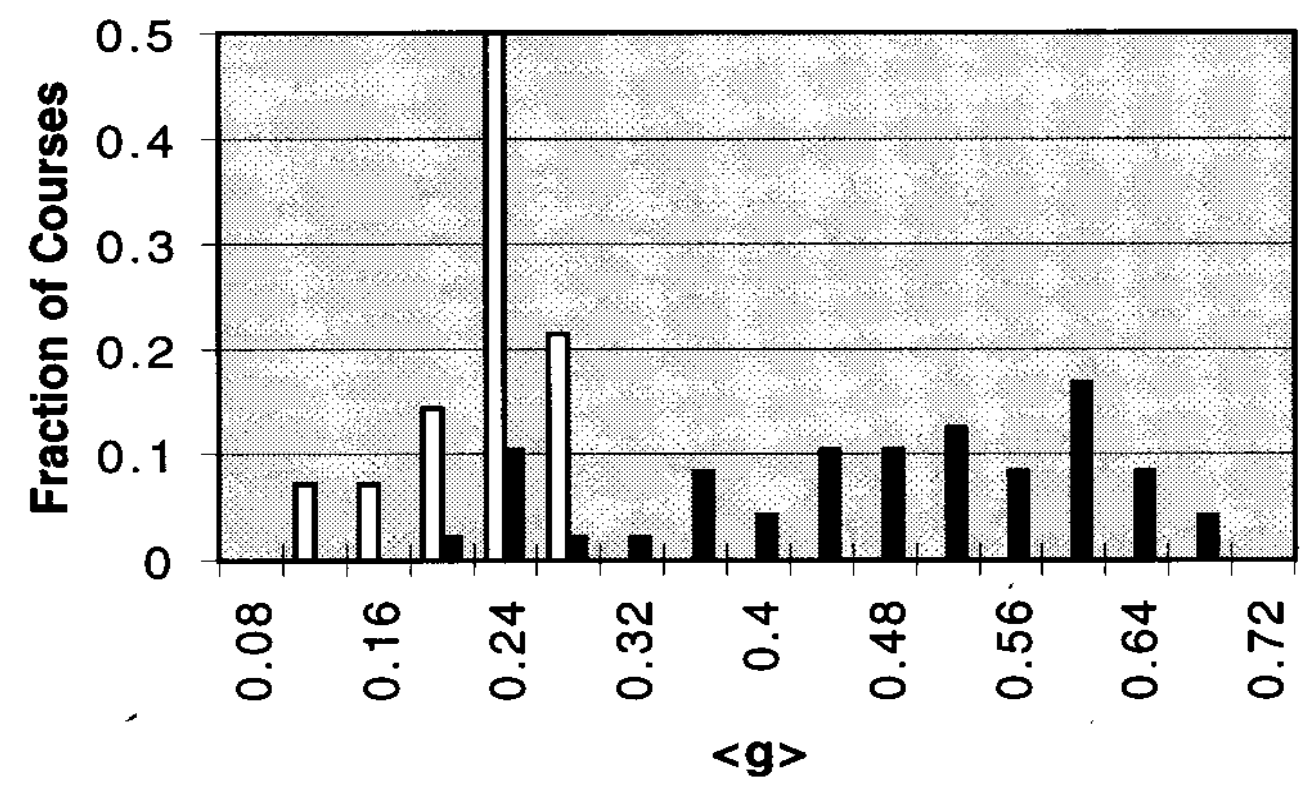

Figure 2. Histogram of the average normalized gain from Hake (1998) - white bars are the traditional classes and the black bars are the IE courses. 
Hake (1998) is frequently cited as empirical evidence that undergraduate physics education research reform efforts have a larger effect on student learning than traditional methods. While the results of this study provided compelling evidence in favor of interactive engagement courses, the actual "effect" of interactive engagement courses over traditional courses could only be indirectly inferred because Hake's (1998) study was not designed for causal inferences to be made. For example, Hake did not aggregate experimental designs in which students are randomly assigned to a treatment and a control group and then their performance is compared afterwards. Rather, Hake relied upon professors and high school teachers who gathered pre and posttest data on their students and then characterized the activities that had occurred in their course as "making substantial use of IE methods" or not. Therefore the non-IE courses cannot be considered a reliable counterfactual for the IE courses. In other words, it is highly unlikely that the non-IE courses represent a trustworthy control group since these courses were not performed at similar times, places, or with similar students. For example, causal claims about the effect of IE activities compared to non-IE activities on student performance cannot be reliably made when the performance of different types of students attending different schools at different times are compared.

While the Hake (1998) study does not provide a synthesis of the effect of interactive engagement versus traditional courses, it does provide compelling evidence that the normalized gains of IE courses were highly variable, spanning a range of normalized gains from about 0.20 to 0.68 , indicating that not all IE-type 
interventions are equally effective. Furthermore, the study showed that some IE courses actually had smaller normalized gains than traditionally taught classes. By combining all of these different interventions together into one category (IE), Hake lost information with respect to why some are more successful than others.

In contrast to the broad Hake approach, other researchers have approached the task of synthesizing the effect of reforms by pooling and averaging data across multiple enactments of a particular innovation. This type of synthesis typically involves replicated studies over the course of several semesters to several years. An example of this type of synthesis is the work that has been done on analyzing implementations of a particular innovation called Peer Instruction (Crouch \& Mazur, 2001; Crouch et al., 2007; Fagen et al., 2002), and similar manifestations (Meltzer \& Manivannan, 2002). Peer Instruction, developed by Eric Mazur at Harvard University, has been implemented and studied for over ten years. Pre- and post-test student data has been collected over the course of these years and the results show that the average normalized gain for Peer Instruction was 0.61 for calculus-based courses, and 0.64 for algebra-based courses (Crouch \& Mazur, 2001). This is on the upper end of the normalized gain distribution from the Hake (1998) data. Although this information is informative, very few innovations have been studied extensively in this manner. This approach does not warrant comparisons to be made across innovations.

In summary, previous quantitative research summaries have either been too broad or too narrow in scope to allow for comparisons to be made across 
innovations. Hake (1998) grouped many different instantiations of undergraduate physics education research-based course innovations together. The finer-grained quantitative synthesis of Beichner et al. (2007), Crouch et al. (2007), Crouch \& Mazur (2001), Fagen et al. (2002), and Meltzer \& Manivannan (2002), focus only on a particular course innovation. However, this approach does not allow for comparisons to be made across innovations.

\section{Research Questions}

Clearly, a comprehensive synthesis of the large number of course innovations that have been developed and enacted in undergraduate physics classes is needed. This synthesis is necessary in order to establish what has been done and what has been effective. In order to satisfy these needs, this thesis will address the following research questions:

(1) What is the range of undergraduate physics course innovations that have been implemented and evaluated?

(2) What is effect of these innovations on student learning?

(3) What are the critical features of more and less effective innovations?

To respond to these research questions I have used complimentary research methods including a descriptive analysis, meta-analysis, and case study analysis. The following chapter describes these methodological approaches. 


\section{CHAPTER III}

\section{METHODS}

The analytic approaches described in this section, target each of the aforementioned research questions. The first research question, What is the range of undergraduate physics course innovations that have been implemented and evaluated, is addressed through descriptive analysis. The second research question, What is effect of these innovations on student learning, is addressed through metaanalysis. The third research question, What are the critical features of more and less effective innovations, is addressed through case-study analysis. The following sections describe the context in which this research is situated and the methods of investigation including the study inclusion criteria, coding procedures, and analytic approaches.

\section{Context of Study}

This research has been situated within a broader NSF-funded project, Undergraduate Course Innovations (UCI). The goal of the UCI project was to investigate the impact of undergraduate course innovations on student learning within four disciplines: biology, chemistry, engineering, and physics (Ruiz-Primo, Briggs, \& Shepard, 2006: Ruiz-Primo, Briggs, Shepard, Iverson, \& Huchton, 2008). The UCI project was overseen by co-principal investigators Dr. Maria Araceli RuizPrimo, Dr. Derek Briggs, and Dr. Lorrie Shepard, and assisted by graduate 
research assistants Robert Talbot and me. The three-year UCI project concluded in December of 2009. The collection and coding of the empirical studies used in this research was done under the umbrella of the UCI project.

\section{Document Collection Procedures}

This project involved a synthesis of previous research and therefore the sample, or the participants, for this study were research papers rather than students or other individuals. Just as the selection of participants in an empirical research study has implications for the results of a study the selection of studies for inclusion in a research synthesis can greatly affect the results (Lipsey \& Wilson, 2001). Because of this, the process by which studies were included or excluded from this research is described in detail here.

Inclusion Criteria

The UCI project staff established four criteria for inclusion of a study in the research. Each study must:

1. focus on undergraduate education in physics;

2. include one or more instructional strategies considered to be an innovation;

3. take place in an actual classroom, rather than in a controlled condition; and

4. be reported in a paper, article, or document developed or published in 1990 or later due to the significant increase in funds provided to undergraduate 
education research (especially to physics) after 1991 (Suter \& Narayanan, 2006).

As stated in the previous chapters, the UCI project team used the term course innovation because it is a general term that encompasses the variety of reformbased instructional strategies, but is not associated with any specific strategy. The defining characteristics of undergraduate physics course innovations is that they center on an active student learning approach that involves: (1) moving away from lecturing as the main or central instructional strategy, (2) shifting the focus from the professor or instructor towards the student, and (3) supporting shared collaboration (Ruiz-Primo, Briggs, \& Shepard, 2006). The major premise underlying course innovations is that they can better facilitate student learning and can help students develop positive attitudes towards science. Undergraduate course innovations involve conceptually oriented tasks, collaborative learning, inquirybased projects, technology, or any combination of these, as described in the previous chapter.

\section{Study Retrieval Methodology}

The retrieval of papers for this project involved three distinct phases. In Phase 1 a collection of seminal articles, deemed "word-of-mouth" papers, were gathered through the help of the UCI project advisory board. In Phase 2 papers were gathered through journal searches. Finally in Phase 3, the sample of papers was further refined and included papers were coded into four main types: 
comparative studies, descriptive studies, background papers, and synthesis papers. These phases are further described below, and are represented in Figure 3.

Although this search was exhaustive and steps were taken to ensure that all eligible papers were gathered through these methods, a few papers may have been missed. However, there is no reason to believe that the sample of papers gathered is somehow systematically different from the overall population of papers that exist which fit our criteria. Therefore it seems likely that they are representative of the field. 


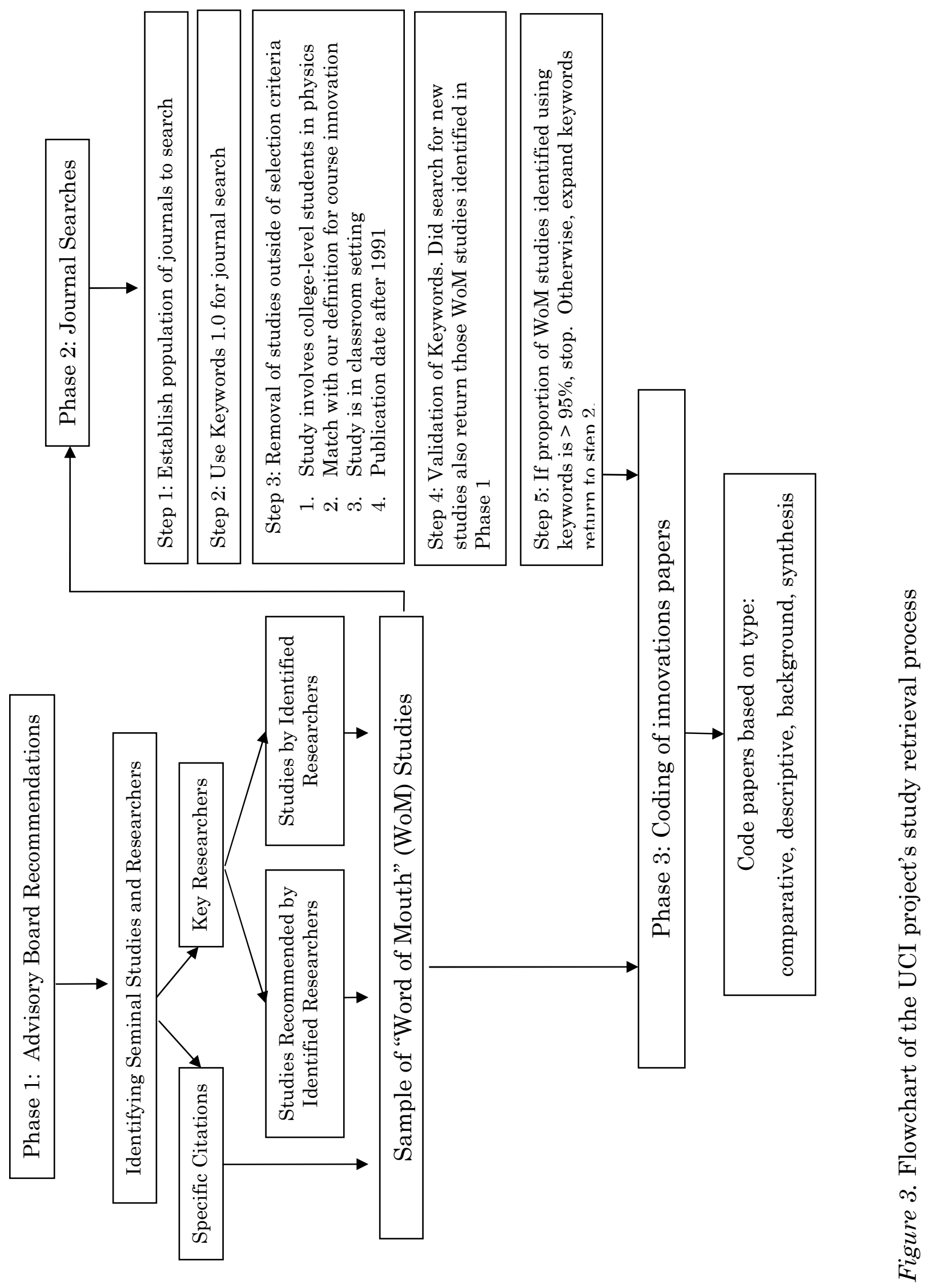




\section{Phase 1 - Word of Mouth Searches}

In Phase 1, Joe Redish, a member of the UCI project's advisory board, provided two sources of information: (1) a list of seminal research papers on innovations, and (2) a list of key researchers who do research on undergraduate course innovations. I compiled publication lists for these key researchers by searching faculty webpages and Google Scholar and then added these papers to the pool of seminal research papers provided by Joe Redish. In addition, I emailed these key researchers and asked them to provide, at their convenience, the same feedback requested of Joe Redish (i.e. a list of seminal research papers and key researchers). The letter sent out to these researchers is shown in Appendix A. Of the 18 researchers that I contacted, ten sent feedback. This information is summarized in Table 1 below. These researchers offered specific seminal papers to include in the database as well as expanded the list of key researchers. I added the recommended papers to the pool and then performed new searches for papers by newly added key researchers. The UCI project staff deemed this pool of papers the "word-of-mouth" papers (WoM). There were a total of 81 papers within the WoM pool. The sources of these papers are shown below in Table 2 . 
Table 1

Information Obtained from Email Correspondence with Word of Mouth Researchers

\begin{tabular}{|c|c|c|c|c|}
\hline \multirow{2}{*}{ Researcher Name } & \multirow{2}{*}{ Email Response } & \multicolumn{3}{|c|}{ Information Provided in Email } \\
\hline & & Paper(s) & Researchers & Other \\
\hline Beichner, Robert & yes & $\mathrm{x}$ & & \\
\hline Chi, Michelene & yes & $\mathrm{x}$ & & \\
\hline diSessa, Andrea & yes & $\mathrm{x}$ & & \\
\hline Etkina, Eugenia & yes & $\mathrm{x}$ & & \\
\hline Hammer, David & yes & & $\mathrm{x}$ & \\
\hline Hestenes, David & yes & & & $\mathrm{x}$ \\
\hline Mazur, Eric & yes & $\mathrm{x}$ & & \\
\hline McDermott, Lillian & no & & & \\
\hline Meltzer, David & yes & $\mathrm{x}$ & & \\
\hline Mestre, Jose & yes & $\mathrm{x}$ & & \\
\hline Reif, Frederick & yes & $\mathrm{x}$ & & \\
\hline Sharon, Bruce & no & & & \\
\hline Sokoloff, David & no & & & \\
\hline Thornton, Ronald & no & & & \\
\hline Van Heuvelen, Alan & no & & & \\
\hline Wieman, Carl & yes & $\mathrm{x}$ & $\mathrm{x}$ & \\
\hline Wittmann, Michael & yes & $\mathrm{x}$ & & \\
\hline Zollman, Dean & no & & & \\
\hline
\end{tabular}

Table 2

Sources of Papers in the Word of Mouth Population

\begin{tabular}{lc}
\hline Source & Number of Papers \\
\hline References from Advisory Board & 2 \\
References from Key Researchers & 4 \\
Google Scholar Searches & 26 \\
Searches on Faculty Webpages & 49 \\
\hline Total Word of Mouth Papers $=$ & 81 \\
\hline
\end{tabular}


Phase 2- Journal Searches and Keyword Validation

From the collection of WoM studies gathered in Phase 1, I compiled a list of all of the journals contained within this pool. There were 27 different journals represented in the $80 \mathrm{WoM}$ papers. I then searched all of these 27 journals for additional papers using the following key words: innovation, active, interactive, learning, engagement, problem, problem-based, problem-solving, collaborative, collaboration, technology, inquiry, inquiry-based, conceptual, formative, and physics as well as university and undergraduate. This set of terms was the first search terms used (i.e., Keywords 1.0). Depending on the journal, different search terms took priority over others. For example, in the physics journals the search term "physics" was not useful, so the other search words took precedence and "physics" was not used. However in journals not situated in the content domain of physics (e.g., the journal Cognition and Instruction), the term "physics" was used as the primary search term. In these cases, we viewed all of the results were viewed if the results were less than 300 . However, if the primary search term "physics" resulted in more than 300 results, adding "university" or "undergraduate" narrowed the search. I only used one keyword term at a time with the exception of non-physics journals where "physics" was always used to filter the data. Then, to determine whether retrieved papers should be selected for the database or excluded, I read titles and abstracts and matched them to the selection criteria.

There were a few journals in which online searches were not available, in which case the journals needed to be searched by looking through the table of 
contents. To avoid reading tables of contents from all journals in the sample, I started by reading WoM papers that were located in these journals to be sure that they met our inclusion criteria. Only one journal met this criterion and therefore this was the only one I searched by table of contents. I further eliminated these journals by looking through the journal's paper elicitations, i.e. "call for research". These journal elicitations did not appear to include empirical research on undergraduate physics education research.

The search terms generally retrieved a large number of papers, many of which did not meet the inclusion criteria previously described. Therefore studies were filtered on the basis of a brief review of the article title and if necessary a reading of the abstract. If it was unclear from this brief review whether a study should be included or excluded, I made the conservative decision to include the study. At this stage, all studies that appeared to meet the inclusion criteria were stored in a centralized location on a designated website.

After the journal searches were complete, I compared them to the WoM studies that had been collected previously in Phase 1. The objective of this step was to compare what had been found (through the journal searches) to what should have been found (through the WoM studies) in order to evaluate the effectiveness of the search terms I used. The results of this analysis are shown below in Table 3. In the instances in which the search terms were not successful at locating the WOM papers with the original list of search terms, I compiled a new list of terms based on the keywords provided in the target WoM study. When this comparative process 
was complete, I conducted new searches with the following list of new search terms (Keywords 2.0): instruction, cognitive, educational tools, educational evaluations, educational innovations, educational courses, curriculum, computer aided instruction, instructional strategies, instructional materials, assessment, student thinking, instruction, teaching, education, student, simulation, teaching /learning theory/practice, and multimedia.

Finally, I set a threshold for determining the validity of this set of keywords. If the search using Keywords 1.0 identified $95 \%$ of WoM studies, this set of keywords was considered sufficiently valid. If the agreement was less than $95 \%$, the search was expanded to include Keywords 2.0. This information is summarized in Table 4 below including the journals searched in Phase 2 and the number of papers collected using Keywords 1.0 and 2.0. The majority of searches resulted between $95 \%$ and $100 \%$ retrieval of WoM papers. There were 4 papers which could not be retrieved through any search terms and therefore there were three journals which had a $0 \%$ retrieval of WoM studies. In summary, after phases 1 and 2 the physics database contained a total of 432 studies: 81 from word-of-mouth sources and 351 from searches using both Keywords 1.0 and 2.0. 
Table 3

Results of WOM Papers Compared to Keyword 1.0 and Keyword 2.0 Searches

\begin{tabular}{|c|c|c|c|c|}
\hline Journal & $\begin{array}{c}\text { WoM } \\
\text { Papers }\end{array}$ & $\begin{array}{l}\text { Papers } \\
\text { found } \\
\text { in } \\
\text { Search } \\
1.0 \\
\end{array}$ & $\begin{array}{l}\text { Papers } \\
\text { found } \\
\text { in } \\
\text { Search } \\
2.0\end{array}$ & $\begin{array}{c}\text { Total } \\
\%\end{array}$ \\
\hline American Journal of Physics & 33 & 11 & 20 & $94 \%$ \\
\hline Cell Biology Education & 1 & \multicolumn{3}{|c|}{ No Search ${ }^{1}$} \\
\hline Change & 1 & 0 & 1 & $100 \%$ \\
\hline Cognition and Instruction & 2 & 2 & 0 & $100 \%$ \\
\hline Computers in Physics & 4 & \multicolumn{3}{|c|}{ No Search ${ }^{1}$} \\
\hline European Journal of Physics & 2 & 1 & 1 & $100 \%$ \\
\hline Interactive Learning Environments & 2 & 2 & 0 & $100 \%$ \\
\hline International Journal of Modern Physics & 1 & \multicolumn{3}{|c|}{ No Search ${ }^{1}$} \\
\hline International Journal of Science Education & 1 & 1 & 0 & $100 \%$ \\
\hline Journal of Applied Developmental Physiology & 1 & 1 & 0 & $100 \%$ \\
\hline Journal of College Science Teaching & 2 & 2 & 0 & $100 \%$ \\
\hline Journal of Computers in Math and Science Teaching & 1 & 1 & 0 & $100 \%$ \\
\hline Journal of Computing in Higher Education & 1 & \multicolumn{3}{|c|}{ No Search ${ }^{1}$} \\
\hline Journal of Educational Multimedia and Hypermedia & 2 & 0 & 0 & $0 \%$ \\
\hline Journal of Interactive Learning Research & 2 & 0 & 2 & $100 \%$ \\
\hline Journal of Online Learning and Teaching & 1 & 1 & 0 & $100 \%$ \\
\hline Journal of Research in Science Teaching & 3 & 3 & 0 & $100 \%$ \\
\hline Journal of Research on Computing Education & 1 & \multicolumn{3}{|c|}{ No Search 1} \\
\hline Journal of Science Education and Technology & 1 & 1 & 0 & $100 \%$ \\
\hline Journal of SMET Education & 1 & 0 & 1 & $100 \%$ \\
\hline Journal of the Learning Sciences & 1 & \multicolumn{3}{|c|}{ No Search ${ }^{1}$} \\
\hline Physical Review Special Topics PER & 2 & 2 & 0 & $100 \%$ \\
\hline Physics Teacher & 9 & \multicolumn{3}{|c|}{ No Search ${ }^{1}$} \\
\hline Physics Today & 2 & 2 & 0 & $100 \%$ \\
\hline Reviews in Physics Education Research & 1 & 0 & 0 & $0 \%$ \\
\hline Science and Education & 1 & 0 & 1 & $100 \%$ \\
\hline Science Scope & 1 & 0 & 0 & $0 \%$ \\
\hline The Science Teacher & 1 & \multicolumn{3}{|c|}{ No Search ${ }^{1}$} \\
\hline Total Papers $=$ & 81 & 30 & 26 & $85 \%$ \\
\hline
\end{tabular}

${ }^{1}$ No search conducted based on the elimination of journal as described above. 
Table 4

Results of Searching Online Physics Journals

\begin{tabular}{|c|c|c|}
\hline Physics Journal & $\begin{array}{c}\text { Papers with } \\
\text { Search } 1.0\end{array}$ & $\begin{array}{c}\text { Papers with } \\
\text { Search } 2.0\end{array}$ \\
\hline American Journal of Physics & 95 & 32 \\
\hline Change & 0 & No Search ${ }^{1}$ \\
\hline Cognition and Instruction & 16 & No Search ${ }^{1}$ \\
\hline Computers in Physics & \multicolumn{2}{|c|}{ No Search² } \\
\hline European Journal of Physics & 23 & 12 \\
\hline Interactive Learning Environments & 15 & No Search ${ }^{1}$ \\
\hline International Journal of Modern Physics & \multicolumn{2}{|c|}{ No Search ${ }^{2}$} \\
\hline International Journal of Science Education & 18 & No Search ${ }^{1}$ \\
\hline Journal of Applied Developmental Psychology & 2 & No Search $^{1}$ \\
\hline Journal of College Science Teaching & 20 & No Search ${ }^{1}$ \\
\hline Journal of Computers in Mathematics and Science Teaching 3 & 4 & No Search ${ }^{1}$ \\
\hline Journal of Computing in Higher Education & \multicolumn{2}{|c|}{ No Search ${ }^{2}$} \\
\hline Journal of Educational Multimedia and Hypermedia ${ }^{4}$ & 4 & No Search ${ }^{1}$ \\
\hline Journal of Interactive Learning Research ${ }^{4}$ & 1 & No Search ${ }^{1}$ \\
\hline Journal of Online Learning and Teaching & 4 & No Search ${ }^{1}$ \\
\hline Journal of Research in Science Teaching & 9 & No Search ${ }^{1}$ \\
\hline Journal of Research on Computing Education & \multicolumn{2}{|c|}{ No Search ${ }^{2}$} \\
\hline Journal of Science Education and Technology ${ }^{5}$ & 37 & No Search ${ }^{1}$ \\
\hline Journal of SMET Education & 2 & No Search ${ }^{1}$ \\
\hline Journal of the Learning Sciences & \multicolumn{2}{|c|}{ No Search ${ }^{2}$} \\
\hline Physical Review Special Topics PER & 23 & 7 \\
\hline Physics Teacher & \multicolumn{2}{|c|}{ No papers found ${ }^{3}$} \\
\hline Physics Today & 10 & 5 \\
\hline Reviews in Physics Education Research & 3 & No Search ${ }^{1}$ \\
\hline Science and Education ${ }^{6}$ & 7 & No Search ${ }^{1}$ \\
\hline Science Scope & 2 & No Search ${ }^{1}$ \\
\hline The Science Teacher & \multicolumn{2}{|c|}{ No Search ${ }^{2}$} \\
\hline Total Physics General Search Papers $(351)=$ & 295 & 56 \\
\hline
\end{tabular}

${ }^{1}$ No secondary search was done for these journals because the original search included the broadest term "physics" and therefore no additional search terms would gather additional papers.

${ }^{2}$ No online search available, journal was eliminated because WoM papers did not meet our criteria.

${ }^{3}$ Journal was searched by hand by looking through table of contents. 


\section{Phase 3 - Coding Studies by Type}

In order to check to be sure that each paper indeed met the inclusion criteria, the last phase of the study retrieval process involved refinement of the papers. Papers that did not meet the inclusion criteria were eliminated and those that did were coded with respect to the type of paper. In order to code the papers I read the abstracts and introductions and skimmed the rest of each paper. I coded each paper as either a: comparative study, descriptive study, background paper, or synthesis paper. Comparative studies involve empirical data for one or more treatment groups along with data from a comparison, or control, group. Descriptive studies include research in which an innovation was implemented and studied without a comparison group. Background papers include foundational innovation research; for example, research on the state of students' preconceptions about a topic, or a theoretical issue. Synthesis papers investigate and compare the results of other empirical papers.

Of the 432 papers gathered from phases 1 and 2, 275 were kept in the database while the remaining 157 were excluded. There were 11 reasons for these exclusions: the research subjects were not undergraduate students $(n=52)$, the paper did not fit our definition of what an innovation is $(n=32)$, the focus was on an assessment $(n=24)$, the paper was an editorial comment $(n=16)$, the focus was on a topic other than physics $(n=12)$, the paper was a book review $(n=9)$, the paper was not an educational paper $(n=5)$, the study was not conducted in a normal classroom environment $(n=2)$, the paper was a comparative paper but there was no 
cognitive outcome measure $(n=2)$, the paper was comparative but there was not enough information to capture the innovation $(n=2)$, or the paper contained duplicate data (i.e. data that was reported in another paper included in the database) $(n=1)$. Of the 275 papers that I retained in the database, 131 were coded as background papers, 83 were coded as comparative studies, 53 were coded as descriptive papers, and 8 were coded as synthesis papers. Appendix B shows a complete reference list of all 83 comparative studies. The breakdown of how these papers were coded is shown below in Table 5 . 


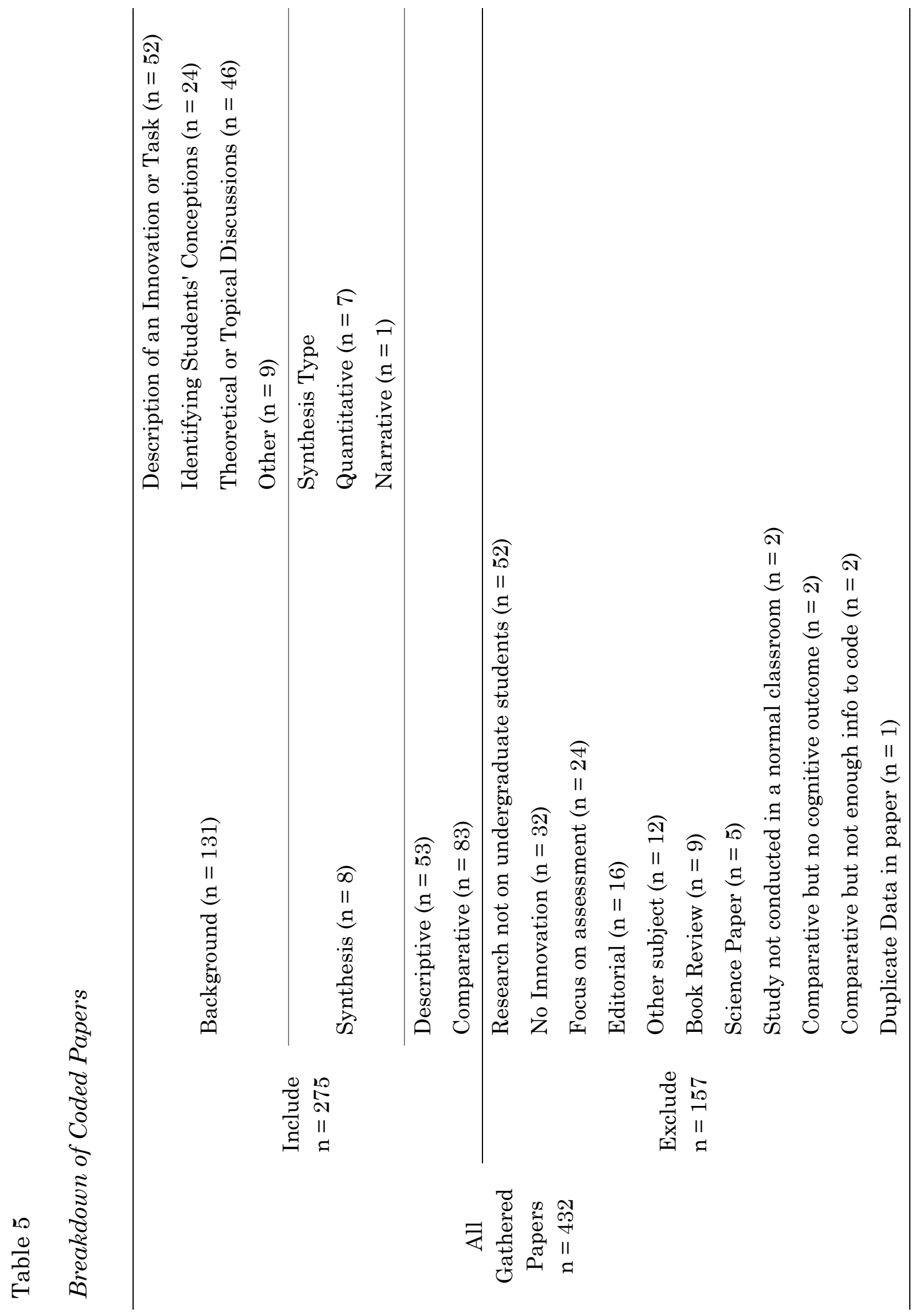


Paper-Study Reconciliation

Previously, the term study was used to indicate a published document. From this point forward a distinction will be made between a published paper and a study (Briggs, 2005). For the purposes of meta-analysis, it is necessary to distinguish between the overall published paper and the studies within it for which a unique effect size can be calculated. For example, any unique combination of sample, treatment, control group, experimental design, and outcome measure can provide a different effect size. Multiple combinations of these factors may exist within a single published paper. For example, it is not uncommon for undergraduate physics education researchers to estimate the effect of a treatment using different outcome measures; for example, the Force Concept Inventory (FCI; Hestenes, Wells, \& Swackhamer, 1992), and the Force and Motion Conceptual Evaluation (FMCE, Thornton \& Sokoloff, 1998). Each of these outcome measures will allow for a different effect size estimate to be calculated. Likewise, any changes to the treatment conditions (e.g. the addition of technology to a tutorial), the control group (e.g. historical results vs. contemporaneous results), or the experimental design (e.g. comparing pre to post results for a single group, comparing pre to post results across two groups) will result in a different effect size.

Several of the 83 papers used in the analysis reported the results of more than one study within the same paper. Each unique combination of these factors will allow for a different effect size to be calculated. Therefore, studies, and not 
papers, were considered the unit of analysis. Consequently, the 83 papers in the database yielded 170 comparative studies.

\section{UCI Coding Framework}

UCI project staff developed an organizational coding framework with the intention of categorizing innovation characteristics and the details of their enactments (Lipsey \& Wilson, 2001). In developing this organizational framework the UCI project staff relied on the expertise of the group members as well as information from seminal reports from the body of research on effective learning environments. In addition, UCI project staff elicited and used feedback from the advisory board meeting which was held in June, 2007. Lastly, some aspects of the codes emerged out of reading the papers. One of the most influential reports in developing this framework was The National Research Council's How People Learn (Bransford, Brown, \& Cocking, 2000), an often-cited summary of educational research on student learning. In distilling the rich information contained in this research report the UCI project team worked in an iterative process to develop a coding system fine-grained enough to capture as much of the variation in course innovations as possible while still allowing for comparisons to be made across innovations. The UCI project team met weekly not only to formulate and refine this framework and coding scheme, but also to build a common language with which to discuss innovation papers as per recommendations for building effective coding systems for meta-analysis (Cooper, Hedges, \& Valentine, 2009). In developing the 
UCI coding framework, three main types of codes arose: (1) the study context, (2) the characteristics of the innovation itself, and (3) the methodological variables. The team hypothesized that these codes encompass most factors which impact the effect that different innovations have on student learning. The entire coding framework is included in Appendix C Framework, and individual sets of codes are described below

\section{Study Context}

A portion of the UCI coding framework captures differences in the context of the studies, or in other words, the logistical aspects of the innovation study. These codes include class size, locus of the innovation, and intensity of the innovation, which are further described in the paragraphs below.

The accumulated body of research on the effect of class size on student achievement warranted the inclusion of class size as a code (Finn \& Achilles, 1990/1999; Glass and Smith, 1978; Hanushek, 1999; Robinson and Wittebols, 1986; and Slavin, 1989). The UCI coding framework operationalized class size as either large, for classes of 30 students or greater, or small, for classes of fewer than 30 students. We chose a threshold of 30 students because most standard size classrooms can accommodate about 30 students.

The UCI coding framework also characterizes the locus of the innovation, i.e. where it is used. Most physics courses, while held in a large lecture class, also include a laboratory and/or a recitation session that are also required in the class. 
Innovations may be located in one particular locus or all three. For example, Washington Tutorials (McDermott \& Shaffer, 1992) were designed specifically for use in recitation sections, whereas Peer Instruction (Mazur, 1999) has been designed for use in lecture classes. The Workshop Physics model (Laws, 1991) involves the merging of all three aspects of traditional physics classes into one classroom, or locus, the studio classroom. Some innovations involve changes only to the way students do homework. In other words, the class is conducted in a traditional manner except that students have online-based homework rather than paper and pencil homework (e.g. Bonham, Deardorff, \& Beichner, 2003). Although the locus of innovations varies, most innovations involve the development of an innovation for a specific locus.

The duration of the innovation is an additional code for the studies. Some studies involved short-term durations where the testing and treatment occurred within a matter of weeks of days. In most studies students were pre-tested at the beginning of a semester in which an innovation would take place and then posttested at the end. In a few studies the duration of the innovation lasted longer than a semester. Studies were coded as having either a short duration, lasting less than a semester; medium duration, lasting for one semester; or long duration, lasting longer than one semester. 
Innovation Characteristics

Theoretical Rationale

The UCI project team developed two main codes for capturing the range of how authors describe the rationale for the innovation they were studying. The first of these codes is for the empirical rationale for the research; that is, whether the author cited and discussed previous research and used this research as evidence for why the particular innovation in question should be successful. The second code involves the theoretical basis for the innovation. This code focuses on whether the author described the theoretical foundations of a particular innovation.

\section{Innovation Type - General Categories}

The most extensive codes relate to the characteristics of the innovation itself. The main organizational codes involve the type of innovation, i.e. whether conceptually oriented tasks, collaborative learning, technology, and/or inquiry-based projects were involved. These categories are not mutually exclusive and often innovations include two or more combinations of these strategies. This list of four innovations formerly included two additional categories: problem-solving and formative assessment. After considering problem-solving as an additional innovation type, the decision was made by the UCI project team to allow the broader category of conceptually oriented tasks to subsume this type of activity. This was more of a logistical decision than a theoretical one. In addition, the UCI project team recognized formative assessment as a possibly influential component of 
any innovation and as such this strategy became subsumed under each of the four main categories. For example, within each of the four innovation types, the coding system includes questions regarding the degree to which formative assessment is used.

Conceptually Oriented Tasks. Within the conceptually oriented tasks category there were codes for the type of task: problem-solving tasks, questions stemming from conceptual inventories, concept maps, and/or predict-observeexplain tasks. Additionally, there were codes for whether these tasks have been developed and/or implemented based on information about common student misconceptions, and whether these tasks provided an opportunity for students to (1) discuss solutions and strategies and conception, and make their particular ideas explicit, (2) react to other students' solutions, strategies, and conceptions, and (3) revise their particular solutions, strategies, and conceptions.

Collaborative Learning. Within the category of collaborative learning there were several sub-codes related to the use of the group work. These codes were how the groups were formed (by the students, teacher, or researcher), the way groups were formed (based on ability, interest, gender, random, convenience, etc.), the stability of the groups (did the groups change or stay the same), roles assigned to group members, attempts to monitor group work, the product of the work 
(individual or group product), and accountability (whether students received grades based on individual work or based on group work).

Technology. Within the technology category, sub-codes focus on the purpose of the technology, i.e. whether it involved simulations, visualizations, or other computational or visual methods to solve problems. In addition, sub-codes focused on who used the technology (teacher or student) and to what degree the technology allowed the opportunity for the students to receive feedback.

Inquiry-based Projects. Within the category of inquiry-based projects were innovations in which students engaged in a research project. Sub-codes for inquirybased projects included the degree to which students were responsible for determining the problem to be solved and the procedure and analysis to use. An additional code indicates whether the project was developed around multiple class sessions or even a full semester.

Innovation Type - Known Instructional Innovations

In addition to categorizing innovations based on one of the four types of innovation, many innovations were classified according to any known course innovations. In undergraduate physics education research there were a number of known course innovations that have been developed and used over the last several 
decades. Shown in Table 6 is a summary of these known course innovations. This

list has been compiled from a number of other physics education research

summaries (Dancy \& Henderson; Hake, 1998; McDermott \& Redish, 1999; Redish, 2003).

Table 6

Known course innovations and their primary developers

\begin{tabular}{|c|c|c|}
\hline $\begin{array}{l}\text { Locus of } \\
\text { Innovation }\end{array}$ & Known Instructional Innovation & Example \\
\hline \multirow{5}{*}{ Lecture } & Active Learning Problem Sheets & Van Heuvelen (1996) \\
\hline & Interactive Lecture Demonstrations & Thornton \& Sokoloff (1990) \\
\hline & Just-in-Time Teaching & $\begin{array}{l}\text { Novak, Patterson, Gavrin, \& Christian } \\
\text { (1999) }\end{array}$ \\
\hline & Overview Case Study Physics & Van Heuvelen (1991) \\
\hline & Peer Instruction/ConcepTests & Mazur (1999) \\
\hline \multirow{6}{*}{$\begin{array}{l}\text { Recitation } \\
\text { and/or } \\
\text { Laboratory }\end{array}$} & Cooperative-Problem Solving & Heller, Keith, \& Anderson (1992) \\
\hline & Investigative Science Learning & Etkina, Murthy, \& Zou (2006) \\
\hline & Environment & \\
\hline & RealTime Physics & Sokoloff, Laws, \& Thornton (2007) \\
\hline & $\begin{array}{l}\text { Socratic Dialogue Inducing } \\
\text { Laboratories }\end{array}$ & Hake (1992) \\
\hline & Tutorials & McDermott, Shaffer, \& Somers (1994) \\
\hline \multirow{2}{*}{$\begin{array}{l}\text { Workshop } \\
\text { and/or } \\
\text { Studio }\end{array}$} & Physics by Inquiry & McDermott, Rosenquist, Shaffer (1996) \\
\hline & Studio Physics & Laws (1991) \\
\hline Homework & Online Homework & Bonham, Deardorff, \& Beichner, (2003) \\
\hline \multirow{3}{*}{ Combination } & Microcomputer-Based Laboratories & Redish, Saul, \& Steinberg (1997) \\
\hline & Simulations & Finkelstein, Adams, Keller, Kohl, \\
\hline & & $\begin{array}{l}\text { Perkins, Podolefsky, Reid, \& LeMaster } \\
(2005)\end{array}$ \\
\hline
\end{tabular}




\section{Methodological Codes}

In addition to the organizational framework discussed above, the UCI project staff developed a coding system to capture variations in the methodological characteristics of innovation studies. The UCI Project staff developed and refined these codes in an iterative manner in much the same manner as the innovation framework codes. These codes were developed based on both the expertise of the UCI project team as well as by recommendations made in the research literature on performing quality research synthesis and meta-analysis.

The methodological codes used in this framework focus on the aspects of experimental designs which can affect the results of a study (Light \& Pillemer, 1984; Lipsey \& Wilson, 2001; Cooper, Hedges, \& Valentine, 2009). These aspects were based on five main categories: (1) the experimental design, (2) the outcome measures used to evaluate the effect of the treatment, (3) the experience of the control group, (4) the methods in which the effect is measured, and (5) the threats to the validity of the study. These codes are shown in Appendix C.

The codes for experimental design include whether the study was an experimental study or a quasi-experiment. In addition, the study was coded regarding whether it was post-test only or whether pre- and post-tests were also given for the treatment and control groups.

The outcome measure used in each study was also coded. These codes included the item format, in terms of whether it was multiple choice or open-ended; how the outcome measure was developed, in terms of whether it was created by the 
authors or borrowed from an outside developer; which outcome measure was used, such as the FCI or FMCE (Hestenes, Wells, \& Swakhammer,1992; Thornton \& Sokoloff, 1998); the reliability of the outcome measure; and whether or not the outcome measure appeared to be aligned with the objectives of the innovation.

UCI Project staff also created codes based on the experience of the control group; for example, how the control groups' experience differed from the treatment group. Occasionally the control group is defined only as the absence of the innovation and this was coded as well. For example, an innovation may involve some treatment which the control group will not receive. In other situations the effect of the treatment is compared to a historical control group. For example, some studies compare the learning gains their students had after some treatment to the mean gain reported in Hake (1998) for traditional classes.

The data for calculating an effect size were also recorded. This data includes the number of students involved in the study, the mean effect for treatment and control groups for pre and post tests, if applicable, and the standard deviations for these means.

Lastly, any threats to the validity of the study were coded. These threats include ambiguous temporal precedence (i.e. the timing of cause and effect is unclear), attrition, selection, history, maturation, regression, testing, instrumentation, low statistical power, violated assumptions for statistical calculations, fishing for statistical significance, unreliability of measures, restriction of range, instructor effects, inadequate explication of treatment, Hawthorne effect 
(i.e. reactivity due simply to being in an experiment), experimenter expectancies, compensatory rivalry (i.e. added effort of one group for the purpose of outperforming the other group), resentful demoralization (i.e. purposeful underperformance of one group in order to prove the other's superiority), and treatment crossover. Based on these factors each coder had the option of selecting the paper as an exemplarily good paper, a particularly poor paper, or neither.

\section{Coding Procedure}

Robert Talbot and I coded the pool of studies with supervision and frequent checks with the rest of the UCI project team. Initially I coded $75 \%$ of the studies and Robert Talbot coded the remaining $25 \%$; however, as this project has developed I have read and become familiar with the remaining $25 \%$ of studies.

I developed a Microsoft Access database as a data entry and management tool for the UCI project. Using this database, data and codes were recorded using a form in which innovation characteristics and methodological characteristics were entered for each study in a simple and economical manner. The database allowed for quick and easy access to the data which could be displayed and retrieved though queries, or exported into other software programs like SPSS or Microsoft Excel for computational analyses. A screenshot of this Access coding database is shown in Figure 4. 


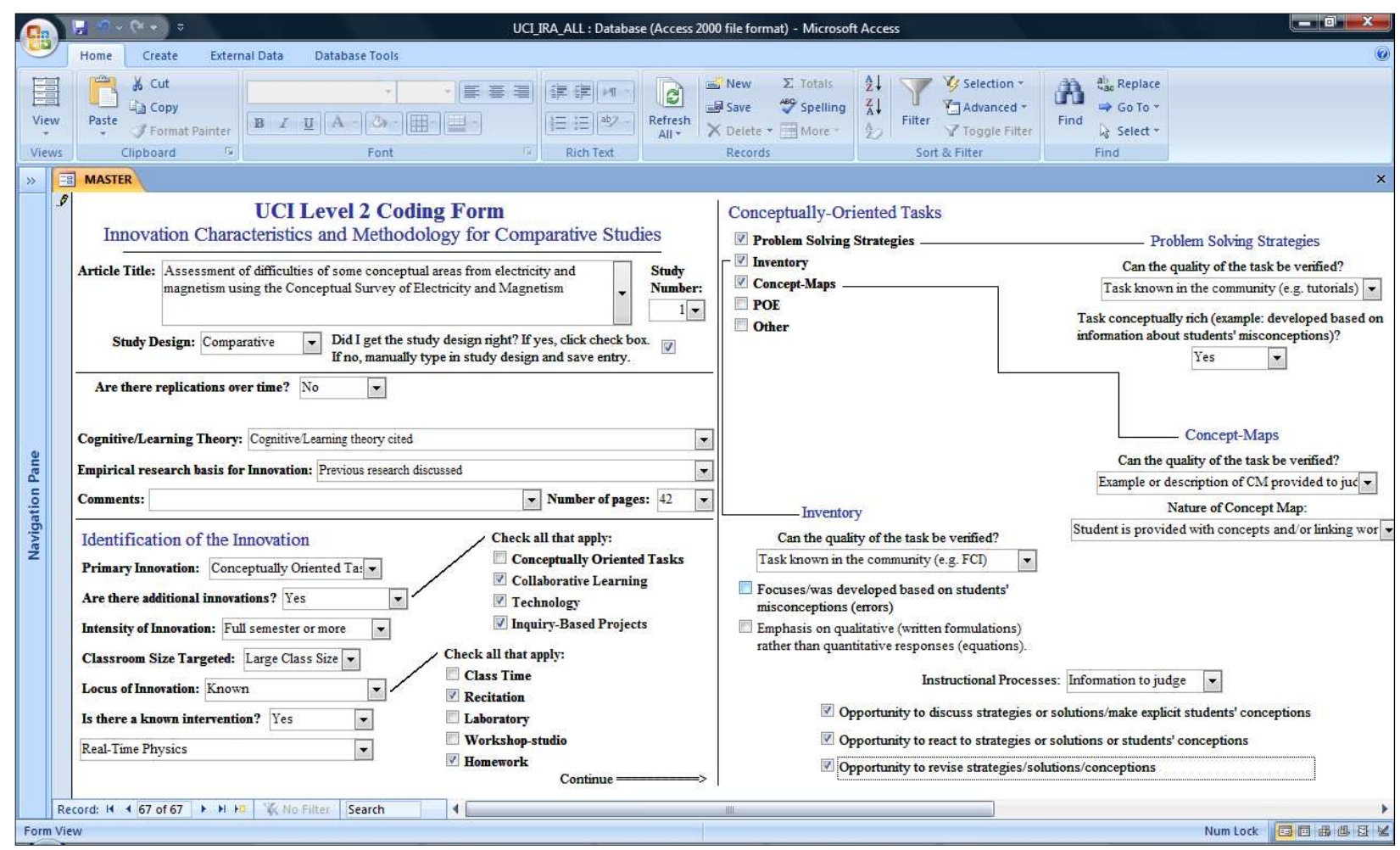

Figure 4. Screenshot of Microsoft Access coding form for the characteristics of the innovation under study.

\section{Coding Reliability}

For the purpose of establishing coding reliability, $27 \%$ of the papers were coded by two people. Coding pairs were formed from four individuals: Dr. RuizPrimo, Dr. Briggs, Robert Talbot, and me. 22 papers, consisting of 54 studies, were coded in this manner. Therefore there were 54 cases with which intercoder agreement could be calculated. The calculation of intercoder agreement was particularly complicated with this data because the codes were a combination of categorical and ordinal variables, therefore a number of approaches were used with the assumption that each index provides a unique approach to measuring the 
consistency of the coding. Intercoder reliability was calculated using percentage of agreement, Cohen's kappa, and the Spearman correlation.

The most straightforward and commonly reported index of intercoder reliability is the percentage of agreement, which is calculated as the total number of agreements divided by the total number of instances. In this analysis the percentage of agreement ranged from 0.75 to 0.99 , across the 54 cases, with a mean of 0.89 and standard deviation of 0.05 .

Cohen's kappa is an arguably better, and typically more conservative, measure of intercoder reliability for situations involving categorical data (Cooper \& Hedges, 1994, Stemler, 2001). Cohen's kappa is often favored over the percentage of agreement because it attempts to take into account the idea that two coders will agree occasionally simply due to chance. Kappa values range between 1 , indicating perfect agreement, and 0 , indicating agreement that is only due to chance. Kappa is based on the assumption that each element is coded with the same categorical rage. Because the data used in this study involves a large number of threaded codes (i.e. codes that lead to additional dependent codes), occasionally a pair of coders will not agree on these threaded codes and ipso facto will not agree on the dependent codes. In these situations kappa cannot be computed. With this data, kappa could be computed for 19 of the 54 studies. Of these studies, Cohen's kappa ranged between 0.7 and 0.9 , with a mean of 0.83 and standard deviation of 0.05 .

Because Cohen's kappa is based on the assumption that codes are categorical, it does not take into account the degree to which variables differ. In cases where 
codes are ordinal, for example the code for the degree to which previous research is cited and described in the paper it would be useful to know the value of the disagreement between raters; in other words, whether they disagree by one, two, or three levels, within the code. In order to account for this, the Spearman correlation was also used to assess intercoder reliability.

The Spearman correlation is a non-parametric correlation for ordinal variables. It provides a measure of the association of two variables which is not based on linearity of the association. For this data the Spearman correlation ranged between 0.84 and 1.00, with a mean of 0.93 and standard deviation of 0.04 .

Despite the difficulties of estimating intercoder agreement with this data, the comparably high values of the percentage of agreement, Cohen's kappa, and the Spearman correlation indicate a high level of reliability between coders. This data supports the assumption that papers were coded in a consistent manner across coders.

\section{Analytic Methods}

In addressing the three aforementioned research questions, three corresponding, complimentary methods of analysis were used. The first research question, What is the range of undergraduate physics course innovations that have been implemented and evaluated, is addressed through descriptive analysis. The second research question, What is the effect of these innovations on student learning, is addressed through meta-analysis. The third research question, What are the 
critical features of more and less effective innovations, is addressed through casestudy analysis. These methods are further discussed in the sections that follow.

Descriptive Analysis

In order to describe the range of PER course innovations, I conducted a descriptive research analysis in which I summarized the coding results with descriptive statistics such as frequency, mean, and standard deviation. These codes are included in the UCI Coding Framework shown in Appendix C. In addition, I narratively described the studies presented within each code. For example, I synthesized and described the similarities and differences in the group of studies which were coded as involving conceptually oriented tasks.

\section{Meta-Analysis}

I conducted a meta-analysis to address the second research question regarding the differential effects of PER course innovations. Meta-analysis is essentially quantitative research synthesis, where the results of empirical research studies are grouped, summarized, and interpreted (Lipsey \& Wilson, 2001). The meta-analytic process was developed by Smith and Glass (1977) and was based on previous research on the standardization and averaging of results from groups of studies. Since this early work, the method of meta-analysis has been further developed and refined (see Light \& Pillemer, 1984; Lipsey \& Wilson, 2001). This 
meta-analysis investigates the overall effect of course innovations and investigates some of the factors associated with more and less effective course innovations.

\section{Effect Size Calculation and Estimation}

Calculating the effect of an innovation involves an experimental design in which causal inferences can be made about the effect of the innovation on student learning. This involves an experiment in which the impact of an innovation is compared to the impact of a control condition. The purpose of a control group is to estimate the impact of the status quo on a group of students had they not been exposed to the treatment (i.e. innovation). However, since it is not possible to compare the impact of both a treatment and a control condition on the same group of students at the same time, it is essential that the students in the two groups are as similar as possible. One way to assign students to treatment and control groups so that they are likely very similar is randomly, since a large group of students randomly assigned to treatment and control conditions are likely to be very similar. With comparable treatment and control groups the effect can be evaluated by examining the difference between the performance of students in the treatment, or innovation, groups versus the performance of students in the control, or status quo, group.

The effect size statistic is a common metric used in meta-analyses to estimate the effect of a treatment, and it allows for the comparison of treatment effects across studies where the dependent variable may not necessarily be the same (Lipsey \& 
Wilson, 2001, p. 48). The effect size statistic standardizes the mean difference between treatment and control groups in the same manner that z-scores are calculated, by scaling the difference with respect to the variance, or standard deviation, of scores. In this thesis, I have used Glass's $\Delta$ to calculate the standardized mean difference in effect size. Glass's $\Delta$ is represented as

$$
E S_{\text {Glass's }}=\frac{\overline{X_{T}}-\overline{X_{C}}}{S D_{C}}
$$

where $\bar{X}$ represents a test score mean for treatment and control conditions (subscripts "T" and "C"), and SD is the standard deviation of the control group (Cooper \& Hedges, 1994). Other modifications to this equation have been proposed including Cohen's d and Hedges's g, in which the difference between treatment and control is standardized by the pooled standard deviation across treatment and control. With regard to the value used to standardize the mean difference, Becker (1988) suggested that the control group standard deviation be used. Her rationale was that treatment conditions may alter the standard deviation of the outcome measure, often shrinking it due to testing or ceiling effects; therefore a more appropriate value with which to standardize the mean difference is the control group standard deviation. For this reason the standard deviation of the control group was used here to calculate effect sizes as shown in Equation 2.

A challenge to calculating effect sizes was that a large number of included studies did not report the standard deviations associated with outcome measures needed to calculate an effect size. This reality is due to the prevalence of an 
alternative metric for calculating the effect of an intervention in undergraduate physics education research, the normalized gain popularized by Hake (1998), The equation for the normalized gain is

$$
<\mathrm{g}>=\frac{(\text { Post }- \text { Pre })}{(100-\text { Pre })},
$$

where "Pre" and "Post" represent the mean fractional percent correct (out of 100) on the pretest and posttest respectively. This calculation is used in pretest and posttest designs with a single group. In experimental designs involving a control group, the difference in the normalized gains is computed, which is represented as

$$
<g\rangle_{\text {Difference }}=\langle g\rangle_{\text {Treatment }}-\langle g\rangle_{\text {Control }}
$$

where the difference is between the normalized gain of the treatment group and the control group.

In order to find the estimated treatment effect in studies that only reported the normalized gain statistic, I sought out a method for estimating an effect size based on the difference in normalized gain of a study. I was able to investigate the relationship between effect size and normalized gain empirically with a sample of our studies $(\mathrm{n}=12)$ for which sufficient data was provided in order to calculate both an effect size as well as the normalized gain. For these studies I established an empirical relationship between the normalized gain and effect size in order to predict an effect size for the studies for which only the normalized gain is reported. The scatterplot of effect size and normalized gain is shown in Figure 5. 


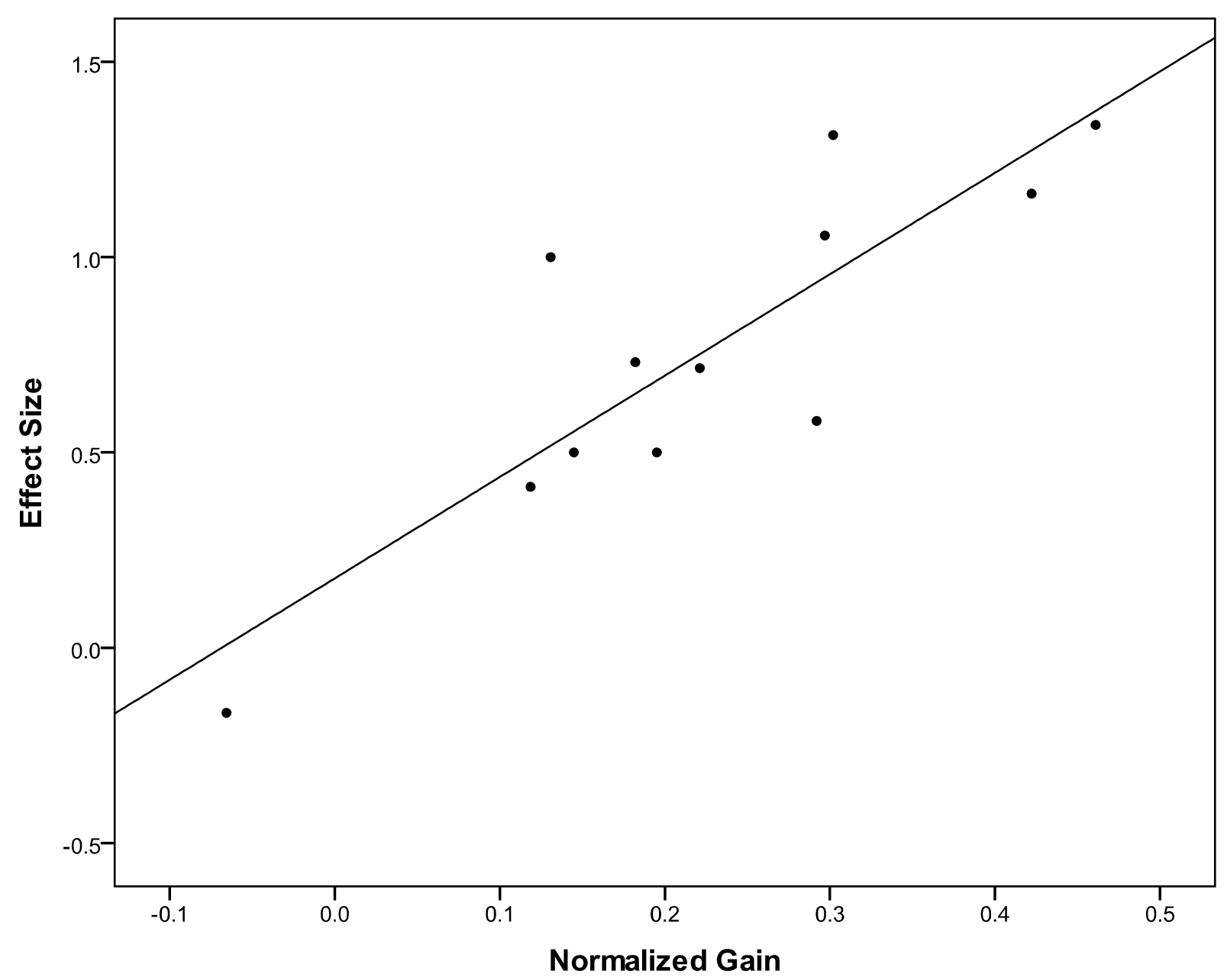

Figure 5. Data and best-fit line for studies in which both the difference in normalized gain and effect size could be calculated.

In order to establish a linear approximation of the relationship between the variables I regressed effect size on the difference in normalized gain. The equation for this relationship is

$$
E S=2.60\left(<g>_{\text {Difference }}\right)+0.18
$$

with a root mean square error of 0.24 , and Pearson correlation of 0.85 . Studies deviate from the line based on the magnitude of the control group standard deviation, and the magnitude of both group's pretest and normalized gains. Positive 
deviations in effect size, i.e. studies below the best-fit line, are a result of above average control group standard deviations and above average treatment pretest scores or normalized gains. Negative deviations in effect size are a result of above average control group pretest scores or normalized gains.

Case-Study Analysis

To respond to the third research question, I conducted a case study analysis (Merriam, 1998; Yin, 1984) to identify the critical features of effective innovations. Initially I intended to select a number of effective innovations for case-study analysis. I expected to include at least one group of studies with a particular innovation combination (i.e. a specific combination of conceptually oriented tasks, collaborative learning, technology, or inquiry-based projects), and a group of studies which all use a particular known innovation. However, the nature of the data only warranted a case-study analysis of one known innovation: Workshop/Studio Physics. The details of this decision are described at the end of Chapter 5. In the following sections I will describe the sources of data and analytical methods in the case study analysis of Workshop/Studio Physics.

\section{Data Sources}

I used three sources of data for this case study: initial and supplementary literature, curricular materials, as well as interviews with innovation developers and key implementers. The initial and supplementary literature used in this 
analysis included published and unpublished papers which described Workshop/Studio Physics. The initial literature set consisted of 10 papers gathered as part of this thesis research. After re-reading these studies, I identified supplementary literature through instances in which the authors cited previous theoretical, background, or empirical works. The supplemental literature consisted of 2 journal articles, 1 book, and 1 dissertation. As expected, the large percentage of journal articles on Workshop/Studio Physics already existed in the database because of the exhaustive nature of our original search methods. Of the two supplementary journal articles, neither were empirical studies and neither were published in journals in which online searches were conducted for this thesis research.

In addition to the initial and supplementary literature sources just described, a key curricular document was gathered as well - the Workshop Physics Activity Guide (Laws, 1997). This is a workbook developed by the initiator of the Workshop/Studio Physics instructional model and it is a curriculum that has been used, at least in part, in most enactments of Workshop/Studio Physics.

In order to obtain descriptions of each innovation in greater detail, I have conducted interviews (Bogdan \& Biklen, 1998) with 4 key implementers of Workshop/Studio Physics: Priscilla Laws, Robert Beichner, Jack Wilson, and Juliet Brosing. I contacted an additional researcher, Karen Cummings, for an interview but she did not respond. An email interview was conducted with Robert Beichner (at his request) while phone interviews were conducted with the other three key 
implementers. Phone interviews were audio recorded and lasted about 45 minutes each. I asked each interviewee about the development of the innovation, and the characteristics of the innovations. The full interview protocol used in these interviews is included in Appendix D. The information gleaned from these interviews has been used to help identify the critical features of the innovation.

\section{Analysis of Data}

The first step in the case-study analysis was to assemble all of the sources of data included in the original study literature, supplementary literature, curricular materials, and interviews. I used a grounded theory approach along with the constant comparative method (Glaser and Strauss, 1967) in order to identify the critical features of Workshop/Studio Physics. This analysis involved an initial close reading of all data sources in which I marked salient words, phrases, and sections. Once this initial read-through and marking was completed, I wrote brief research memos to summarize the key ideas and developing themes - deemed "features", within each data source. An example of this coding and a research memo are included in Appendix E. Next, I compared features within each data source and identified areas of commonality.

While most features were present among all data sources, some were not. For example, the role of the instructor was a feature that did not come up in any of the initial memos for the literature documents and curriculum materials. However, every person interviewed mentioned the role of the instructor. In this situation, I re- 
read the documents in order to establish whether this feature had been overlooked in the first analysis. In this particular instance it had not, however this provides an example of the constant comparative method used in the analysis.

I used the constant comparative method continuously until I reached a point in which no new information was being gleaned from any data source. Once the common features had settled out of the analysis, I produced a final research memo. The common features presented in this memo were deemed the critical features of Workshop/Studio Physics.

In order to illustrate the evolution of the coded text over the course of the coding process I've included an example, shown in Table 7, of how the codes I used changed over time. I developed 33 codes in the documents I coded initially, which I iteratively clustered and reduced into an increasingly smaller set of codes. This process occurred as I gathered more data and wrote more memos, and was able to identify commonalities among the codes. I ultimately clustered the larger sets of codes into 5 critical characteristics. In addition I have provided a table with a brief description of each of the critical characteristics and come examples from the coded data (see Table 8). 


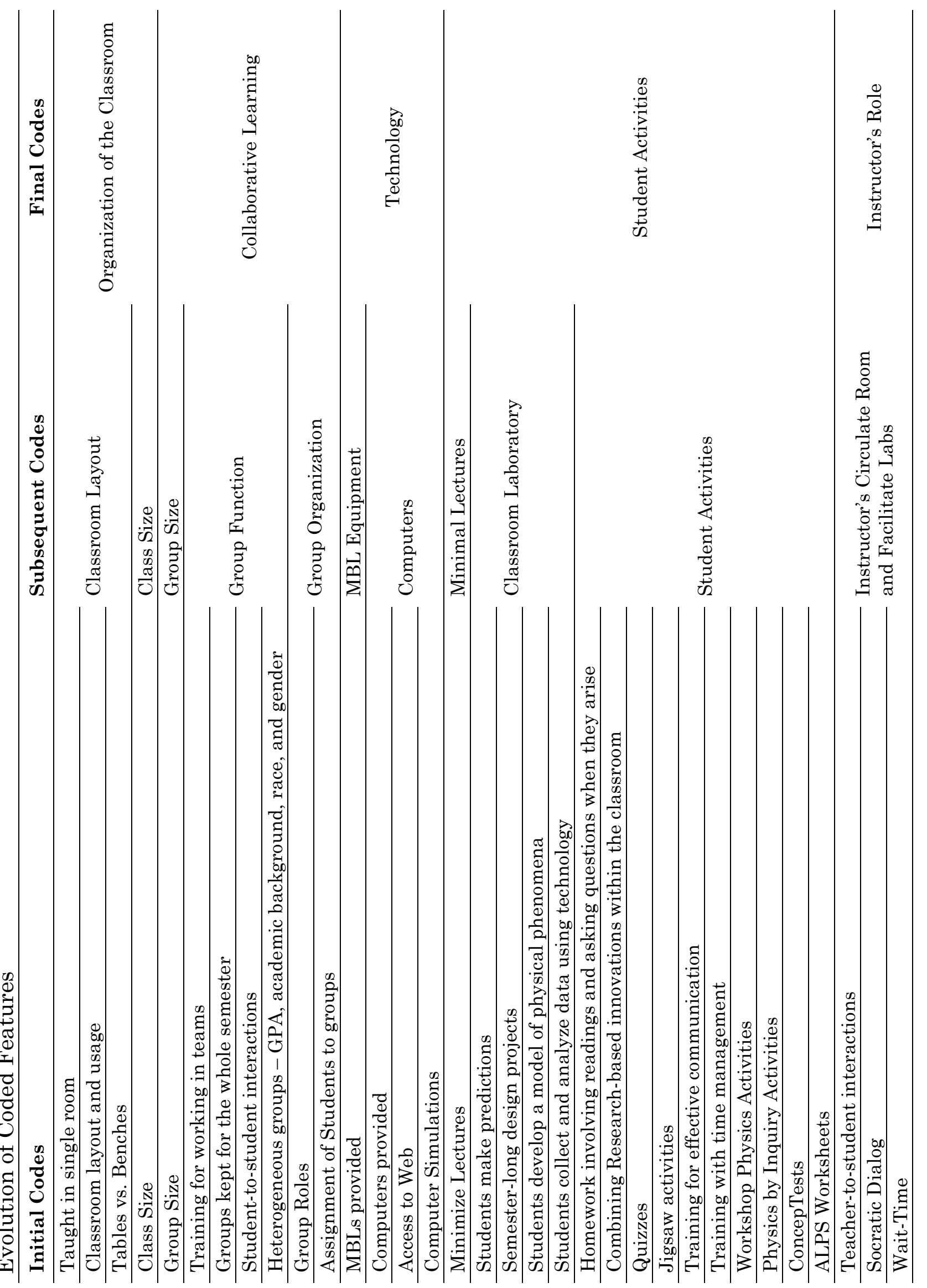




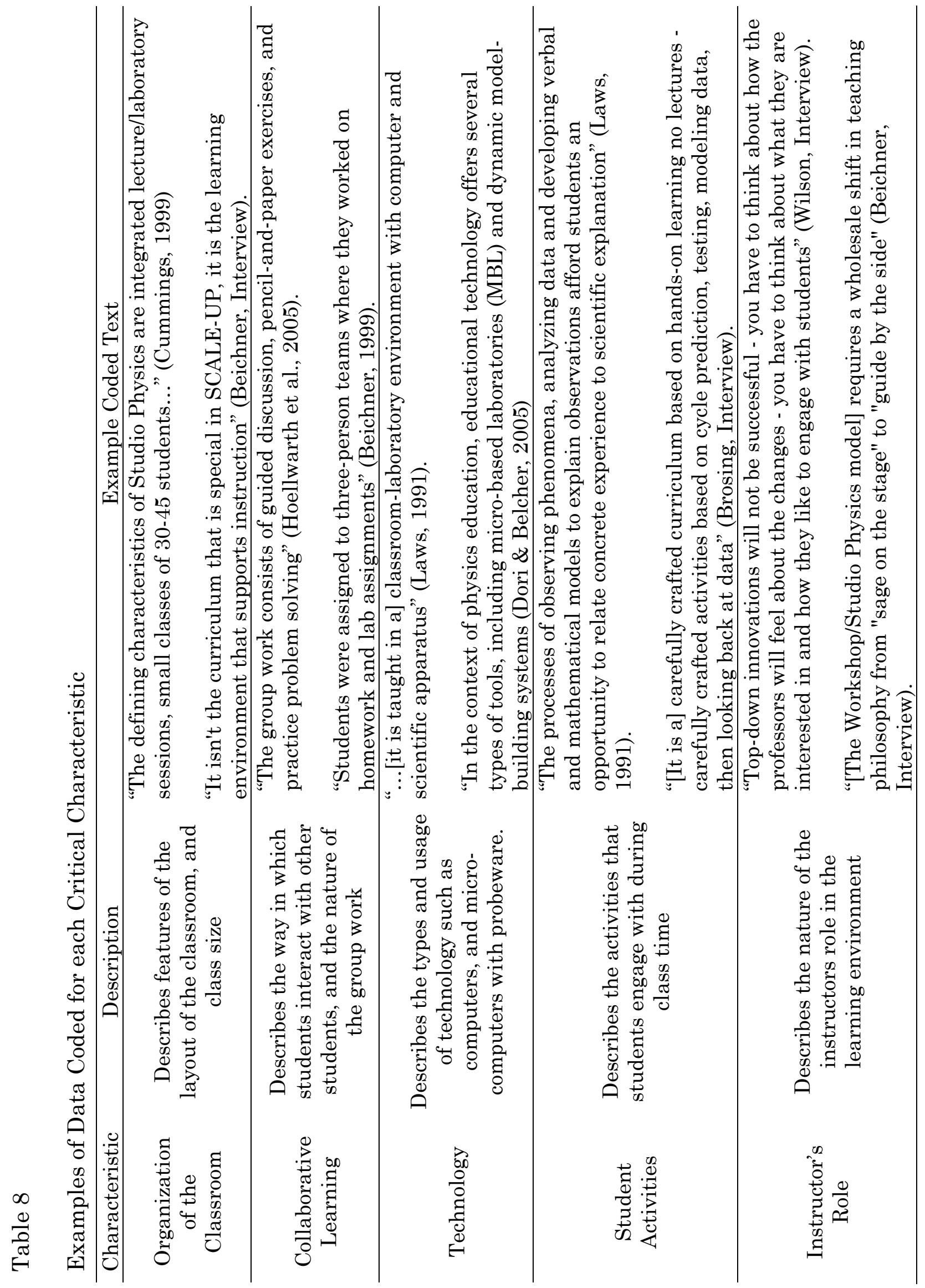


The final step in the case study analysis was to look for confirming and disconfirming evidence. In this step I attempted to identify the presence, partialpresence, or absence of the critical features of Workshop/Studio Physics among the other innovations which were shown to have relatively high or low effect sizes. For this analysis, I re-analyzed the remaining studies in the pool. 


\section{Summary of Analytic Methods}

In order to address the three aforementioned research questions three corresponding analytical methods have been used. The first research question, What is the range of undergraduate physics course innovations that have been implemented and evaluated, has been evaluated though a descriptive analysis. In this analysis the coded features of each study has been summarized quantitatively. The second research question, What is the effect of course innovations on student learning, has been evaluated through meta-analysis. In this analysis the effect of the innovation studies on student learning has been summarized quantitatively. The third research question, What are the critical features of more and less effective innovations, has been evaluated through a case study approach. In this analysis the most effective group of innovations, those involving Workshop/Studio Physics, have been analyzed in order to identify the critical features of this innovation. Finally these critical features were compared to other effective and less effective innovations. The following three chapters describe the results of each of these three corresponding research questions. 


\section{CHAPTER IV}

\section{DESCRIPTIVE ANALYSIS}

This chapter presents the results of a descriptive analysis of course innovations enacted in undergraduate physics education. The data for this analysis consists of the codes applied to each paper, resulting in frequency counts for the categorical variables and means and standard deviations for the continuous variables. To illustrate the range of the studies included in the meta-analysis that will be performed in chapter five, this chapter summarizes four types of codes: (1) characteristics of the innovations, (2) the rationale for the study, (3) the implementation of the innovations, and (4) the methodological characteristics of the studies.

\section{Innovation Characteristics}

In this thesis, innovations have been characterized as involving collaborative learning, conceptually oriented tasks, technology, inquiry-based projects, or any combination of these. Table 7 shows the number of studies with each innovation combination. The innovation types have been abbreviated in order to simplify the table, e.g. CL for collaborative learning, COT for conceptually oriented tasks, Tech for technology, and IBP for inquiry-based projects. 
Table 9

The frequency and percentage of each innovation combination type

\begin{tabular}{lcc}
\hline Innovation Type* & Frequency & Percent \\
\hline CL & 9 & 5.3 \\
COT & 24 & 14.1 \\
Tech & 25 & 14.7 \\
CL \& COT & 39 & 22.9 \\
CL \& Tech & 6 & 3.5 \\
COT \& Tech & 12 & 7.1 \\
Tech \& IBP & 1 & 0.6 \\
CL \& IBP & 2 & 1.2 \\
CL \& COT \& Tech & 47 & 27.6 \\
CL \& COT \& IBP & 2 & 1.2 \\
CL \& Tech \& IBP & 3 & 1.8 \\
\hline Total & 170 & 100.0 \\
\hline
\end{tabular}

${ }^{*} \mathrm{CL}=$ Collaborative Learning, COT $=$ Conceptually Oriented Tasks, Tech $=$ Technology and IBP = Inquiry-Based Projects

The most common innovation type in this sample of papers is collaborative learning combined with conceptually oriented tasks and technology. Other common innovation types are conceptually oriented tasks alone and combined with collaborative learning and combined with technology. Technology alone was also a common innovation type. In terms of the total number of studies with each innovation type either alone or in combination, conceptually oriented tasks have the highest frequency with 124 , collaborative learning has a frequency of 108 , and technology has a frequency of 94 . Innovations that include inquiry-based projects in combination with other innovations were the least common innovation type (8 studies). This was somewhat surprising given the prevalence of research on inquirybased activities in K-12 science education (e.g. Minner, Levy, \& Century, 2010). 


\section{Known Instructional Innovations}

Many studies involve the evaluation of known instructional innovations. These are innovations that are cited, described, and commonly known throughout the undergraduate physics education community as a proper noun. For example, of these well known instructional innovations are Tutorials and Peer Instruction. These two known instructional innovations typically fall under the category of conceptually oriented tasks combined with collaborative learning and technology. Although the largest number of research studies on these innovations have been published by the developers (Lillian McDermott and Eric Mazur respectively), many other researchers have replicated the innovations and studied them in other settings.

Of the 170 studies, 97 studies employed a known instructional innovation. Table 8 shows the frequency of all known instructional innovations. Because a large number of these studies (35\%) involve unique combinations of known instructional models, I have chosen to display the data in terms of the total frequency of each known instructional innovation. Therefore the frequency sum will be greater than 97 because of the use of multiple known instructional innovations. 
Table 10

Frequency of known instructional innovations

\begin{tabular}{lcc}
\hline Known Instructional Innovation & Frequency & Percent \\
\hline Active Learning Problem Sheets & 4 & 3.0 \\
Cooperative Group Problem Solving & 17 & 12.7 \\
Interactive Digital Video & 2 & 1.5 \\
Interactive Lecture Demonstrations & 12 & 9.0 \\
Investigative Science Learning Environment & 1 & 0.7 \\
Micro-Computer Based Laboratories & 8 & 6.0 \\
Online Homework & 11 & 8.2 \\
Overview Case Study & 1 & 0.7 \\
Peer Instruction/ConcepTests & 12 & 9.0 \\
Physics by Inquiry & 6 & 4.5 \\
Real-Time Physics & 8 & 5.9 \\
Simulation & 5 & 3.7 \\
Tutorials & 24 & 17.9 \\
Workshop/Studio Physics & 23 & 17.2 \\
\hline
\end{tabular}

The most frequently used known instructional innovation within the sample of studies was Tutorials, followed very closely by Workshop/Studio Physics, Cooperative Group Problem Solving, Peer Instruction, Interactive Lecture Demonstrations, and Online Homework. These are the top 6 frequently used known instructional innovations and they represent $74 \%$ of the total.

\section{Tutorial Topic}

An additional aspect of the innovation is the physics topic covered. Table 9 provides the frequency for the physics topic covered in each innovation. These topics 
are, in alphabetical order: astronomy, which covers the physical and chemical properties of matter outside the Earth; electricity and magnetism, which covers innovations on electrostatics DC circuits, electronics, and magnetism; general physics, which covers a broad survey of introductory physics topics; mechanics, which includes kinematics, Newtonian dynamics, momentum, and energy; modern physics, which covers relativity and quantum mechanics; optics, including wave motion and theories of light; thermodynamics, including the deal gas law, work, and heat: and the "other" category, which covers innovations on measurement, programming skills, and integrated concepts that cross-cut the aforementioned categories.

Table 11

Frequency of innovation topic

\begin{tabular}{lcc}
\hline Topic & Frequency & Percent \\
\hline Astronomy & 6 & 3.5 \\
Electricity and Magnetism & 27 & 15.9 \\
General Physics & 35 & 20.6 \\
Mechanics & 85 & 50.0 \\
Modern Physics & 4 & 2.4 \\
Optics & 4 & 2.4 \\
Thermodynamics & 1 & 0.6 \\
Other & 8 & 4.7 \\
\hline
\end{tabular}

Innovations on the topic of mechanics were the most frequent among the sample of studies, accounting for $50 \%$ of the total studies. Innovations involving 
general physics and electricity and magnetism were also common, accounting for $20.6 \%$ and $15.9 \%$ respectively. The least common topics include thermodynamics, optics, and modern physics.

\section{Theoretical and Empirical Basis for Innovation}

Of the 170 papers, 81 papers (46.6\%) cited some sort of theory of mind or theory of learning. The most commonly cited theory was constructivism, or the perspective that students come into the classroom with existing ideas, that these ideas influence what students learn, and that knowledge is a constructed entity (citing Clement, 1982; 1993; Driver, 1989; Driver \& Bell, 1986; Papert \& Harel, 1991; Redish, 1994; Resnick, 1983; Scott, Asoko, \& Driver, 1992; Scott, Dyson, \& Gater, 1987; von Glaserfeld, 1983; 1995). Other commonly cited theories, in order of most to least commonly cited, were conceptual change theory and the theory of conceptual conflict (citing Hewson \& Hewson, 1984; Posner, Strike, Hewson, \& Gertog, 1982), sociocultural learning theory (citing Vygotsky, 1978, 1986), cognitive load theory and working memory theory (citing Anderson, 1983; Baddeley, 1986; Chandler \& Sweller, 1991; Johnstone \& El-Banna, 1986; Miller, 1956; Sweller, 1994), cognitive apprenticeship (citing Brown \& Palincsar, 1989; Collins, Brown, \& Newman, 1989), Ausubel's learning theory (citing Ausubel, 1963), the work of B.F. Skinner (citing Lindsey, 1972), and self-efficacy (Bandura, 1977).

The large majority of these papers include only a mention of the theory and one or more citations. One paper in particular states in the abstract that, 
"Vygotsky's zone of proximal development is offered as a pedagogical explanation for the effectiveness of PI [Peer Instruction]" (Lenaerts, Wieme, and Van Zele, 2003); however, nowhere else in the paper is the work of Lev Vygotsky described or cited. In only a few cases was the theory elaborated upon in more than one or two sentences.

One exemplary case of a well elaborated use of theory in an innovation paper is Gautreau \& Novemsky (1997). In this paper the authors give a two page summary of the influences and implications of the work of Vygotsky on the innovation they developed and implemented. Clear ties are made between Vygotsky's theory of how "external knowledge and abilities become internalized" (p. 426, Gautreau \& Novemsky, 1997) and the authors' innovation. The instructor initiates learning by formally introducing new physics concepts in a lecture format, which they call "first teaching" (p. 426). This information is new and therefore likely far above the ability of students at that point in time. Next, in "second teaching" (p. 426) the students work in collaborative groups where the ability and knowledge of the students as a team is greater than that of any one student. This is where students have the opportunity to internalize and "own" (p. 426) knowledge and abilities that have previously been introduced. While the idea of "first teaching" and “second teaching" may not be consistent with Vygotsky's theory (Vygotsky, 1986), it is still an example of a paper which provides an elaborated theory of learning and describes its relationship to the innovation. 
In addition to the theory cited, each paper was also coded for the empirical rationale provided through previous studies referenced. Of the 170 papers in the database, 154 papers (91.0\%) cited previous research as a rationale for the study the authors have carried out. For example, Reay, Bao, Li, Warnakulasooriya, \& Baugh (2005) describe several studies which report that students benefit from learning that involves a series of steps rather than a singular all-inclusive presentation of some concept, and that students benefit from problems that involve some conflict with the students' previous conceptions. Based on the results of this research the authors designed an innovation that involves question sets interspersed within lectures. This type of innovation is also commonly referred to as Peer Instruction (Mazur, 1999). A summary of the relationship between the theoretical and empirical rationale of papers is shown in Table 10.

Table 12

Crosstabulation between studies' theoretical and empirical rationale Theoretical Rationale

\begin{tabular}{llcc} 
& & No & Yes \\
\hline Empirical & No & $12(7.1 \%)$ & $4(2.4 \%)$ \\
Rationale & Yes & $77(45.3 \%)$ & $77(45.3 \%)$ \\
\hline
\end{tabular}

The majority of papers $(\mathrm{n}=154,90.6 \%)$ include an empirically based rationale for the study with an even split between those that also include a theoretical rationale and those that do not. Of the papers that did not include an 
empirical rationale, the majority $(\mathrm{n}=12,7.1 \%)$ also did not include a theoretical rationale.

It may be the case that the reason for the theoretical and empirical rationale in papers being so short is due to the size of the papers themselves as a result of possible page constraints in some journals. Table 11 shows the mean number of pages by the type of rationale used.

Table 13

Mean and Standard Deviation of Article Page Length by Rationale Type Theoretical Rationale

\begin{tabular}{llcc} 
& & No & Yes \\
\hline $\begin{array}{l}\text { Empirical } \\
\text { Rationale }\end{array}$ & No & $6(3.5)$ & $7(0.5)$ \\
& Yes & $10(5.6)$ & $16(10.9)$ \\
\hline
\end{tabular}

Papers with no stated theoretical or empirical rationale had the lowest mean with pages per paper with 6.2 pages. Papers that described both a theoretical and empirical rationale had an average of 16.3 pages almost double that of the other group.

\section{Innovation Implementation}

Three elements of the implementation of the innovations were coded for: the class size, the locus of the innovation, and whether the class was an introductory or advanced course. While the innovation locus categories are not mutually exclusive, 
meaning an innovation can take place in one or more of these locations, each study was placed in only one category for class size. Tables 12 and 13 show the frequencies of these variables.

Table 14

Frequency of class size among innovations

\begin{tabular}{lcc}
\hline Class size & Frequency & Percent \\
\hline Larger than 30 students & 126 & 74.1 \\
Less than 30 students & 39 & 22.9 \\
No information & 5 & 2.9 \\
\hline
\end{tabular}

Table 15

Frequency of the locus of the innovations

\begin{tabular}{lcc}
\hline Locus of Innovation & Frequency & Percent \\
\hline Lecture & 57 & 28.2 \\
Recitation & 44 & 21.8 \\
Laboratory & 47 & 23.3 \\
Workshop/Studio & 23 & 11.4 \\
Homework & 31 & 15.3 \\
\hline
\end{tabular}


The largest number of studies $(\mathrm{n}=126,74 \%)$ involved classes of greater than 30 students per class. This is in accordance with the finding that the largest number of studies involve an innovation in the lecture component of the class $(\mathrm{n}=$ 57, 28\%), as most lecture classes are held in large lecture halls. However when class size is cross-tabulated with locus, the large majority of studies (between $77-81 \%$ ) across each locus have large class sizes - meaning that even among innovations that take place in the recitation portion of the class the majority of studies are still coded as having large class sizes. One explanation for this is that the threshold value of 30 students may be too low to distinguish different class size (i.e. many recitations may hold more than 30 students).

Innovations are either implemented in introductory or advanced courses. Of the 170 studies, 137 (81\%) took place in an introductory course. The remaining 33 studies (19\%) involved innovations implemented in an advanced physics course.

\section{Study Characteristics}

The 170 studies described in this descriptive analysis are all comparative studies; however there is variability among the manner in which studies are implemented and the type of control group used. Figure 6 shows the frequencies of each variable. 

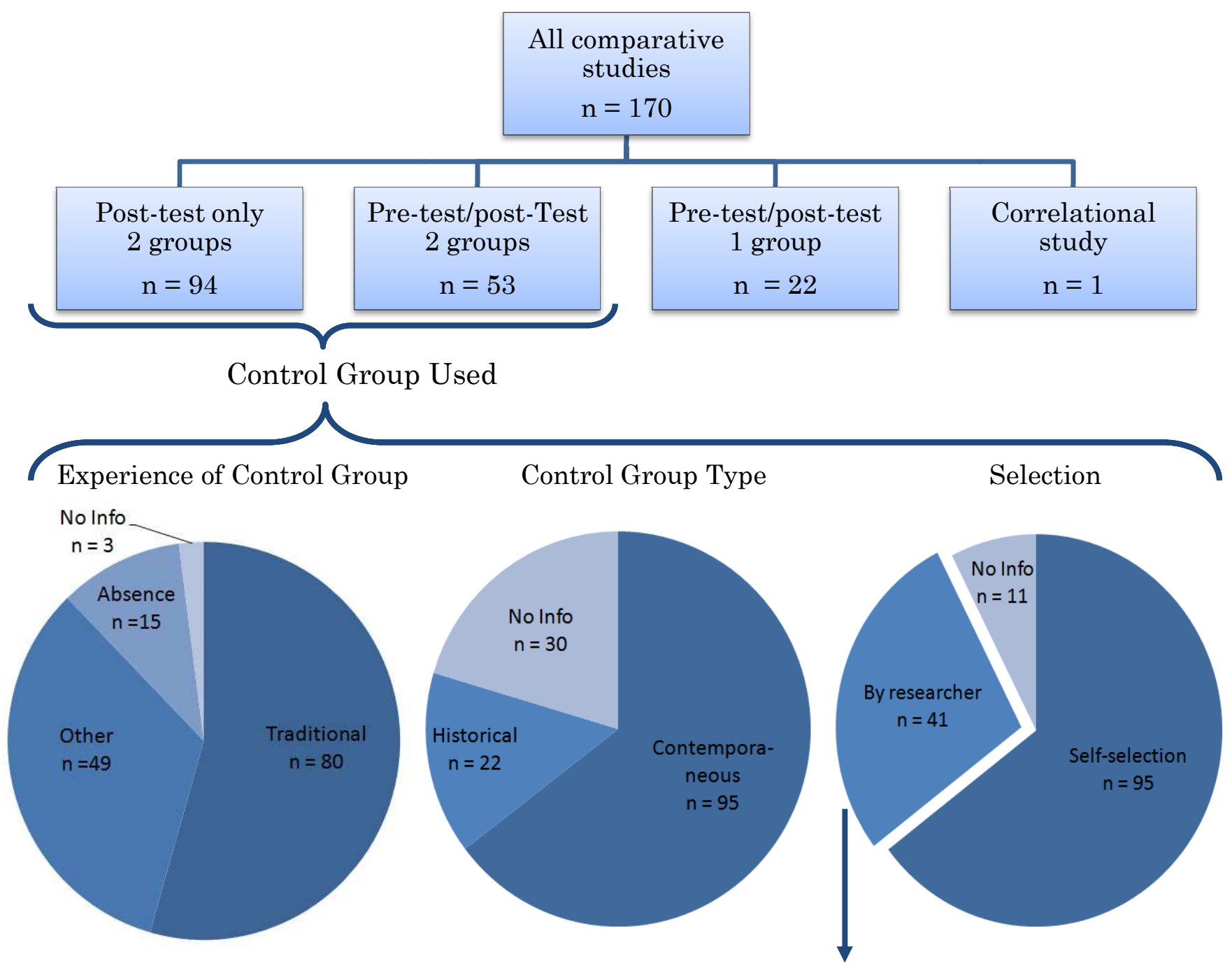

Selection By Researcher Type

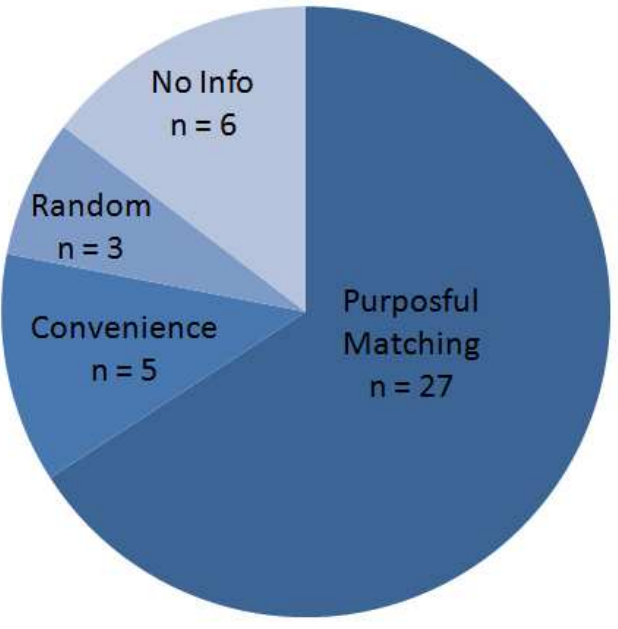

Figure 6. Frequencies of study characteristics 
The large majority of studies $(n=147,87 \%)$ compared the results of students in the treatment group to those in a control group. Of these studies, most ( $\mathrm{n}=94$, $64 \%$ ) used only posttest student scores to compare across groups. The remainder used both a pre and a post test for both groups $(n=53,36 \%)$. Some studies used a group's pretest scores as a proxy for a control group $(\mathrm{n}=22,15 \%)$. In other words students were measured before and after an intervention and the students' scores were compared. Lastly, one study had a correlational design, in which students' scores were correlated with the degree to which they were exposed to the treatment.

Of the 147 studies which had a control group, most involved traditional instruction $(\mathrm{n}=80,54 \%)$. In some cases, the control group experience is actually another innovation. In these situations the researcher compared the effect of some innovation against another innovation $(\mathrm{n}=49,33 \%)$. In very few cases, the control group received no instruction $(\mathrm{n}=15,10 \%)$.

Most of the 147 studies used a contemporaneous control group as a comparison $(\mathrm{n}=95,65 \%)$, and a smaller number involved a historical control group $(\mathrm{n}=22,15 \%)$. Studies that used historical control groups often compared the results of students in a previously published paper, typically Hake (1998), to the students in their study.

Another variable among studies with control groups is the manner in which students are assigned to the treatment or control group. The large majority were self-selected $(n=95,68 \%)$ meaning that students were either assigned to a particular class section through the registrar's office or they sign-up for a particular 
course section based on their schedule restrictions. In about one-fourth of the studies the students were assigned to treatment and control groups by the researcher $(\mathrm{n}=41,28 \%)$. Within this group of studies, the large majority $(\mathrm{n}=27$, 77\%) involved purposeful matching by the researcher in order to make the groups as similar as possible. There were 3 studies for which the students were randomly assigned to treatment and control - these are the only randomized controlled experiments in the dataset.

\section{Outcome Measure Characteristics}

Each comparative study used an outcome measure to evaluate the effect of an innovation on student learning. These outcome measures differed with respect to the type of outcome measure used. Outcome measures in these studies included multiple choice questions, open-ended questions, performance tasks, or interview protocols to evaluate student leaning. The frequencies of these item types are shown in Table 14. 
Table 16

Frequency of Outcome Measure Item Types

\begin{tabular}{lcc}
\hline Locus of Innovation & Frequency & Percent \\
\hline Multiple-Choice & 82 & 48.2 \\
Open-Ended & 55 & 32.4 \\
Performance Task & 5 & 2.9 \\
Open-ended and performance task & 1 & 0.6 \\
Interview Protocol & 3 & 1.8 \\
No Information & 24 & 14.1 \\
\hline
\end{tabular}

The most common item type is multiple-choice with 82 of the 170 studies using this type of outcome measure. The second most common item type is openended items $(\mathrm{n}=55,32 \%)$. The least common outcome measures involve performance tasks and interview protocols.

Researchers either use outcome measures have been specifically developed for a particular study, or outcome measures have been developed previously by an external researcher. Of the 170 studies, 84 (49\%) involved outcome measures that were internally developed, 61 (36\%) involved externally developed outcome measures, and 25 (15\%) did not report how the outcome measure was developed. The externally developed outcome measures include some well known outcome measures, specifically within the topic of mechanics. Of the 61 studies involving externally developed outcome measures, 25 (41\%) used the Force Concept 
Inventory, and 12 (20\%) used the Force and Motion Conceptual Evaluation. The Mechanics Diagnostic Test and the Mechanics Baseline Test were also used in one study each.

The studies in general provided very little information on the reliability of the outcome measure, regardless of whether it was developed internally or externally. For example only 27 studies out of 170 provided some measure of the reliability, whether it be a measure of the inter-rater reliability $(n=18)$ or the Cronbach's alpha $(\mathrm{n}=9)$. Even fewer studies provided any information on the validity of the outcome measure within the test administration $(n=9)$.

\section{Threats to the Validity of the Study}

Validity is a measure of the truth of a claim. The comparative studies investigated in this thesis involve making claims about the effect that an innovation has on student learning. Factors which may limit the validity of these claims are called threats to validity. Of the 170 studies, 137 (81\%) had at least one threat to the ivalidity of the claims made. The main two threats to validity which were a factor in these studies were internal validity and construct validity.

Internal validity involves the factors which hinder or support claims made about the cause and effect of something. There were $120(71 \%)$ studies which had at least one threat to the internal validity of the study results. The most prevalent internal validity threats, in order of frequency, were: selection, attrition, testing, and instrumentation. Selection is a threat in situations where the initial state of the 
students in the treatment and control conditions may not have been equal. This is a factor particularly in cases where students are not randomly assigned to treatment and control groups. Attrition involves the differential drop-out rates of students in the treatment versus the control groups. Testing involves the effect that repeated testing has on student performance. Lastly, instrumentation is a threat to validity in situations where the treatment and control groups were given different outcome measures. In these four situations, claims made about the effect of a treatment are more suspect than in situations where there is no internal validity threat.

Construct validity involves the factors which involve the accurate and complete description of what occurred in the treatment and control groups. This is especially important in meta-analysis where students are grouped and combined based on the description of what happened in the two groups. There were 85 studies (50\%) which had at least one construct validity threat. The most predominant threats were the inadequate description of the treatment or control conditions, instructor effects, and treatment crossover. The inadequate description of either the treatment or control conditions involves situations where the author may simply state that they did peer instruction as the innovation without explaining further. This is problematic because peer instruction can take many forms including whether technology is used, the degree to which peer interactions take place, and the type and frequency of items used. Instructor effects involve situations where the treatment and control groups had a different teacher, which introduces the issue that the presence of a particular instructor may be impacting the results of the 
study. Treatment crossover involves situations where the control group received part of the treatment either intentionally or non-intentionally.

\section{Summary}

The results of this analysis have provided a numerical summary of the types of innovations being implemented and evaluated in undergraduate physics education. With respect to the innovation types being used, the large majority of studies use combinations of collaborative learning, conceptually oriented tasks, and technology. Within the sample of studies, very few use inquiry-based projects alone or in combination with other innovation types which may be surprising given the prevalence of this type of this type of activity in K-12 science reform. Within these innovation categories are a large number of known innovations which have been adopted and enacted by members of the undergraduate physics education research community. Among these known instructional innovations two of the more frequently used are Tutorials and Workshop/Studio Physics. Most innovations focus on introductory courses within the topic of mechanics.

The large majority of studies provide some rationale for the innovation, either based on previous empirical work or based on some theory of mind or learning. However, very few studies provide an elaboration of this rationale. Instead many provide only a brief explanation consisting of a few sentences and a single citation. This phenomenon may relate to the length of articles being published on undergraduate physics course innovations. For example, there was a degree of 
correlation between the use of rationale and paper length. However, it is unclear whether article length is restricting the author's ability to provide an elaborated rationale, or whether the lack of an explicated rationale in papers is what allows them to be shorter.

Within this sample of studies, the majority of studies took place in a lecture hall. However there were a fair number of studies taking place in the recitation and laboratory sections of a course. Fewer studies have taken place in a Workshop environment or in homework. Most studies take place in a large classroom consisting of more than 30 students. However, it was found that this code was somewhat unreliable because even the classes which one might expect to have "small class sizes", such as recitations, did not with our data because the threshold value of 30 students was too low. To put it differently, even classes taking place in more intimate settings like recitations and laboratories had more than 30 students.

With respect to the methodological characteristics of studies, most studies used a posttest only approach across a treatment and control group to evaluate the effect of an innovation. The control group typically consisted of a contemporaneous class which experiences a traditional form of instruction. Studies typically involve self-selection into the treatment and control groups. Due to the issues of selfselection and the lack of pretest data with the majority of studies, selection bias is one of the major threats to the validity of these studies. The validity and reliability of the outcome measure administration is another issue within these studies. Only 
in a few instances is information about the quality of the testing instrument described in the studies. 


\section{CHAPTER V}

\section{META ANALYSIS RESULTS}

The previous chapter presented results of the descriptive analysis in which individual study characteristics were summarized. In this chapter, the effect of these innovations on student learning has been quantitatively summarized through meta-analysis. This analysis included the calculation of the overall mean effect size and standard deviation for the reviewed studies. An additional analysis was conducted in order to investigate the relationship between innovation type and effect size.

\section{Effect Size Calculation}

Of the 170 comparative studies on undergraduate physics course innovations, 91 studies (54\%) had to be excluded from the analysis for two reasons: either the paper did not provide the relevant data for an effect size to be calculated $(n=83)$, or an effect size was provided in the paper but the manner in which it was calculated differed from the one used in this thesis $(n=8)$. For the 79 studies $(46 \%)$ which could be included in the analysis, effect sizes were calculated in two ways based on the data that was provided in the paper: (1) for studies in which the treatment and control group means and standard deviations were provided $(n=43)$, effect sizes were calculated using Equation 2 (see page 66). For studies in which only the normalized gain was provided or could be calculated based on the data provided in 
the study $(n=36)$, effect sizes were estimated using the linear approximation method described in the previous chapter (see page 69 ). Figure 7 illustrates the breakdown of the 170 comparative studies.

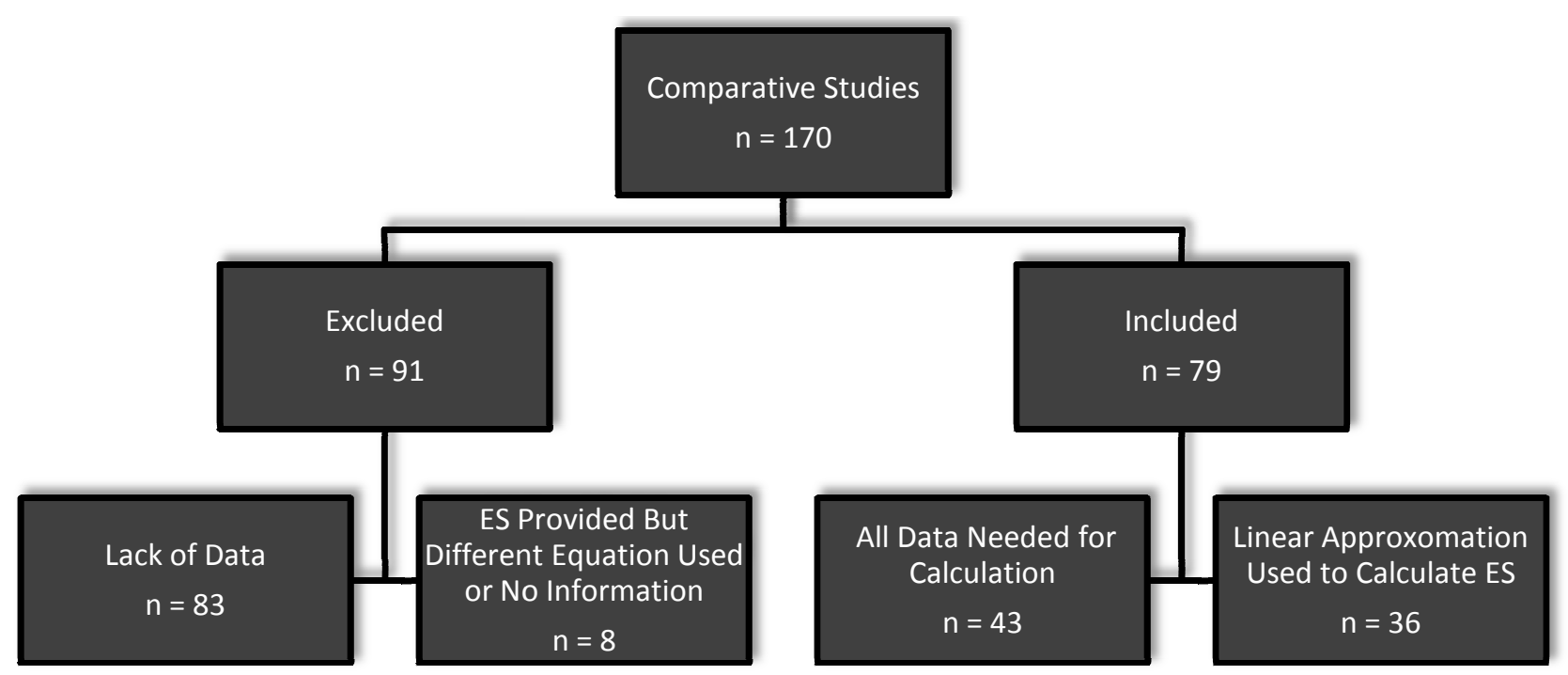

Figure 7. Flowchart describing the breakdown of comparative studies into included and excluded studies.

\section{Effect Size Descriptive Statistics}

The effect sizes for the 79 included studies ranged from -0.62 to 2.98 with a mean of 0.72 , a median of 0.67 , and a standard deviation of 0.57 . Out of these studies, 95\% $(\mathrm{n}=75)$ have positive effect sizes. The distribution is positively skewed (skewness $=1.44)$ and the bulk of the data is situated more tightly about the mean as compared to a normal distribution (kurtosis $=4.54)$. 
Overall, innovations included in this analysis appear to have a positive effect on student cognitive outcomes. Figure 8 shows the histogram of the effect sizes; each bin represents half of a standard deviation and the data is anchored on the mean $($ mean $=0.72)$.

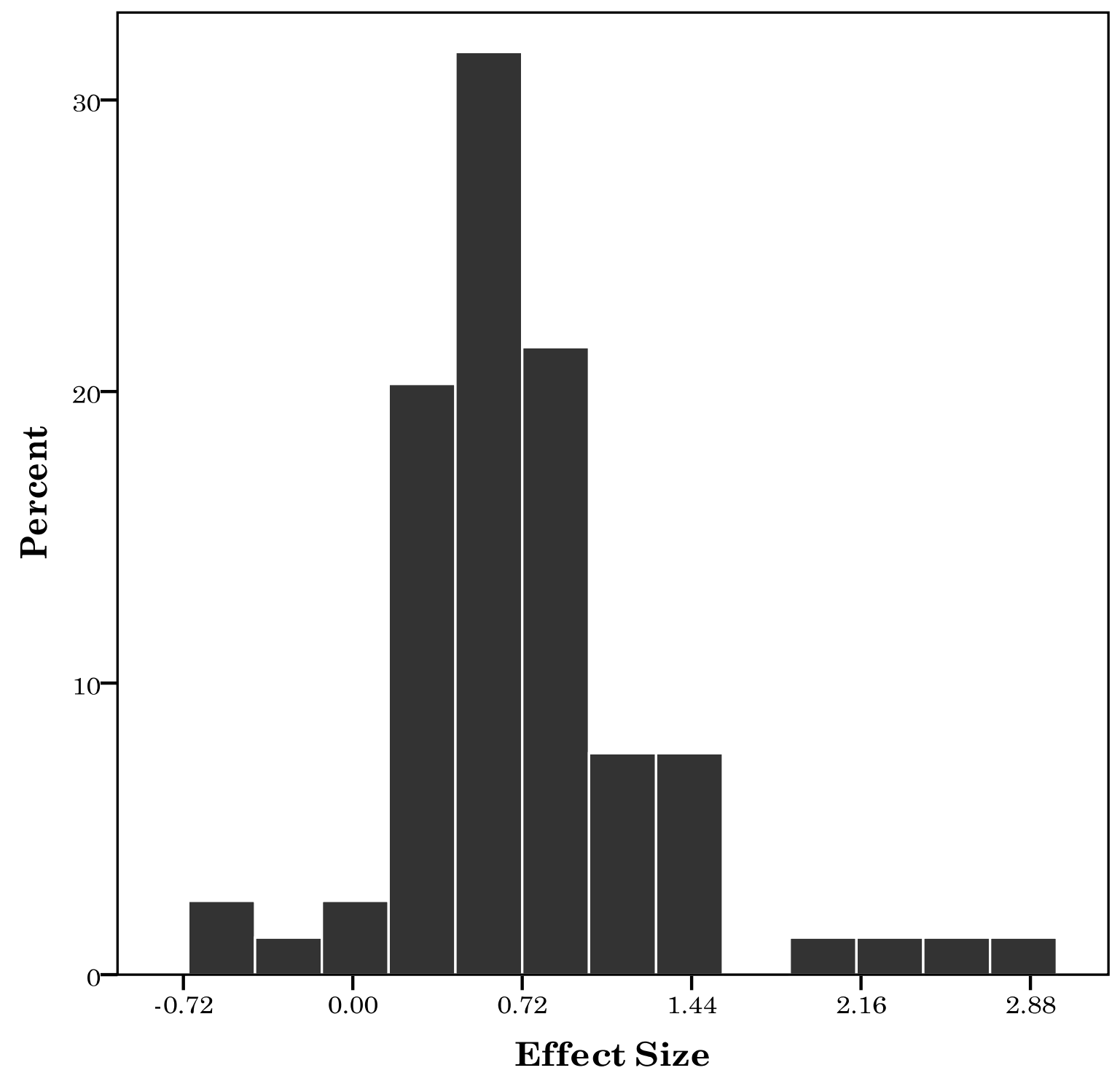

Figure 8. Histogram of Effect Size Estimates for All Studies 
Comparison of Results to Previous Quantitative Analysis

For the 36 studies which provided a normalized gain as an effect estimate, the results were very similar to those reported in Hake (1998). The average effect in normalized gain units for Hake's data was 0.25 , which is the difference between the normalized gain for "interactive engagement" classes $(<\mathrm{g}>=0.48)$ and the normalized gain for traditional classes $(<\mathrm{g}>=0.23)$. Although the studies I analyzed did not always involve traditional control group conditions, the mean difference in normalized gain was 0.19 . That this value is slightly smaller than Hake's value makes logical sense, not only because of differences in the control group conditions, but also because Hake's data relied on the self-reporting of previously unpublished data which may have biased his results slightly upwards. In addition to the overall mean normalized gain, the range of changes in normalized gains I have found is similar to that reported by Hake. His data ranged from about -0.08 to about 0.60 , whereas the data in the present sample ranged from -0.11 to 0.45 .

Variability of Effect Size Distribution

A commonly used statistical meta-analytic tool is the test of homogeneity (see Cooper \& Hedges, 1994; Lipsey and Wilson, 2001). This test evaluates whether the observed variability in effect sizes is larger than that which would be expected from the sampling error within the studies alone. Sampling error is the variation resulting from studying a sample of subjects as opposed to the population as a whole. In this analysis, sampling error pertains to the sampling procedures upon 
which the individual effect sizes were based. In other words, if there is a single population of effect sizes among all innovations, the effect size observed in any one study will differ from the population mean effect size only due to the sampling error within the study.

Sampling error may result from a biased sampling procedure where a sample is selected from the population in a way that insures that the sample has different properties than the population. Additionally, it may result from selecting too small of a sample size in which case the properties of the sample may be different from the population as a result of chance.

In order to illustrate this concept of sampling error, consider the following example. Imagine that you would like to measure the effect of exercise on body weight for adult Americans. If your sampling procedure includes only younger subjects, the results of the analysis may be different than for all adults.

Alternatively, say you decide next to randomly sample people for your study but you only survey 4 individuals. Just by random chance you may have selected a group of people who have an abnormal relationship between exercise and body weight. This will again result in a very different average effect among the sample compared to the population. If, however, you randomly sample a much larger number of individuals, say 10,000, the chances that the average effect of exercise on weight will be different than that of the population will diminish. While your sample will likely include some anomalous cases, there is a much smaller chance that the 
relationship found within the large sample will be drastically different than that of the population.

In this example, the test of homogeneity can be used to test whether there is an overall average effect of exercise on body weight. If there is, the average effect of any study will differ from the average population effect due mainly to sampling error. In other words if there is an overall population average effect of exercise on body weight, the predominant error present among studies has to do with sampling.

If a number of studies on exercise and body weight were examined, the results of the test of homogeneity would indicate whether the variation in effect sizes is larger or smaller than that which would be expected from the sampling error within studies. To put it differently, the test attempts to account for the sampling error of each study and tests whether the observed variability in effect size is larger or smaller than that which is expected as a result of this error. Going back to the example, the null hypothesis of the statistical test is that there is an overall population average effect of exercise on body weight. If the variation in effect size is larger than that which is expected from sampling error, the null hypothesis is rejected. This means that the distribution of effect sizes is heterogeneous. With respect to the example, this would mean that the effect of exercise on body weight is not homogeneous and is variable depending on some other factor, such as type of exercise, exercise duration, or nutrition.

The test of homogeneity is used in this analysis in order to examine whether the observed variability in effect sizes may be due to the sampling error among the 
studies or whether the variation in effect size is likely the result of some characteristic of the study, such as the type of innovation or the methodological characteristic of the study.

The test of homogeneity is based on the Q statistic which is represented as

$$
Q=\sum_{i=1}^{k}\left(\frac{1}{v_{i}}\right)\left(E S_{i}-\overline{E S}\right)^{2}
$$

where $\mathrm{k}$ is the number of effect sizes, $\mathrm{v}_{\mathrm{i}}$ and $\mathrm{ES}_{\mathrm{i}}$ are the individual variances and effect sizes for $\mathrm{i}=1$ to $\mathrm{k}$, and $\overline{E S}$ is the mean effect size. The variance is estimated with the equation:

$$
v_{i}=\frac{n_{T_{i}}+n_{C_{i}}}{n_{T_{i}} n_{C_{i}}}+\frac{E S_{i}^{2}}{2\left(n_{C i}-1\right)}
$$

where the subscripts $\mathrm{T}$ and $\mathrm{C}$ represent the treatment and control groups respectively. If the $\mathrm{Q}$ statistic exceeds the critical value for a chi-square distribution with k-1 degrees of freedom, then the null hypothesis of a homogenous treatment effect is rejected. Therefore, a statistically significant $Q$ statistic indicates a heterogeneous, rather than homogeneous, distribution.

The application of this statistical test in the present context might be considered somewhat dubious for two main reasons. First, it assumes random sampling of participants within each study, which is rare in educational research and completely absent from this dataset. Second, the large spread of the data shown in Figure 8, along with the fact that the data includes studies involving a range of innovations, outcome measures, and methodological designs, already makes it 
apparent that there is heterogeneity in effect size. Nonetheless, I have applied this test to see whether it corroborates my visual presentation of the results above.

The $Q$ statistic for this data was found to be significant $(p<0.0001)$ and therefore the null hypothesis was rejected, indicating that the distribution of effect sizes is likely heterogeneous. Therefore the results suggest that there is not one common effect of innovations; rather, the variability of effect sizes is heterogeneous and likely due to other characteristics of the studies.

In this case the results of the analysis support my previous claims; namely, that the effect size statistics are highly variable, and are likely a result of variations in the characteristics of the studies themselves. Therefore the next step was to attempt to account for the variation in effect size based on the characteristics of these studies.

\section{Accounting for Effect Size Variability}

The purpose of this investigation has been to better understand the relationship between study characteristics and effect size. The variation in study effect sizes may be due to a number of variables which have been coded for, including characteristics of the design and implementation of the innovation, and methodological characteristics of the study. To put it differently, at least some of the observed variability in effect size is due to the different types of innovations used; however, some amount of the variability may be due to other factors such as the study design, the type of control group, and the outcome measure used. Therefore, 
in order to explore the connection between innovation types and effect size only studies with similar methodological characteristics should be considered. This poses a problem, given that there are only 79 studies for which an effect size could be calculated; therefore, it is unlikely that a large enough number of methodologically similar studies will exist in order for an analysis of innovation characteristics to be conducted. Therefore, in order to be as careful as possible about this process, the analysis has been one of increasing accuracy - similar to a funnel. At the top is every study for which an effect size could be calculated $(n=79)$. As the analysis continues down the funnel, only studies with similar methodological characteristics are kept. The next section describes the methodological characteristics which represent cut points along the funnel.

Analysis of Methodological Characteristics

\section{Study Design Implementation}

There are three ways in which the 79 comparative studies with effect sizes have been carried out: two group posttest only designs, pretest-posttest two group designs, and pretest-posttest single group designs. Table 15 shows the effect size descriptive statistics for each study's design implementation. 
Table 17

Effect Size Descriptive Statistics by Design Implementation

\begin{tabular}{lccc}
\hline Design Implementation & Number of Studies & Mean ES & Standard Deviation \\
\hline Posttest only 2 groups & 23 & 0.40 & 0.41 \\
Pretest-Posttest 2 groups & 48 & 0.69 & 0.69 \\
Pretest-Posttest 1 group & 8 & 1.87 & 1.74 \\
\hline
\end{tabular}

Although the effect size statistic is intended for the purpose of comparing the effect of different treatments across studies (Lipsey \& Wilson, 2001), the studies with different design implementations have very different mean effect sizes. The group with the largest mean effect size is the pretest-posttest single group studies. In these studies students' pre-test scores are compared to their post-treatment scores. The major problem with this design is that it does not involve the use of a unique control group. Effect sizes calculated in this way exaggerate the effect of the treatment. Furthermore, the underlying purpose of innovations has been to improve upon the traditional model of physics instruction. Pretest-posttest single group design does not allow for this comparison to be made in the effect size calculation.

In the other two study designs students' scores are compared across a treatment and control group. The mean effect size for studies which included a pretest were much higher than for studies with posttests only, despite the fact that effect sizes were calculated in the same way (i.e. using Equation 2). This difference raises an interesting question, namely what happens to the mean effect size when 
an adjustment is made for differences in pretest scores across treatment and control conditions. How does this adjustment change the mean effect size for these studies?

Several authors have proposed alternative methods for calculating effect size for studies in which pre and posttest scores are used (Becker, 1998; Morris, 2007). Morris (2007) conducted an analysis of several different methods and concluded that one method in particular was superior to others. The equation used in this method is

$$
E S_{\text {Pre-PPost-Test Two Groups }}=\frac{\left(\bar{X}_{\text {T_Post }_{-}}-\bar{X}_{\text {T_Pre }_{-}}\right)-\left(\bar{X}_{\mathrm{C}_{\_} \text {Post }}-\bar{X}_{\mathrm{C}_{-} \text {Pre }}\right)}{S D_{\text {Pooled_Pre }}},
$$

where $\bar{X}$ represents a test score mean for treatment and control conditions (subscripts "T" and "C") administered at the beginning and end of a study period (subscripts "PRE" and "POST"), and $S D$ is computed as the weighted average of the standard deviations across treatment and control groups with the equation

$$
S D_{\text {Pooled_Pre }}=\sqrt{\frac{\left(n_{\mathrm{T}_{-} \text {Pre }}-1\right) S D_{\mathrm{T}_{\text {_Pre }}}^{2}+\left(n_{\mathrm{C}_{\_} \text {Pre }}-1\right) S D_{\mathrm{C} \_ \text {Pre }}^{2}}{\left(n_{\mathrm{T} \_ \text {Pre }}-1\right)+\left(n_{\mathrm{C} \_ \text {Pre }}-1\right)}},
$$

where $n$ represents the sample size.

The effect size for the 48 studies which include a pretest was re-calculated using this equation, yielding a mean effect size of 0.74 and standard deviation of 0.42 , compared to 0.69 and a standard deviation of 0.33 , the mean effect size found with standard posttest only calculation. The difference in the mean effect size across groups with different study designs, i.e. across studies with and without pretest 
scores, becomes greater when the pretest scores are taken into account in the effect size calculation.

The difference in the mean effect size between studies with and without a pretest is due, at least in part, to the equations used in the calculations. Figure 9 shows the algebra used to put the pretest-posttest two group effect size equation in terms of the posttest only equation in order to understand the specific factors driving the calculation. The results indicate that there are two factors affecting the difference between the pretest-posttest statistic and the posttest only statistic: factor " $\mathrm{A}$ " which is the ratio between the control groups' posttest standard deviation and the pooled pretest standard deviation, and factor " $\mathrm{B}$ " which is the difference between pretest scores for treatment and control groups standardized by the pooled pretest standard deviation. 


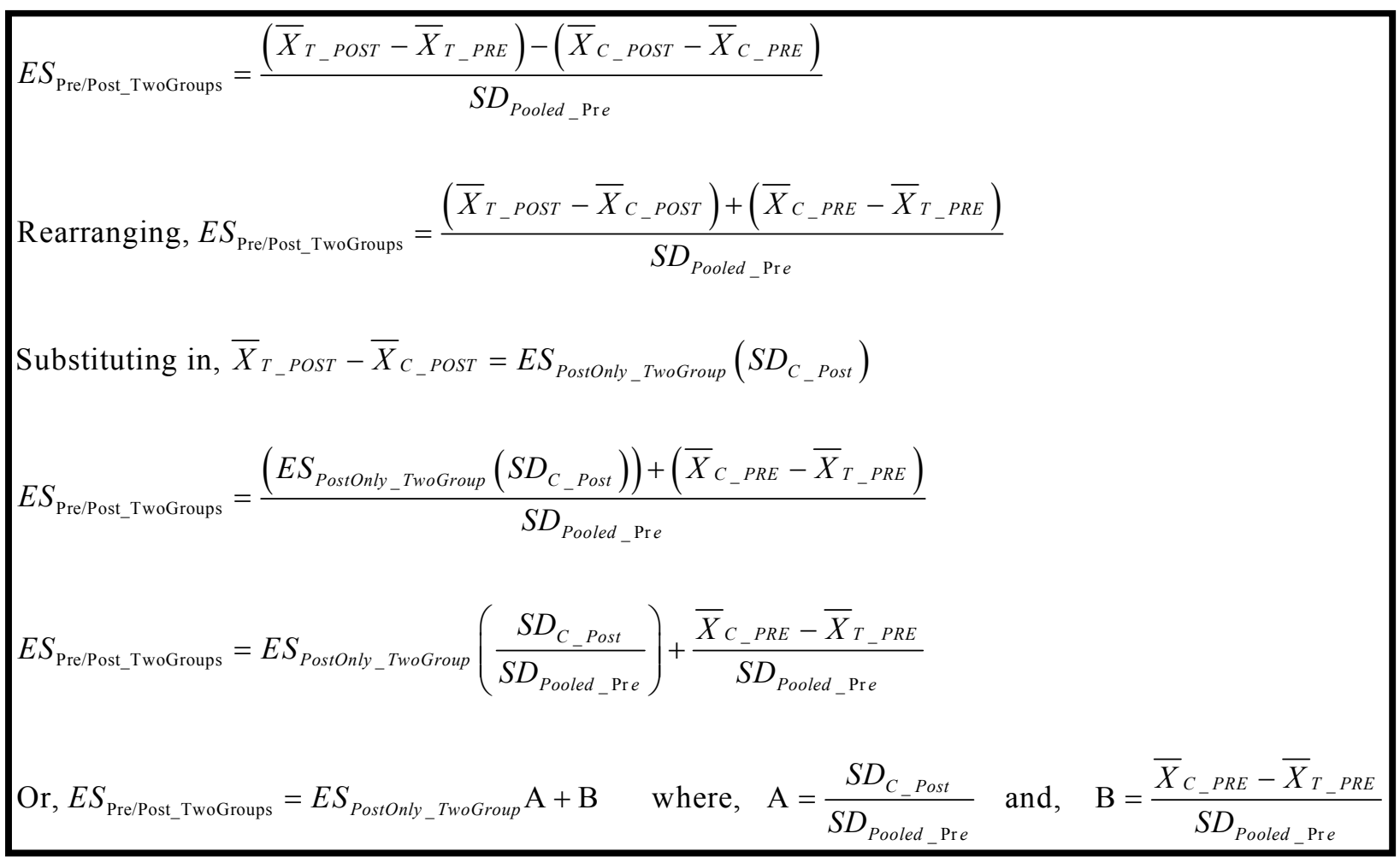

Figure 9. Equating Pretest-Posttest Effect Size in terms of Posttest Only Effect Size

Increases in both factors A and B will increase the difference between the effect size calculations. For the 48 studies:

$$
\begin{aligned}
& \bar{X}_{A}=1.13(\mathrm{SD}=0.19, \min =0.88, \max =1.57) \\
& \bar{X}_{B}=0.11(\mathrm{SD}=0.34, \min =-0.65, \max =0.70)
\end{aligned}
$$

where $\bar{X}$ is the mean value for factors $\mathrm{A}$ and B. That $\bar{X}_{\mathrm{A}}$ is larger than 1 indicates that, on average, the control group's posttest standard deviation is larger than the pooled pretest standard deviation. That $\bar{X}_{\mathrm{B}}$ is positive indicates that, on average, the control group's pretest mean is larger than the posttest mean. This indicates that the selection bias in most studies actually has a negative impact on effect size, meaning that effect estimates may actually be higher than those calculated. This 
empirical data explains why it is that on average, for the same studies, an effect size calculated using the pretest-posttest approach will be larger than effect sizes found with the posttest only approach. This will be the case anytime the control group's posttest standard deviation is larger than the pooled pretest standard deviations, and/or the control group has a higher pretest score.

The difference in the effect size across the two different types of calculations for pretest-posttest 2 group studies indicates that each method provides a different picture of the effect of a study. For the studies with pretest data, the effect size shifts when differences in the mean pretest scores and standard deviations across the treatment and control groups are taken into account. To mitigate that threat of selection bias in the present analysis, effect sizes will be calculated using Equation 9 which takes into account pretest scores. In order to illustrate how the use of Equation 9 mitigates the threat of selection bias I will provide a brief example from the data.

Wick \& Ramsdell (2004) investigated the effect of their course innovation with two different control groups. In other words, all aspects of the study remained constant except that two different control groups were used. The first control group consisted of students who chose not to participate in the project, i.e. treatment, and who received traditional-style instruction. Using this control group the posttest only effect size calculation (i.e. Equation 2) yielded an effect of 1.00. The second control group was a selection of students from the first control group who had comparable SAT and pretest scores to the students in the treatment group. The authors were 
correct in assuming that students who chose to participate in the treatment tended to be higher achievers than those in the control group. When this second control group is used the effect of the treatment, again using the posttest only calculation shown in Equation 2, was only 0.41. However, when the effect size calculation which takes into account pretest data is used (Equation 9), the effect size of the first study drops from 1.00 down to 0.49 . However, the effect size for the second study in which the control group was statistically similar to the treatment group at the start of the experiment, the effect size increases from 0.41 to 0.52 when the pretest data is taken into account. Therefore when Equation 9 is used, the two effect sizes for this innovation are comparable (differing only by 0.03). This illustrates the mitigating effect that accounting for pre conditions in the effect size calculation can have on the threat of selection bias.

In summary, the previous section suggests that studies of different design implementations have significantly different mean effect sizes for some known and other unknown reasons. The pool of studies which include pretest and posttest scores for both a treatment and control group represent the largest group with 48 studies. In addition, this study design is subject to fewer threats to internal validity than those that do not include a control group and do not include pretest data, especially when the pretest conditions are taken into account in the effect size calculation. Therefore studies which include pretest and posttest data across two groups represent the first cut-point in the analysis. Only these 48 studies have been included in the subsequent analysis. 


\section{Control Group Characteristics}

In order to disaggregate the possible differences in studies with different types of control groups, two types of control groups were coded: control groups with a traditional experience, and those which experience something else (typically another innovation or some aspect of an innovation). The mean effect size for these groups is shown in Table 16 below. Studies involving a traditional-style control group had a higher mean effect size compared to the studies with an "other" type of control group: however, this difference is minimal.

Table 18

Effect Size Descriptive Statistics of Studies with a Control Group by Type of Control

\begin{tabular}{lccc}
\hline Control Group Type & Number of Studies & Mean & Standard Deviation \\
\hline Traditional & 31 & 0.75 & 0.45 \\
Other & 17 & 0.73 & 0.35 \\
\hline
\end{tabular}

The largest group consisted of the 31 studies which use a traditional control group. This group allows for the best comparison across different innovations because the control group experience is held somewhat constant. While there are some variations amongst "traditional" classes, there are far more among the "other" treatment group category. In addition, one of the primary motivational factors for innovation has been to improve upon the traditional model of undergraduate physics education. Therefore studies which use a traditional control group allow for 
this comparison to be made directly. For this reason, studies which include traditional control groups represent the second cut-point in the analysis. Only these 31 studies have been included in the subsequent analysis.

\section{Outcome Measure Characteristics}

Researchers use outcome measures which are either developed internally for the specific needs of a study, or those which have been developed externally, or both. There are several examples of papers in which the effect of a treatment is examined using two different outcome measures. In one extreme case, two different outcome measures used in the exact same study accounted for the smallest and the second largest effect sizes in the entire pool (Hoellwarth, Moelter, \& Knight, 2005). In this study a negative effect size (-0.62) was found when an internally developed highly quantitative problem-solving exam was used to calculate the effect. A very large positive effect size (1.34) was found when the externally developed Force Concept Inventory was used to calculate the effect. Clearly, as this study indicates, the outcome measure used in a study has an impact on effect size. Although the Hoellwarth, Moelter, and Knight (2005) study had a lower effect size for the internally developed outcome measure that for the internally developed outcome measure, these results were not typical. Table 17 provides the mean effect size for studies with each type of outcome measure development. 
Table 19

Effect Size Descriptive Statistics by Outcome Measure Development

\begin{tabular}{lccc}
\hline Outcome Measure Development & $\mathrm{n}$ & Mean & Standard Deviation \\
\hline Externally & 26 & 0.69 & 0.43 \\
Internally & 5 & 1.09 & 0.43 \\
\hline
\end{tabular}

The studies using internally developed outcome measures had higher mean effect sizes than those using internally developed outcome measure. The difference across studies using different outcome measures may be because internally developed outcome measures are often very closely linked to the intended purpose of the innovation and tend to be more sensitive to changes in students (Ruiz-Primo, Shavelson, Hamilton, \& Klein, 2002). For example, Redish, Saul, and Steinberg (1997) also used the Force Concept Inventory but reported their results in two different ways. In one study the full FCI was used and in the other a sub-section of the FCI was used. When the full FCI was used the effect of the treatment was 0.65 . When the sub-section of the FCI was used, which consisted only of items closer to the specific content covered in the innovation, the effect was 1.21 . While both of these studies use the FCI, the study that used only a sub-section of the FCI was coded as an internally developed outcome measure because it was altered from the original FCI in order to suit the needs of the study.

An additional aspect of outcome measures is the type of item included on the instrument. Within the 31 studies in this part of the analysis there were two 
different item types: multiple-choice and open-ended. Table 18 shows the mean effect size for these studies.

Table 20

Effect Size Descriptive Statistics by Outcome Measure Item Type

\begin{tabular}{lccc}
\hline Outcome Measure Development & $\mathrm{n}$ & Mean & Standard Deviation \\
\hline Multiple-Choice & 28 & 0.80 & 0.41 \\
Open-Ended & 3 & 0.26 & 0.63 \\
\hline
\end{tabular}

The three studies which use an outcome measure with open-ended items had a much lower mean effect size than the 28 studies which use multiple-choice items. The three studies with open-ended items all come from the same paper which investigated the effect of three slightly different innovations. The outcome measure consisted of a single item for which student responses were scored prior to and after instruction. Single item instruments pose an issue for the validity and reliability of the measure, as well as for the study. Therefore these three studies have been eliminated in the third cut.

In summary, the third cut of studies has to do with the characteristics of the outcome measure used. At this cut-point studies have been eliminated if the outcome measure is not a multiple-choice test which has been externally developed. There are 23 studies which are similar with respect to the methodological characteristics described above. 


\section{Summary of Methodological Characteristics}

The preceding analysis has identified three methodological factors which impact the magnitude of the effect size of a study: study design, control group type, and outcome measure type. A linear regression analysis was used to evaluate the degree to which these factors account for the variability in effect size. Overall, these factors account for $47 \%$ of the variance in effect size. Table 19 shows the parameter estimates and significance for each predictor variable.

Table 21

Parameter Estimates for the Linear Regression

\begin{tabular}{llcc} 
& & $\begin{array}{c}\text { Parameter } \\
\text { Estimates }\end{array}$ & Significance \\
\hline & Intercept & 0.75 & 0.00 \\
\hline \multirow{2}{*}{ Cut 1 - Study Design } & Pretest-Posttest 1 Group & 1.11 & 0.00 \\
& Posttest Only 2 Groups & -0.38 & 0.02 \\
\hline Cut 2 - Control Group & Other Control Group & -0.01 & 0.95 \\
\hline \multirow{2}{*}{ Cut 3 - Outcome Measure } & Internally Developed & 0.10 & 0.50 \\
& Open-ended Items & -0.21 & 0.19 \\
\hline
\end{tabular}

$\mathrm{R}=0.69, \mathrm{R}^{2}=0.47, \mathrm{RMSE}=0.45$

The parameter estimates for the model ranged between extremely large (1.11) and near zero (-0.01) for the variables. In addition, the significance values 
were highly variable ranging between 0.00 and 0.95 . However, the purpose of this analysis was not to explain variability or have significant parameter estimates. The purpose of this analysis was to reduce the pool of papers to more and more methodologically similar studies in order to investigate the possible relationship between innovation type and effect size. However, as it turned out, a good deal of the effect size variability was likely due to the way in which the innovations were studied rather than the characteristics of the innovation itself. This is the phenomenon that I wanted to illustrate through the use of a regression analysis.

\section{Analysis of Innovation Characteristics}

The goal of this meta-analysis has been to understand the relationship between innovation characteristics and effect size. The strength of a relationship of this type lies in the number of studies which have similar innovation characteristics. A challenge in this meta-analysis is that the methodological characteristics of the studies have a large impact on effect size, regardless of the innovation used. Therefore, as more and more methodologically similar studies are considered, it follows that the number of studies will decrease.

This meta-analysis has been conducted as a multi-stage process of increasing accuracy and decreasing sample size, which balances the accuracy of analysis with the strength of findings. The first analysis was done with all of the studies for which an effect size could be calculated $(n=79)$. The second was done after the studies which did not make the first cut regarding the study design implementation were 
eliminated $(n=48)$. The third was done after the studies which did not make the second cut regarding the control group were eliminated $(n=31)$. The fourth was done after the studies which did not make the third cut regarding the outcome measure development and item type were eliminated $(n=23)$. As studies were cut and the analysis progressed, the accuracy of the analysis increased; however, the strength of the findings decreases as the total number of studies decreased. The goal in this process of continually whittling down the sample has been to strike a balance between the accuracy and strength of the findings.

The innovation characteristic first considered in this meta-analysis is the innovation category type. The mean effect sizes for each group are shown in Table 20. In order to simplify the analysis, only groups with more than 3 studies are shown and those with less than 3 have been combined into an "other" category. 


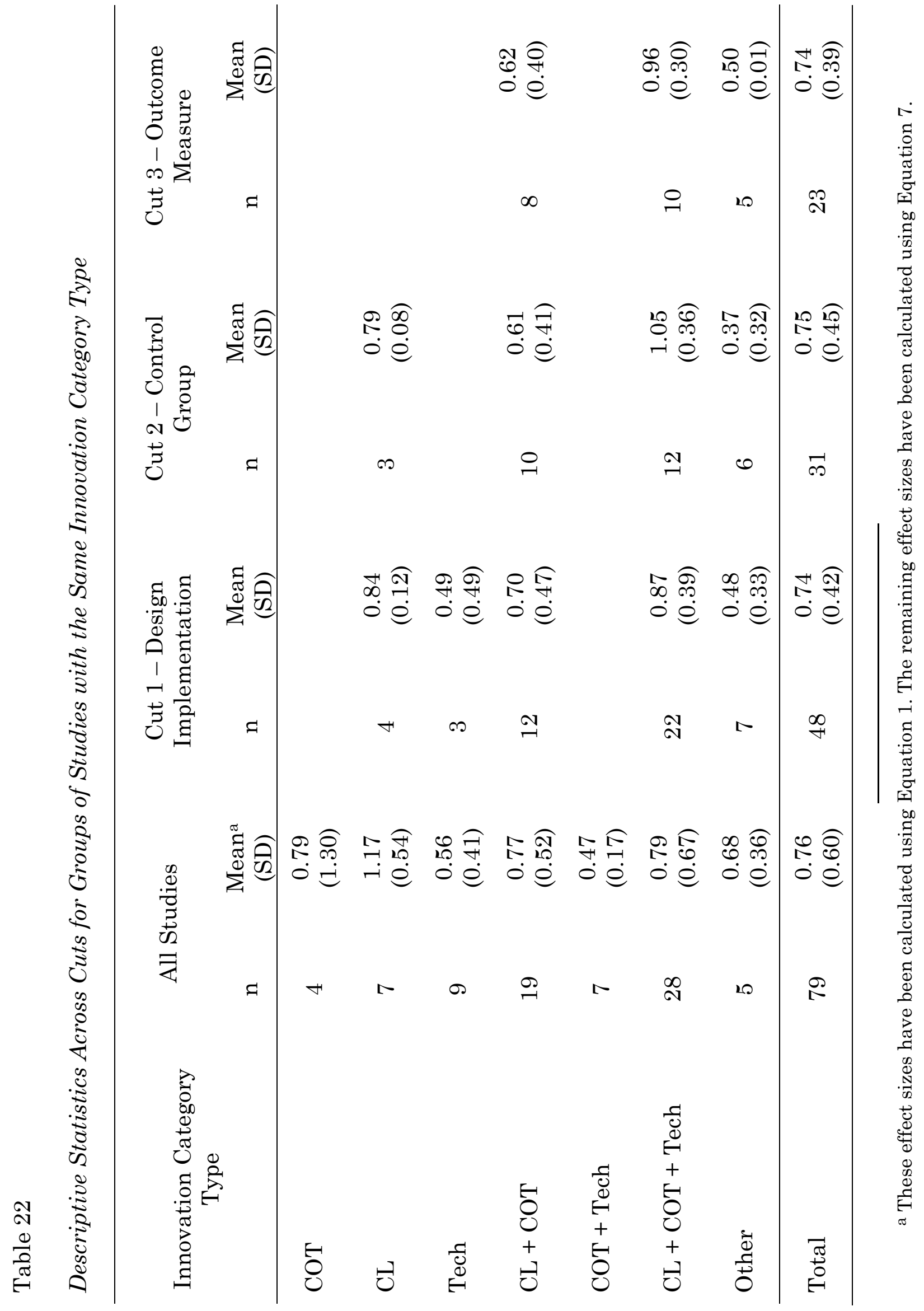


The most dramatic shift in the mean effect size for groups occurs after the first cut. The elimination of studies which do not involve a control group and do not include pretest data lowers the mean effect size of all groups except for innovations involving collaborative learning, conceptually oriented tasks, and technology. This category also has the highest mean effect size after the first cut. This trend continues after the second and third cut - innovations with collaborative learning, conceptually oriented tasks, and technology continue to have the highest mean effect size of any other group. After the last cut the predominant trend is between innovations with collaborative learning and conceptually oriented tasks with and without technology. At cut-point 3 the group with the addition of technology has a higher mean effect size by 0.35 . The innovations with the addition of technology have higher mean effect sizes than those with just collaborative learning and conceptually oriented tasks across all three cut-points.

In addition to the innovation categories, the known instructional innovations have also been considered in accounting for the variability of study effect sizes. Table 21 shows the descriptive statistics for the effect size within each group. Most studies which employ known innovations use them in combination with other known innovations rather than alone. However, because there are so many different combinations the table summarizes the statistics for any study which uses the known innovation either alone or in combination. In other words, the categories for known instructional innovations are not mutually exclusive, and most involve overlaps. 


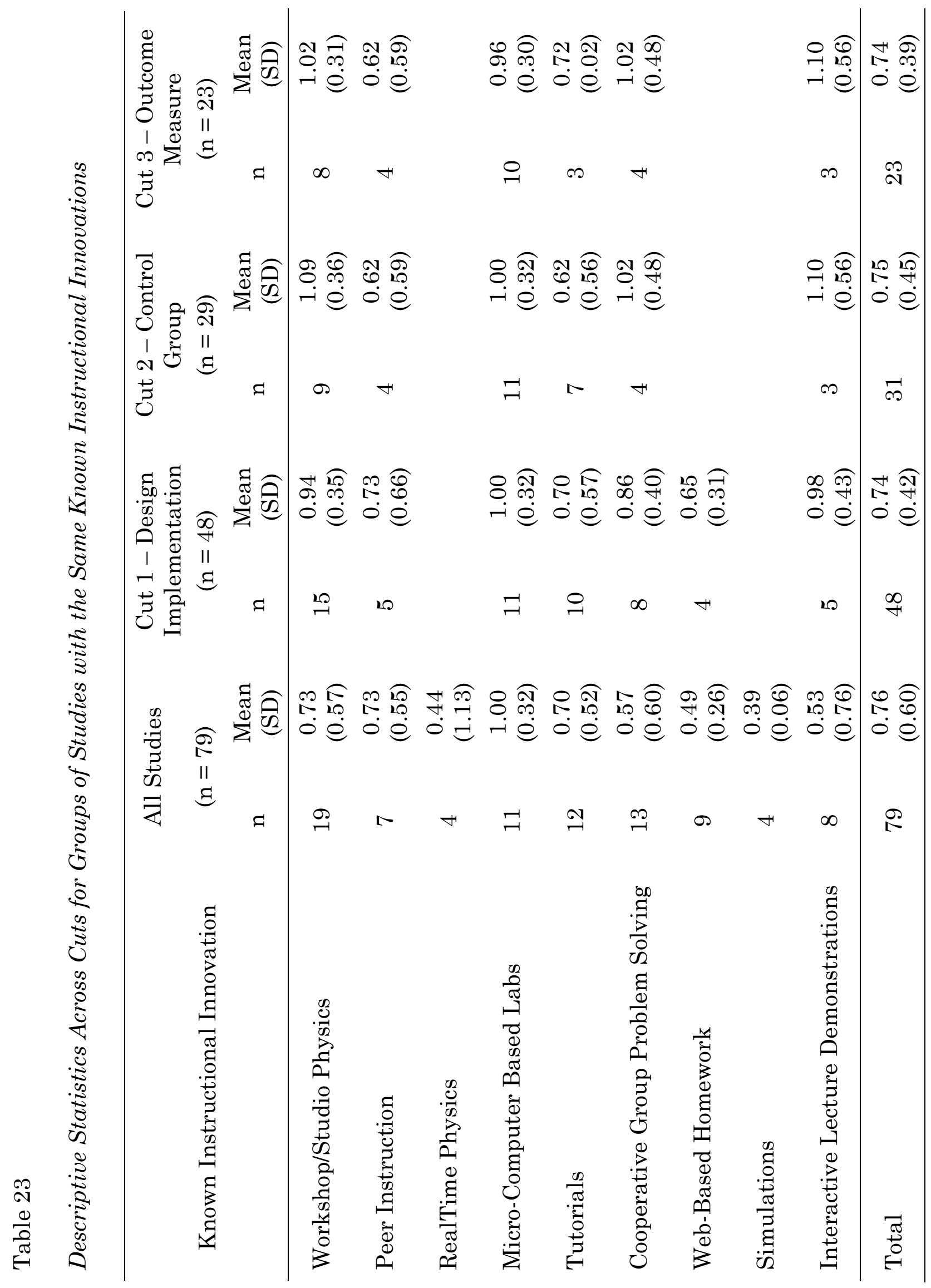


The major trend in the mean effect sizes across Table 21 is that innovations using Workshop/Studio Physics, Micro-Computer Based Labs, Cooperative Group Problem Solving, and Interactive Lecture Demonstrations have the highest mean effect sizes. There are three known instructional innovations which have particularly low mean effect sizes: RealTime Physics, web-based homework, and simulations. However, after the first cut is made the remaining known instructional innovations have mean effect sizes which are either close to the overall mean or are much higher.

A closer analysis of the studies with high effect sizes revealed that they all have one known instructional innovation in common: Workshop/Studio Physics. In other words, of the 10 studies using micro-computer based labs 8 involve Workshop/Studio Physics, and all of the studies using Cooperative Group Problem Solving and Interactive Lecture Demonstrations also use Workshop/Studio Physics. Of the 23 studies left after the third cut there is only one Workshop/Studio Physics implementation with an effect size in the lower $50 \%$ of the effect size distribution. Of these 23 studies, there are 14 which use known instructional innovations and 7 of the top 8 use Workshop/Studio Physics.

In summary this meta-analysis has shown that, after controlling for differences in the methodological characteristics of studies, innovations involving collaborative learning, conceptually oriented tasks, and technology have higher mean effect sizes than those that involve other innovation types. In addition, studies that involve Workshop/Studio Physics have higher mean effect sizes than 
those that use other known instructional models. Upon closer analysis, however, there is a significant overlap between studies coded as involving collaborative learning, conceptually oriented tasks and technology and studies involving Workshop/Studio Physics. Table 22 shows the degree of overlap across these studies. Studies are listed according to increasing effect size. 
Table 24

Relationship Between Innovation Type and Known Instructional Innovation

\begin{tabular}{|c|c|c|c|}
\hline Paper Citation & Effect Size & $\mathrm{CL}+\mathrm{COT}+\mathrm{Tech}$ & Workshop Physics \\
\hline Cheng et al. (2004) & -0.24 & & \\
\hline Larkin (2005) & 0.01 & & \\
\hline Zhou et al. (2005) & 0.49 & & \\
\hline Wick et al. (2004) & 0.49 & & \\
\hline Hoellwarth et al. (2005) & 0.52 & $\mathrm{X}$ & $\mathrm{X}$ \\
\hline Wick et al. (2004) & 0.52 & & \\
\hline Cheng et al. (2005) & 0.52 & & \\
\hline Cheng et al. (2005) & 0.55 & & \\
\hline Redish et al. (1997) & 0.70 & $\mathrm{X}$ & \\
\hline Redish et al. (1999) & 0.72 & & \\
\hline Redish et al. (1997) & 0.73 & $\mathrm{X}$ & \\
\hline Lenaerts et al. (2003) & 0.75 & & \\
\hline Cheng et al. (2005) & 0.75 & & \\
\hline Lasry et al. (2007) & 0.79 & & \\
\hline Sorensen et al. (2006) & 0.89 & $\mathrm{X}$ & $\mathrm{X}$ \\
\hline Redish et al. (1999) & 0.92 & $\mathrm{X}$ & $\mathrm{X}$ \\
\hline Beichner et al. (1999) & 0.96 & $\mathrm{X}$ & $\mathrm{X}$ \\
\hline Cataloglu (2007) & 0.99 & & \\
\hline Beichner et al. (2007) & 1.02 & $\mathrm{X}$ & $\mathrm{X}$ \\
\hline Beichner et al. (1999) & 1.02 & $\mathrm{X}$ & $\mathrm{X}$ \\
\hline Johnson et al. (2001) & 1.16 & & \\
\hline Hoellwarth et al. (2005) & 1.17 & $\mathrm{X}$ & $\mathrm{X}$ \\
\hline Hoellwarth et al. (2005) & 1.62 & $\mathrm{X}$ & $\mathrm{X}$ \\
\hline
\end{tabular}


Of the 10 studies involving collaborative learning, conceptually oriented tasks, and technology, 8 are also Workshop/Studio Physics enactments. Furthermore, all of the CL+COT+Tech studies which are above the mean of 0.78 are also Workshop/Studio Physics. This evidence indicates that the Workshop/Physics model has a high positive effect on student learning on average. But what is it about this innovation that is resulting in such high effect sizes?

In order to gain a more comprehensive understanding of the critical features of the Workshop/Studio Physics instructional model a case study analysis has been conducted. The following chapter describes the results of this case study analysis.

\section{Summary}

The overall mean effect size for innovations within the sample of studies was 0.76 for all 79 studies and 0.74 for the 23 methodologically similar studies. These two effect sizes are remarkably similar, suggesting some stability in the effect of these innovations on student learning, at least within the sample of studies sampled. To place this effect size in the context of previous meta-analyses on educational interventions, the federally funded Reading First initiative in California reported an effect size of only 0.082 (Haager, Heimichner, Dhar, Moulton, \& McMillan, 2008), and yet this was identified as a "significant impact on student achievement in California" (p. 1). The authors' assessment of the effect size they found highlights just how rare it is to find large effect sizes in educational studies. Similarly, Hattie and Timperley (2007) report mean effect sizes for 13 different meta-analyses on the impact of feedback on student learning. The mean effect sizes 
for these 13 studies range between 0.12 and 1.24. The mean effect size I found in this dissertation ranks among the top 4 mean effect sizes in the meta-analyses described in Hattie and Timperley (2007).

Comparisons to these meta-analyses indicate that the mean effect size I found in this dissertation is high in the context of studies of educational reforms, suggesting just how much of an impact these innovations have on student learning. While overall the sampled studies have large positive effect sizes, there was one innovation in particular which stood out in the analysis as particularly effective Workshop/Studio Physics. 


\section{CHAPTER VI}

\section{CASE STUDY OF WORKSHOP/STUDIO PHYSICS}

The analyses in the previous chapter highlighted Workshop/Studio Physics as an instructional innovation which, on average, had the largest effect on student learning. I conducted a case study analysis of Workshop/Studio Physics in order to help illustrate the classroom practices. The goal of this analysis was to identify the critical features of this innovation.

I drew upon three sources of data for this case study which I will briefly review here. The first source of data was published journal articles on Workshop/Studio Physics which already existed in the sample of papers - this included 9 articles. Of these articles 1 was a descriptive study, 3 were comparative studies for which effect sizes could not be calculated, and 5 were comparative studies for which effect sizes could be calculated. In addition to these papers, I used several supplementary documents. These included 2 journal articles, 1 book, and 1 dissertation on a Workshop/Studio Physics enactment. In addition, a popular Workshop/Studio Physics curriculum, the Workshop Physics Activity Guide, was used. Lastly, interviews were conducted with 4 key implementers of Workshop/Studio Physics: Priscilla Laws, a professor at Dickenson College and the original developer of Workshop/Studio Physics; Jack Wilson, the president of the University of Massachusetts who was one of the first implementers of Workshop/Studio Physics while he was a physics professor at Rensselaer 
Polytechnic Institute; Robert Beichner, a key implementer and developer of the Workshop/Studio Physics model at North Carolina State University, and Juliet Brosing, a key implementer at Pacific University.

In the next sections I provide a brief overview of the Workshop/Studio Physics innovation followed by a section describing each of the 5 critical characteristics I identified. Following these sections is a summary of the critical characteristics and a table summarizing the analysis of the case study documents.

In the last section of this chapter I describe a further content analysis of the 23 studies with similar methodological characteristics which were described at the end of the preceding meta-analysis chapter. The purpose of this analysis was to look for confirming and disconfirming evidence for the presence of the critical characteristics of Workshop/Studio Physics among other studies with high and low effect sizes. In other words, the studies left in the meta-analysis after cut 3 have been re-coded for the 5 critical characteristics of Workshop/Studio Physics. Finally, I conducted a mini-meta-analysis has been conducted to see whether these features are common among other studies with high effect sizes, or are absent among studies with low effect sizes.

\section{Overview of Workshop/Studio Physics}

Workshop/Studio Physics involves the integration of the lecture, laboratory, and recitation components of a physics course which are traditionally separated. Workshop classes are held in a classroom rather than a lecture hall and can 
accommodate around 50 students with 1 to 2 instructors or instructor's assistants. Students work in collaborative groups at round tables or large work benches. The majority of class-time is spent on student activities and group-work with a very minor amount spent on lectures and whole-class activities.

The first Workshop-style courses were initiated at Dickinson College in the late 1980s by Professor Priscilla Laws (Laws, 1991). According to Laws, this work grew out of a desire to teach students transferable inquiry skills. These skills involve the "development of enough knowledge in an area of science to allow intelligent study and observation to lead to subsequent learning without formal instruction" (quote by Arnold Arons and cited in Laws, 1991, p. 25). Laws' "classroom laboratories" (Laws, 1991, p. 25) eliminated formal lectures in favor of focusing class time on activities in which students actively participate in observing phenomena, collecting and analyzing data through the use of specially designed micro-computers and data probes, and developing models to explain their observations (Laws, personal communication, 2011). These activities have been organized and published in a popular activity guide called The Workshop Physics Activity Guide (Laws, 2004).

Building on Laws' model, Workshop-style innovations have since been developed and enacted at universities across the country. However, it is difficult to trace the degree to which these innovations were based upon Laws' original work. As Laws conveyed to me in an interview, an interesting sociological phenomenon is 
that subsequent researchers who adopt the innovation do not always cite its originator. As Laws stated,

"If an institution adopts an innovation that was developed at another institution, they give the other institution credit if they feel [that] they are lower status. If they feel that they are higher status they give it their own name and don't credit the originators."

For example, Laws' innovation is called Workshop/Studio Physics at Dickinson College and Pacific University (Laws, 1991; Brosing, personal communication, 2011), Studio Physics at Rensselaer Polytechnic University (Wilson, 1994), New Studio Physics at Kansas State University (Sorensen, Churukian, Maleki, \& Zollman, 2006), SCALE-UP at North Carolina State University (Beichner et al., 2007), and Cockpit Physics at the US Air Force Academy (Wilson, personal communication, 2011), to name a few.

While the specific instantiation of Workshop/Studio Physics at these universities has been somewhat different, I have identified five critical characteristics through this case study analysis. These five critical characteristics are: (1) the organization of the classroom, (2) the use of collaborative learning, (3) the use of technology, (4) the type of student activities used, and (5) the role of the instructor. These five critical characteristics are described in the sections below. The final section provides a summary. 
Organization of the Classroom

One of the defining characteristics of Workshop/Studio Physics is the integration of the traditionally separate lecture, laboratory, and recitation components of a course (Cummings, Marx, Thornton, Kuhl, 1999) so that students meet only in the workshop classroom. The integrated classroom environment was mentioned in each of the articles used in this case study and by all four of the Workshop/Studio Physics interviewees. Occasionally a university will not offer a recitation section in traditionally taught courses and therefore the Workshop courses implemented at these places involve the integration of the laboratory and lecture sections only (see Cummings et al., $1999 \&$ Hoellwarth et al., 2005). In one paper (Sornesen et al., 2006) the authors purposefully combined the laboratory and recitation sections while retaining the separate lecture component of the course. However, the Sorensen et al. (2006) study had the second to lowest Workshop/Studio Physics effect size within the final pool of 23 studies in the metaanalysis described above.

The integration of the different course components naturally requires a classroom environment that is a hybrid as well. Studio courses are typically held in laboratories or classrooms, rather than lecture halls, which are organized with seats surrounding round tables or benches. These rooms are often organized so that there is no distinct front or back to the room (e.g. Dori \& Belcher, 2005), or such that the work tables radiate from some central location where instructors can present information to the class as a whole (e.g. Redish, 2003). In one Workshop/Studio 
Physics class, student worktables are organized so that they can be supervised at all times by the instructor (e.g. Wilson, 1994). In this instantiation, workstations are arranged so that when students are working together on an assigned problem, they turn away from the center of the room and focus on their own small-group workspace. The instructor is able to see all workstation screens from the center of the oval, and thereby receives direct feedback on how things are going for the students (Wilson, 1994, p. 520). While the Workshop/Studio Physics instantiation described in Wilson (1994) involves rectangular workstations, most Studio classrooms involve round tables that can accommodate between 2 (e.g. Redish, 2003) and 9 students (e.g. Dori \& Belcher, 2005, and Beichner et al., 2007). Beichner et al., (1999) implemented Studio classes with both rectangular and circular workstations and found that the circular tables allowed instructors to circulate the room more easily.

While most studio classes are held in specially designed classrooms, when these facilities are not available laboratories or regular classrooms are repurposed. Barak, Harward, Kocur, and Lerman (2007) investigated the enactment of a Workshop/Studio Physics course in a standard lecture hall environment. While this enactment had a fairly high effect size of 0.40 , it is significantly lower than the effect size found for a companion study done at the same university which was 1.31 (see Dori, Hult, Breslow, Belcher, 2007). It is difficult, however, to directly compare these two studies because they took place within different courses with different 
students. Therefore the Barak et al. (2007) study cannot be considered an exact comparison to the Dori et al. (2007) study.

The physical layout of Workshop/Studio Physics classes also results in a reduction in the number of students that can be accommodated in one class compared to traditional instruction. Most traditional lecture classes can accommodate 300 or more students in a single class; however, Workshop/Studio classes are designed for a much smaller number of students, comparable to a large recitation section. In the original Workshop course, Laws (1991) designed classes to accommodate around 25 students per class. However, this is likely because the innovation was created at Dickinson College which is a relatively small liberal arts college. Most Workshop classes are designed to accommodate between 30 and 60 students (e.g. Beichner et al. 1999, Cummings et al. 1999, Hoellwarth et al., 2005, Sorensen et al. 2006, and Wilson, 1994). One project in particular, the SCALE-UP Project at North Carolina University, investigated the extent to which a Workshop course could be scaled to include up to 100 students in a single class section (Beichner, et al., 2007). Despite this difference, the effect size for the SCALE-UP study $(\mathrm{ES}=0.90)$ was exactly the same as the effect size for a similar study at the same university with class sizes between 30 and 35 (Beichner, 1999, ES = 0.90).

The instructor-to-student ratio may be one of the reasons why the SCALE-UP sections with 100 students were just as effective as those with 30 students, because the SCALE-UP project increased the number of instructors along with the number of students per class. In this study, researchers retained North Carolina State 
University's instructor-to-student ratio of around 1:33 across both studies (Beichner et al. 1999, 2007). Most studies had instructor-to-student ratios of between 1:33 and 1:40 (Cummings et al. 1999, Hoellwarth et al., 2005, and Sornesen et al., 2006) with a few notable outliers. Redish (2003) reported a ratio of 1:15, and Wilson (1994) reported a ratio of 1:55. Unfortunately, these outliers did not report data from an empirical study, and therefore it is not possible to assess the impact of the instructor-to-student ratio on student learning using this data.

In summary, one of the critical characteristics of Workshop/Studio Physics is the unique organization of the classroom environment. In this innovation, classes take place in a single location rather than in traditionally separated lecture, recitation, and laboratory classrooms. In fact, the results of one study (Sorensen et al., 2006) described above suggest that the integration of all three class components is an essential characteristic for highly effective Workshop/Studio Physics enactments.

The Workshop/Studio Physics classroom environment is arranged with large round tables for students to work at. While this classroom environment necessitates a decrease in the number of students within each class, the empirical results from two studies (Beichner et al. 1999, 2007) indicate that it is the reduced instructor to student ratio, and not just the reduction in class size, which is essential in a Workshop/Studio Physics enactment. The next section describes another critical characteristic of Workshop/Studio Physics: collaborative learning. 


\section{Collaborative Learning}

Collaborative group work is a key aspect of each enactment of Workshop/Studio Physics. The organization of the Workshop/Studio Physics classroom, described above, is built around student group work. In fact, the explicit mention of group work was present in every paper with the exception of one which instead describes the innovation as involving an increase in student-to-student interactions (Barak, Harward, Kocue, \& Lerman, 2007). In addition, when asked to describe the innovation of Workshop/Studio Physics, all four interviewees mentioned group work. There is quite a range, however, in the degree to which the nature of the group work is described, mainly in the articles. For example, Cummings et al. (1999), Hoellwarth et al. (2005), and Redish (2003) stated only that students worked in groups without any additional information. Several other studies describe the number of students in each group; for example, Wilson (1994) reported that students work in groups of two, while Dori et al. (2005) reported that students work in groups of three, Sorensen et al. (2006) reports that students work in groups of four, and Laws (2004) describes in the Workshop Physics Activity Guide that the number of groups be variable depending on the specific task and the availability of laboratory materials.

In a few instances the authors provided additional information into the nature of the group work. For example, Beichner et al. (1999) stated that students work in carefully designed groups of three which are heterogeneous with respect to ability, gender, and race. In addition, while these groups were kept for the whole 
semester, group roles were explicitly taught and rotated periodically. Lastly, individual course grades involved a group component along with an individual component. The later instantiation of this innovation, the SCALE-UP project (Beichner et al., 2007), altered the model such that groups were shifted three or so times a semester while keeping them heterogeneous with respect to ability and gender. In addition, students received specific instruction for working in collaborative groups effectively. As rationale for these carefully organized collaborative groups, the authors cited the seminal work of David and Roger Johnson (e.g. Johnson \& Johnson, 1994).

The studies which included structured collaborative learning (Beichner et al. 1999, 2007) have some of the highest effect sizes for Workshop/Studio Physics, ranging from 0.92 to 1.02 . Although, the use of structured vs. unstructured group work was not explicitly examined in any study on Workshop/Studio Physics, the result suggest that this may be a particularly effective feature within the overall critical characteristics of collaborative learning. The next section describes the use of technology in Workshop/Studio Physics which is an additional critical characteristic.

Technology

In interviews, Priscilla Laws, Robert Beichner, Jack Wilson, and Juliet Brosing described technology as a central component of Workshop/Studio Physics. In addition, each of the text documents described the use of technology in the 
Workshop/Studio Physics model. In most Workshop/Studio Physics courses a laptop computer is provided for every two students, and in one study (Barak et al. (2007) each student was required to use their own laptop computer in class. The computers are used for a variety of purposes, including viewing and manipulating simulations (Beichner et al., 1999, 2007, Laws, 2004, \& Sornesen et al., 2006), computation and graphing using spreadsheets (Laws, 1991), and web-based assignments (Beichner et al., 2007). Micro-computers affixed with probes were used for real-time display and collection of data (Laws, 2004, \& Sorensen et al., 2006).

In an interview I conducted, Laws stated that the advent of the personal computer was a catalyst for the original Workshop/Studio Physics model. Laws described for me the first time she was able to see the cooling curve for a glass of hot water in real-time through the use of a temperature probe. Such experiences led her to imagine how the use of such technology might benefit undergraduate students. Laws stated that the use of real-time data collection and modeling tools not only allows students to learn content in a hands-on way, but the experience conveys to students a key concept underlying Workshop/Studio Physics: nature is the authority, not the instructor. In other words, according to Laws a key idea is that physics concepts are based on observable physical phenomena, rather than the constructions of a textbook, professor, or other authority. However, she did specify that while technology is an enabling tool in the classroom it is not necessary because students will still benefit from collecting and modeling data without the use 
of high-tech computing tools. She believes that it is the hands-on nature of the activities from which students benefit.

\section{Student Activities}

An additional critical characteristic of Workshop/Studio Physics classes is the type of activities in which students engage. One of the main underlying premises of Workshop/Studio Physics is the minimization (Beichner et al., 1999; 2007;

Hoellwarth et al., 2005) or elimination of lectures (Laws, 1991). While one instance of Workshop/Studio Physics involved a separate lecture portion of the course (see Sorensen et al., 2006), this is a very uncommon approach and is not aligned with the original innovation design developed by Laws (1991; personal communication, 2011).

While lectures are minimized, student-centered activities are maximized in Workshop/Studio Physics. The predominant amount of class-time is taken up by student activities usually in small groups as described above. These activities consist mainly of hands-on labs (Barak et al., 2007) in which students are required to make predictions, collect and analyze data, and develop some model of physical phenomena (Laws, 1991, 2004, \& Beichner et al., 1999, 2007). This type of activity is referred to as a "discovery lab" or "lab demo" by Sornesen et al., (2006, p. 1078).

Despite there being no set curriculum for Workshop/Studio Physics there are a number of known curricula and student workbooks that were used. These curricula include: Active Learning Physics Sheets, ConcepTests, Cooperative Group 
Problem Solving, Interactive Lecture Demonstrations, Physics by Inquiry, RealTime Physics, and VideoPoint (Beichner et al, 1999, Cummings et al., 1999, Hoellwarth et al., 2005, \& Laws, 2004).

One of the most ubiquitous curricula used among enactments of Workshop/Studio Physics in this case study is the Workshop Physics Activity Guide which was written by Priscilla Laws (Laws, 2004). The Workshop Physics Activity Guide consists of worksheets which guide students through experiments in which they observe, interact with, and/or gather data on some physical phenomena. These activities often require a kinesthetic component, which was an initial motivator of Workshop/Studio Physics (Laws, 1991), such as throwing baseballs, smacking bowling balls, breaking pine boards, building circuits, and igniting paper with compressed gas. There is a common cycle of activities within the Workshop Physics Activity Guide which involves having students make predictions, collect data and test predictions, model data, and then look back and summarize the experiment in order to draw conclusions (Laws, \& Brosing, personal communication, 2011).

Despite the variety of activities and curricula used in Workshop/Studio Physics classes there are two common themes among these activities. The first commonality is a real-world context to the problems and activities students engage with. Many of these activities involve or invoke a connection to the physical world as opposed to a theoretical or ideal situation. For example, Cooperative Group Problem Solving (see Heller, Keith, \& Anderson, 1992) involves teaching students specific problem solving strategies for questions that are "context-rich" or involve a 
real-world context with which the student is likely familiar (Cummings et al., 1999, \& Hoellwarth et al., 2005). This is an example of invoking a real-world context in teaching problem solving. Similarly, the activities in the Workshop Physics Activity Guide involve a real-world connection as they require students to engage in an actual physical situation where they need to make observations and collect and analyze data. Beichner et al. (2007) refers to these real-world activities as "tangibles" (p. 13). An example of a "tangible" problem is "Use a laser pointer to determine the thickness of a single hair from your head" (Beichner et al., 2007, p. 14). Beichner et al., (2007) also refers to "ponderables", which are similar to the "context-rich" problems described above. These are questions that invoke a realworld context but do not require physical interaction to answer like "tangibles" do. An example of a "ponderable" is, "Design a car radio antenna optimized for your favorite FM station" (Beichner et al., 2007, p. 15).

The second commonality of Workshop/Studio Physics activities is that they draw upon the findings of physics education research with respect to known student difficulties, prior knowledge, or misconceptions (Priscilla Laws, personal communication, 2011). Laws stated in an interview with me that in her development of the Workshop Physics Activity Guide she relied heavily on the research of Lillian McDermott, Ron Thornton, and David Sokoloff on common student difficulties in physics. In addition, many of the instructional activities used in Workshop/Studio Physics including Interactive Lecture Demonstrations (Sokoloff \& Thornton, 1997), Peer Instruction (Mazur, 1997), and RealTime Physics (Sokoloff, 
Thornton, \& Laws, 1999) are based upon common student difficulties as highlighted by physics education research (Redish, 2003).

The effectiveness of Workshop/Studio Physics may lie, at least in part, with the use of reform-oriented student activities. For example, the results of one research study indicate that the type of activities used in Workshop/Studio Physics has the largest impact on the effect of the course. For example, S. Marie Cooper studied one of the initial enactments of Workshop/Studio Physics at Rensselaer Polytechnic University (Cooper, 1995). The implementers were surprised to find that the innovation did not seem to significantly improve student understanding (Cummings et al., 1999). The FCI was given to students before and after one semester of Workshop/Studio Physics and the average normalized gain for the group was 0.22 (effect size $\left.{ }^{2}=0.82\right)$, which was slightly smaller than the average normalized gain of 0.23 (effect $\operatorname{size}^{2}=0.86$ ) for traditional classes reported in Hake (1998). Based on her dissertation research Cooper (1995) stated that the deficiency was in the amount of time allotted to student explanation. In situations when time was tight, instructors often neglected the post-laboratory follow-up discussions with students. As Cooper states: "classes that neglected follow-up discussions demonstrated markedly lower results on the corresponding parts of the Motion and Force Conceptual Evaluation (sic) than those groups that retained them, despite the appearance of understanding during the activities" (p. 113-114).

${ }^{2}$ Effect size was calculated using the linear approximation method using the equation $\mathrm{ES}=0.082+$ $3.364(<\mathrm{g}>)$ 
One of the generally accepted reasons for the initially disappointing results at Rensselaer had to do with the types of student activities (Beichner, personal communication, 2011; Laws, personal communication, 2011). In a subsequent study at Rensselaer Polytechnic Institute, Cummings et al., (1999) argued that the deficiency with the initial enactments of Workshop/Studio Physics was that the activities,

"are predominantly traditional activities adapted to fit a studio environment and incorporate the use of computers...the activities used are not based on the findings of the physics education research in that they do not attempt to directly address known student misconceptions and employ neither cognitive conflict nor bridging techniques" (emphasis in original, p. S38).

Cummings et al. (1999) made an attempt to improve upon the results by implementing two well-known instructional approaches which are rooted in physics education research: Interactive Lecture Demonstrations (Sokoloff \& Thornton, 1997), and Cooperative Group Problem Solving (Heller, Keith, \& Anderson, 1992; Heller \& Hollabaugh, 1992). Their results indicate that the new sections had effect sizes between 0.51 and 1.07 compared to the Workshop/Studio Physics sections which used the "traditional" activities. These would represent substantial effect sizes in a situation where a completely traditional control group had been used; therefore these results are particularly high given that the control group was a Workshop/Studio Physics course without research-based activities. These results 
suggest that the particular activities used in a Workshop/Studio Physics enactment may have a profound influence on the impact of the innovation.

Instructor's Role

The role of the instructor is the last key component of the Workshop/Studio Physics instructional model. Surprisingly, this component was only uncovered after I conducted interviews with Workshop/Studio Physics implementers because the role of instructors was cursory or absent in the written texts. When the role of instructors was mentioned in the papers it was only to convey how the teacher might orient or re-direct the class. For example, Beichner et al. (1999) describes that the instructor would often use the phrase "Monitors off" in order to get student back on task and away from the distraction of web-surfing and email. One of the only other mentions of the instructor in this paper states, "At this point the instructor directed the students to build their own simulations" (p. S17). The actions of the instructor in Beichner et al. (1999) were described only in terms of the logistics of the class rather than what their role was in helping students learn.

The role of the instructor is slightly elaborated upon more in a paper by the North Carolina State University group (Beichner et al., 2007). In this paper the stated role of the instructor was "to coach the students during activities by assisting them in answering their own questions" (p. 5). These interactions between students and teacher are further described as "Semi-Socratic dialogs, where students are asked to explain their thinking...to help students resolve cognitive conflict” (p. 6). 
While this description is brief, it is the only written description of the role of the instructor in Workshop/Studio Physics classes within the sample of papers.

In the interviews I conducted, however, all the innovators described that the actions of the teacher were one of the key components for the effective enactment of a Workshop/Studio Physics course. The role of the instructor in Workshop/Studio Physics is very different from the role of the instructor in traditional undergraduate physics instruction. Robert Beichner at North Carolina State University and Juliet Brosing at Pacific University both described the role of the professor in Workshop/Studio Physics as the "guide on the side" as opposed to the "sage on the stage" (Juliet Brosing, personal communication, 2011). Brosing further described the Workshop/Studio Physics teaching philosophy, stating that the instructor acts as the class facilitator. Their job is to walk about the class and "probe students' understanding" by "asking questions", "challenging misconceptions", and prompting students to "extend their ideas" and "think deeper" (personal communication, 2011) An additional aspect of the instructor's role in Workshop/Studio Physics is to capitalize on the opportunity to get to know students on an individual basis. The organization of the innovation naturally allows personal relationships to develop between instructor and students due to the smaller class sizes, increased class time (since students are in the same class rather than separate laboratory and recitation classes), and the fact that instructors are freed from their position at the front of the room and allowed the opportunity to walk around the room and interact with students. Robert Beichner stated that a key component of the Workshop/Studio 
Physics model is that "the instructor shows a real interest in how each individual is doing and whether or not they are learning" (personal communication, 2011). Similarly, Juliet Brosing stated that the Workshop/Studio Physics model helps to foster relationships between the instructor and the students because of the increased time they have together. The increased interactivity allows instructors to be able to get a better feel for what students are understanding and what they are struggling with.

An additional role of instructors in the Workshop/Studio Physics innovation is to orient students at the beginning of the course. Juliet Brosing stated to me that a key aspect of the effective enactment of Workshop/Studio Physics involves student buy-in. As Brosing stated, "an implementation [of Workshop/Studio Physics] is effective when you first convince students that it is a worthwhile approach to leaning, to get student buy in, because it's a lot more work [than a traditional physics course]...they used to call it Sweatshop Physics" (personal communication, 2011). It is important for instructors to be armed with responses to student questions such as: "Why are we learning this? What is it good for?" (Beichner et al., 1999, p. S17).

In addition to the importance of student buy-in is the importance of instructor buy-in. Unless instructors understand the purpose of Workshop/Studio Physics activities and value the model and buy-in to the effectiveness of the innovation, the enactment will not be as effective as one in which this critical piece is in place. The effective enactment of Workshop/Studio Physics relies on instructor 
buy-in. Jack Wilson stated in an interview with me that you can provide the whole Workshop-physics package to an instructor; including the facilities, curriculum, and technology, but the most important component of an effective enactment is instructor buy-in. Wilson stated that when instructors are accustomed to lecturing they may not be comfortable with relinquishing their perceived physical control of the class, and that the experience of allowing students to get up out of their seats and talk with each other may be disconcerting.

For instance, in her dissertation on Workshop/Studio Physics at Rensselaer Polytechnic Institute, S. Marie Cooper described how instructors and teaching assistants fell back on their standard practice of presenting and explaining the solutions of homework problems which had not been an intended practice. Instead, the original structure of the Workshop/Studio Physics model was to have students present their own solutions and explanations of homework problems to the class. Cooper credits a portion of the ineffectiveness of this Workshop/Studio Physics enactment to the fact that students were not given this opportunity to explain their thinking. She stated as one of her concluding recommendations: some arrangements [should] be made for the introduction of faculty to the essential design of the course and the cognitive science which underlies that design...Without a strong reason for embracing new forms of instruction, instructors will tend to revert to more comfortable and familiar patterns, especially when students seem to be encountering difficulty" (Cooper, 1995, p. 117). 
When instructors are not aware of or comfortable with the underlying rationale behind reform efforts, the enactment of the reform in their classrooms may not reflect the original vision. Unless the instructor understands and respects the purpose of Workshop/Studio Physics approach, the enactment will be disjointed and the instructor may fall back to a more traditional form of instruction. This phenomenon has been observed within the context of K-12 education (Cohen, 1990; Hubbard, Stein, \& Mehan, 2006); however, the phenomena may apply to higher education as well.

To prepare instructors in the Workshop physics approach, New Workshop/Studio Physics instructors at Pacific University go through an extended training program. A key aspect of this training involves learning from prior instructors about when students may require assistance with reconciling their experimental results with their prior knowledge (Brosing, personal communication, 2011). For example, Laws, the originator of Workshop/Studio Physics, described an example of a lab on Newton's $3^{\text {rd }}$ Law where students collect data with force probes attached to carts on a track. She described how many students' preconceptions were validated by the experiment because the probes were not affixed properly. It is important for instructors to understand where these pivotal moments may be within the sequencing of activities and recognize them as times where they should check in with students.

In summary, the role of instructors in Workshop/Studio Physics is a critical characteristic of the model which, surprisingly, was only described as such in 
instructor interviews. The role of instructors in the innovation was not described sufficiently in any of the written texts used in this case study. However, instructor interviews illuminated the importance of the role of the instructor in facilitating the class, interacting with students, and answering their questions. In order for instructors to be able to fill their role in Workshop/Studio Physics, their buy-in to the instructional approach is essential.

Summary of Critical Characteristics

In summary, there are five critical characteristics of Workshop/Studio Physics courses that are essential to this innovation. These characteristics are:

1) A classroom that integrates the lecture, recitation, and laboratory portions of a traditional course into a cohesive learning environment,

2) An emphasis on structured collaborative group work for students,

3) The incorporation of technology in the collection, analysis, and interpretation of scientific data within student activities,

4) The use of student activities which are rooted in the findings of physics education research and which have some real-world context, and

5) Instructors who understand and adhere to the underlying principles of the Workshop/Studio Physics model and function as facilitators.

Table 23 provides a summary of the nature of these characteristics within the texts considered in this case study. While all five characteristics were described by key implementers of Workshop/Studio Physics in interviews, interestingly, detailed 
descriptions about the role of the instructor (the $5^{\text {th }}$ critical characteristic) were not described in the published articles analyzed in the case study. In other words, the descriptions of the role of the instructor were either cursory or absent in the written work gathered for this study. 


\begin{tabular}{|c|c|c|c|}
\hline & : & 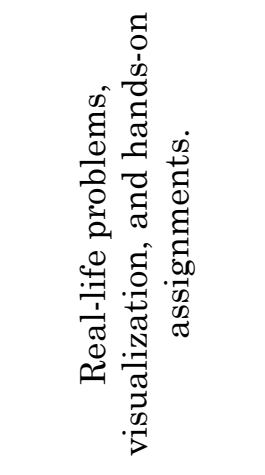 & 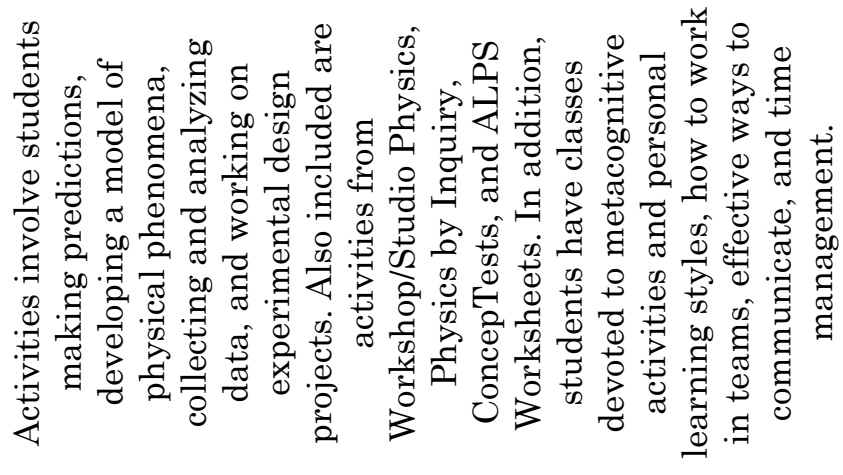 \\
\hline 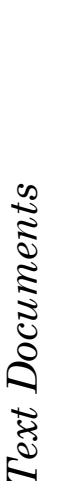 & 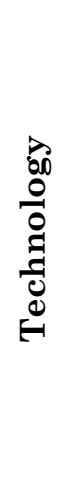 & 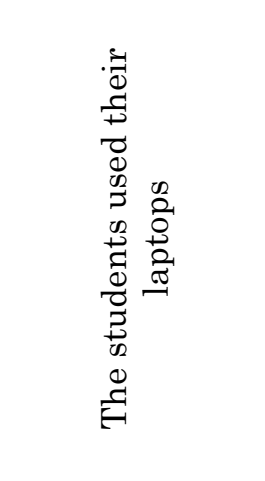 & 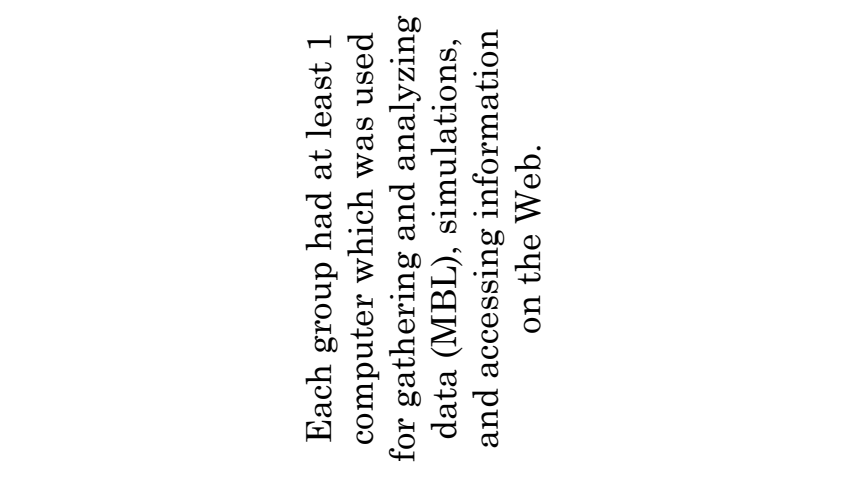 \\
\hline 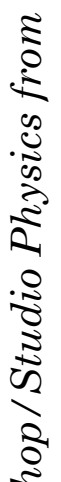 & 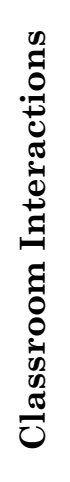 & 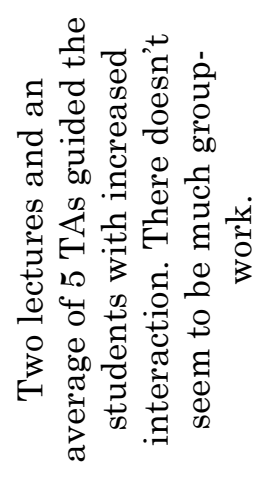 & 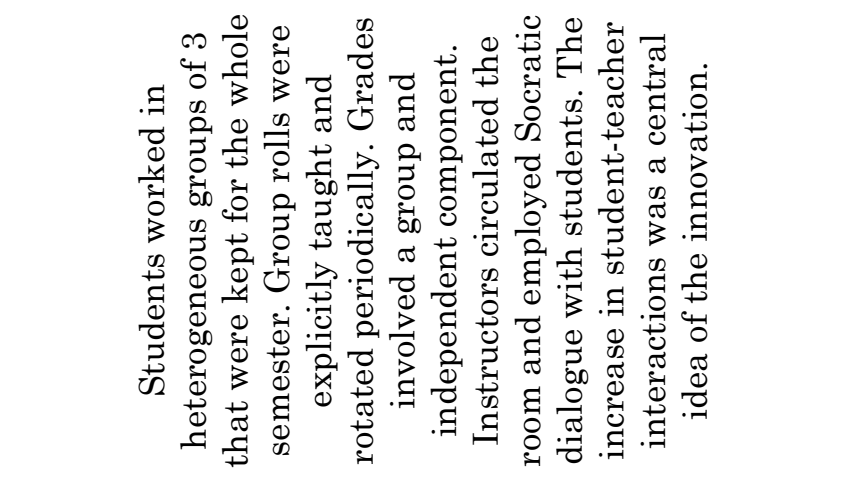 \\
\hline 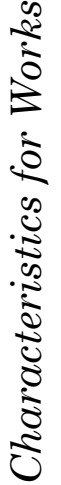 & 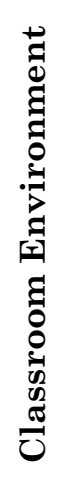 & 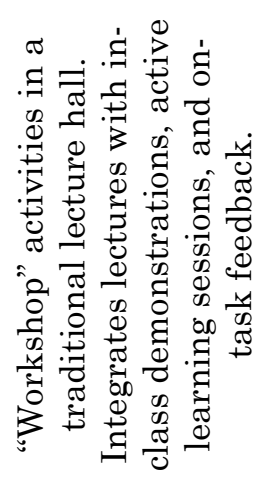 & 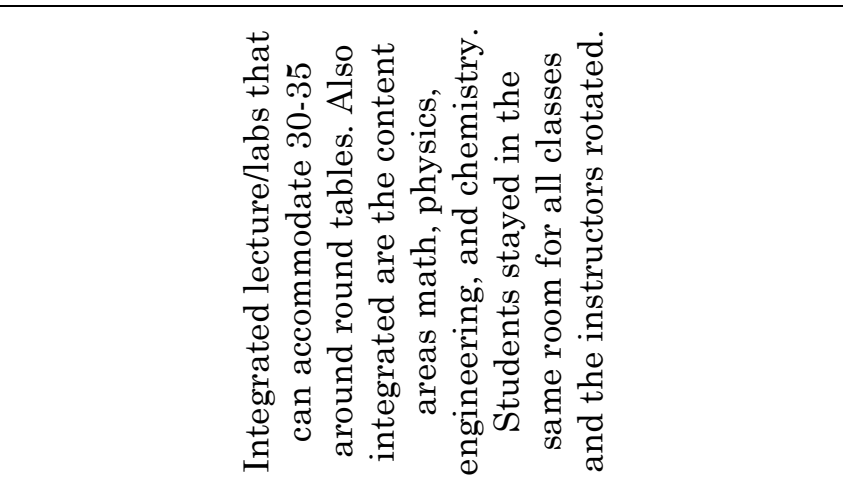 \\
\hline 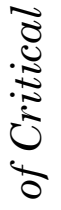 & 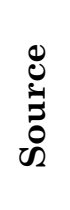 & 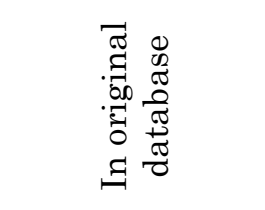 & 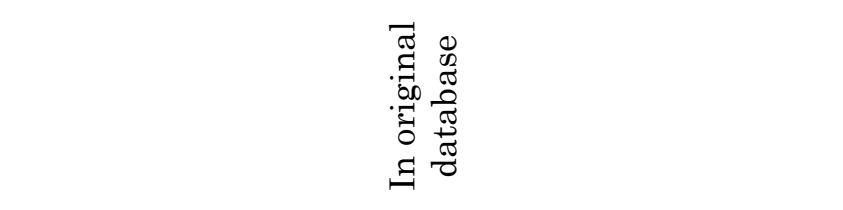 \\
\hline 旅 & $\begin{array}{c}\dot{0} \\
\stackrel{\partial}{\sigma} \\
\stackrel{0}{\sigma}\end{array}$ & 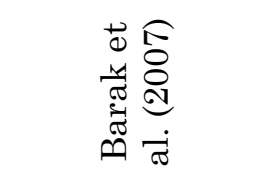 & 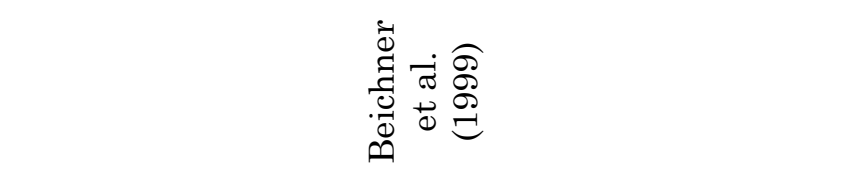 \\
\hline
\end{tabular}




\begin{tabular}{|c|c|c|}
\hline : & 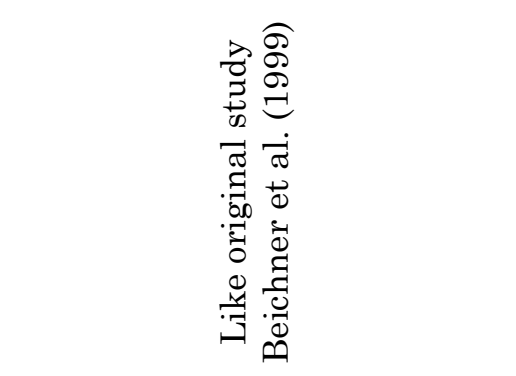 & 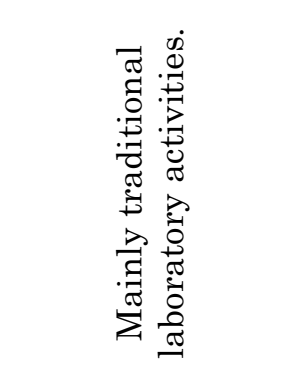 \\
\hline 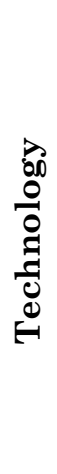 & 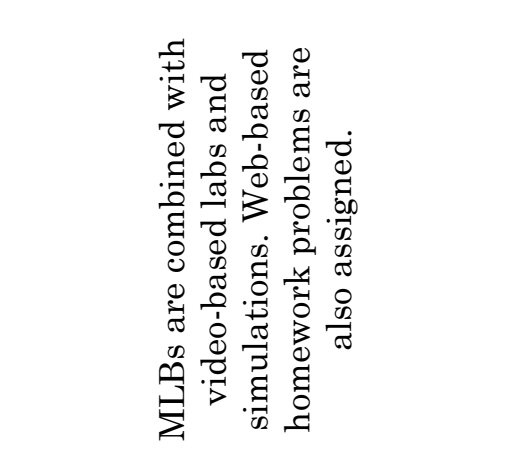 & 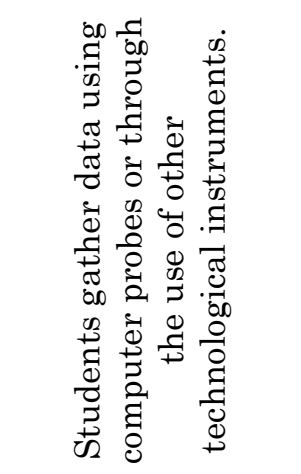 \\
\hline 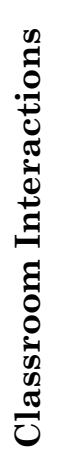 & 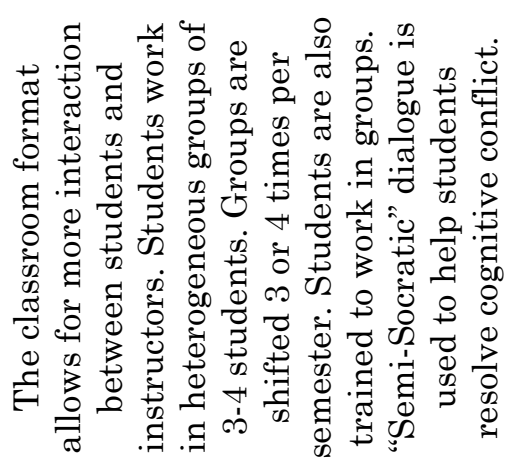 & 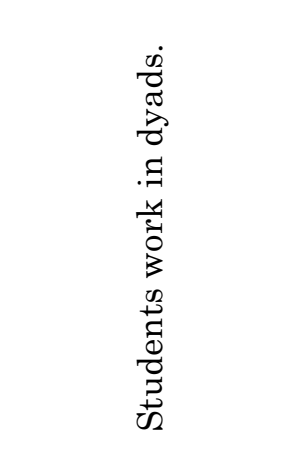 \\
\hline 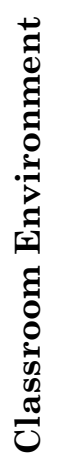 & 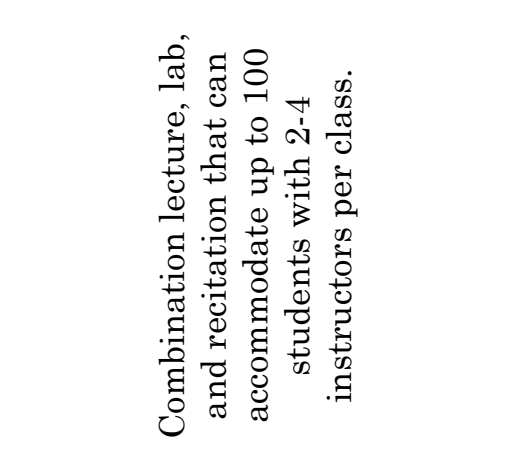 & 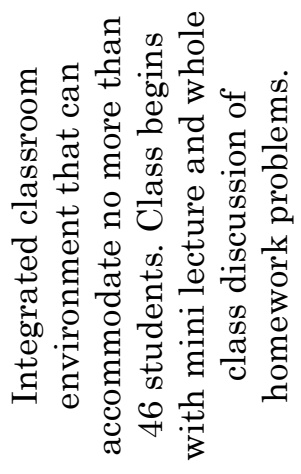 \\
\hline 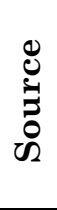 & 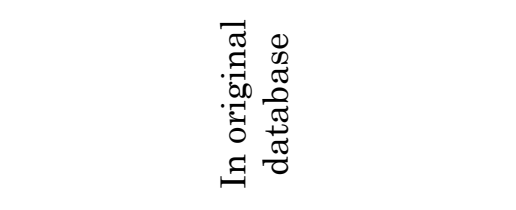 & 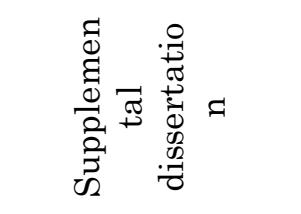 \\
\hline 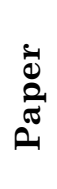 & 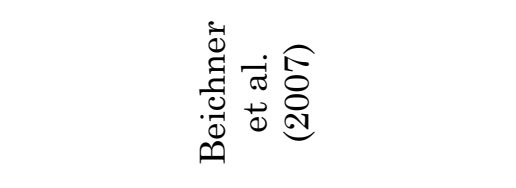 & 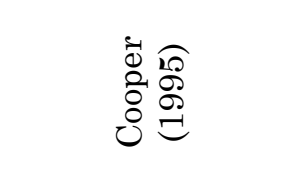 \\
\hline
\end{tabular}




\begin{tabular}{|c|c|c|c|c|}
\hline$\underbrace{0}_{\substack{0 \\
:}}$ & 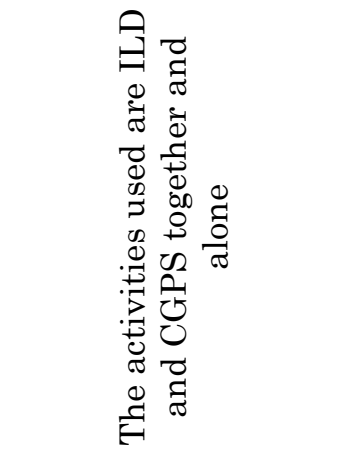 & 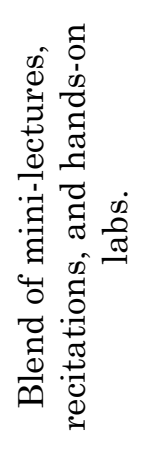 & 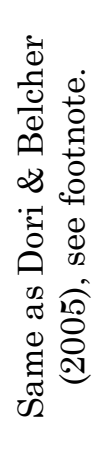 & 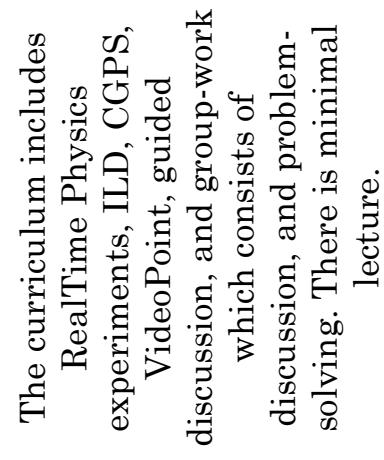 \\
\hline 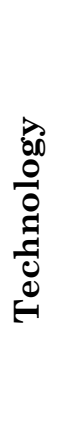 & 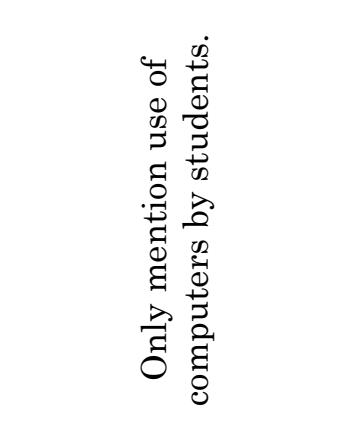 & 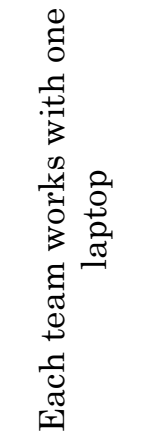 & 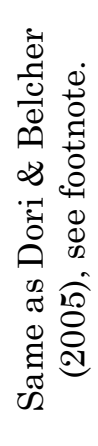 & 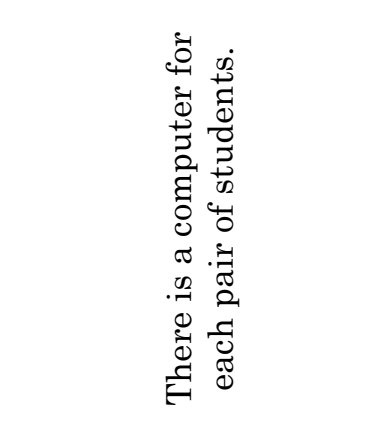 \\
\hline 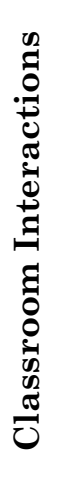 & 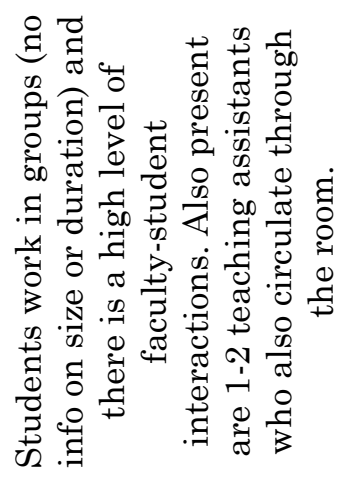 & 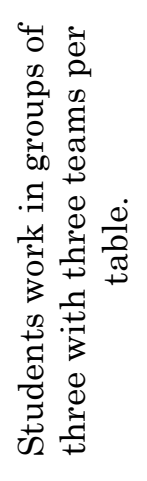 & 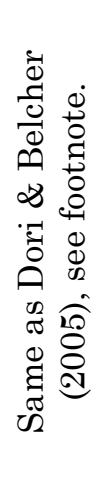 & 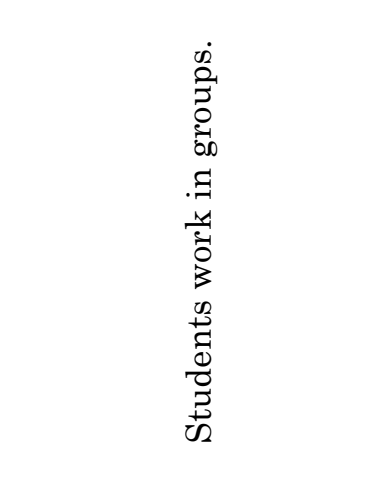 \\
\hline 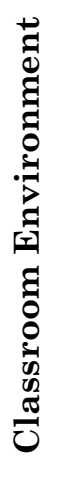 & 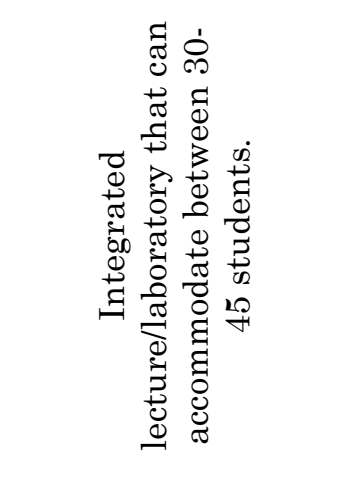 & 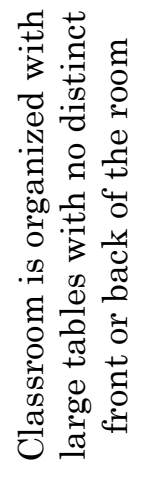 & 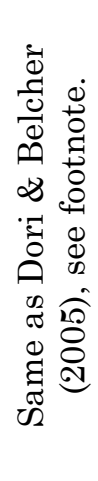 & 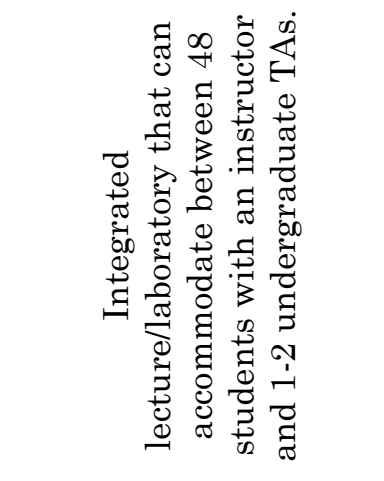 \\
\hline 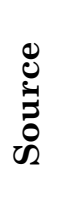 & 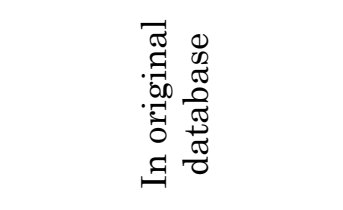 & 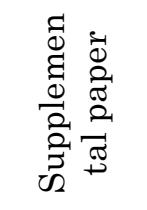 & 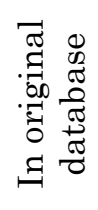 & 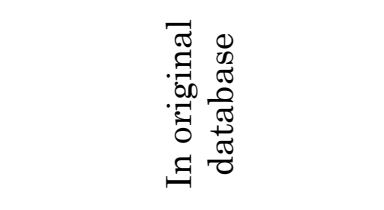 \\
\hline $\begin{array}{l}\dot{0} \\
\stackrel{0}{\sigma} \\
\text { مे }\end{array}$ & 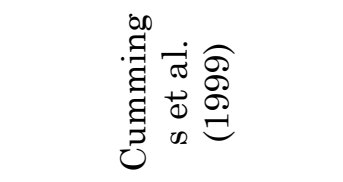 & 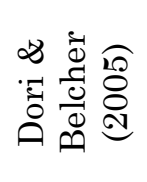 & 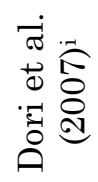 & 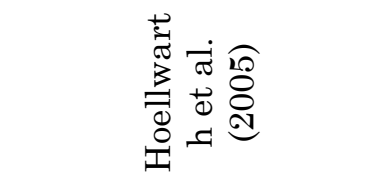 \\
\hline
\end{tabular}




\begin{tabular}{|c|c|c|c|}
\hline 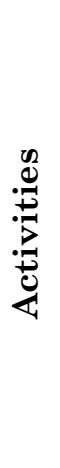 & 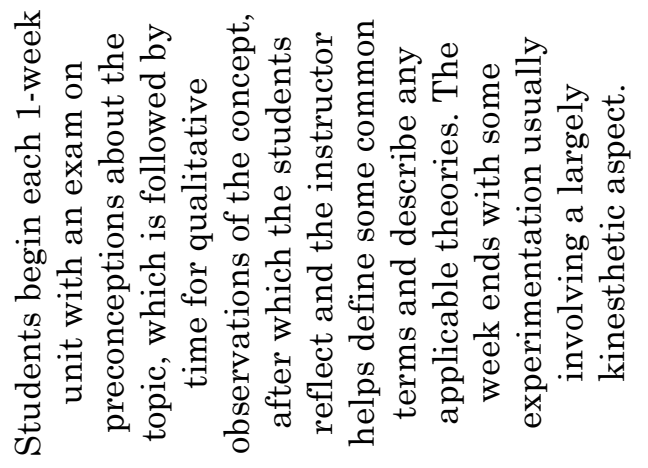 & 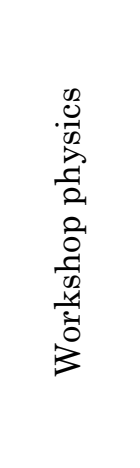 & 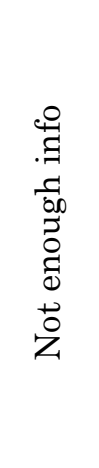 \\
\hline 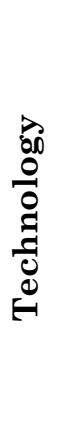 & 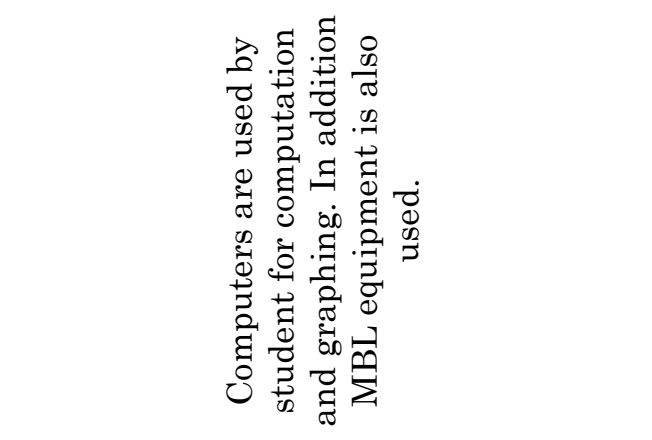 & 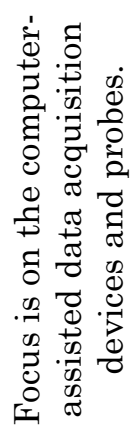 & 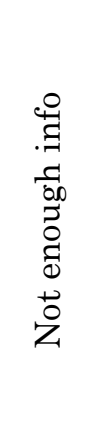 \\
\hline 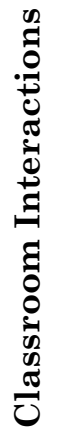 & 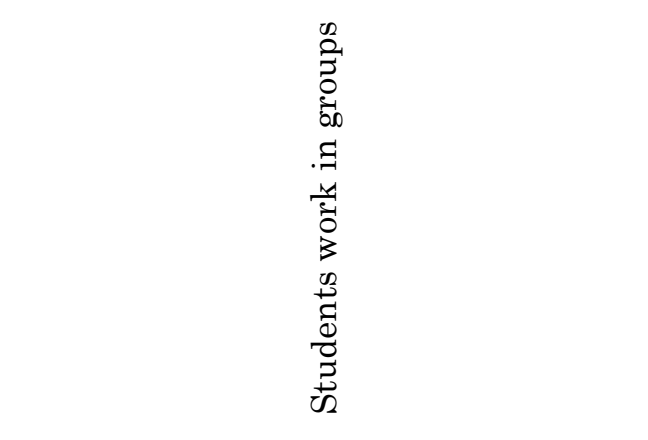 & 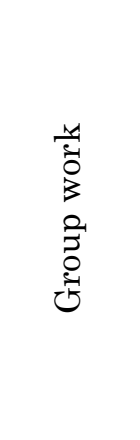 & 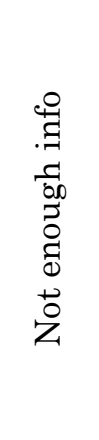 \\
\hline 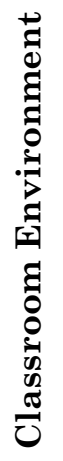 & 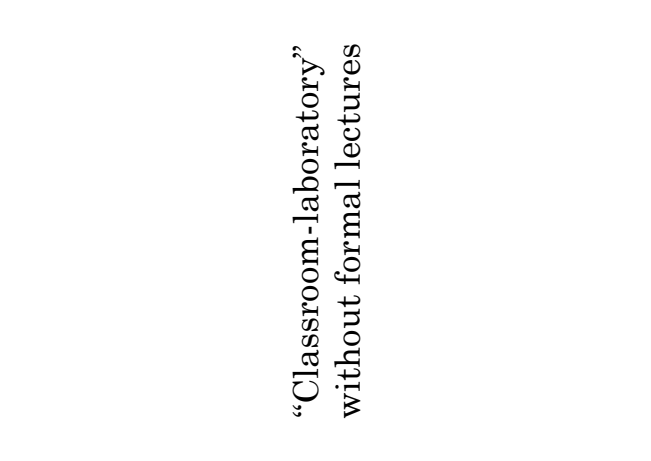 & 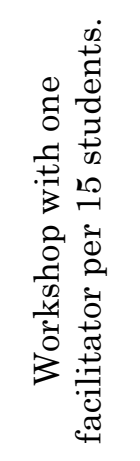 & 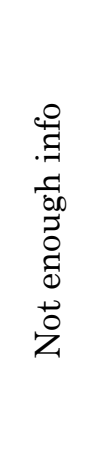 \\
\hline 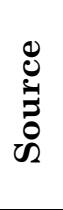 & 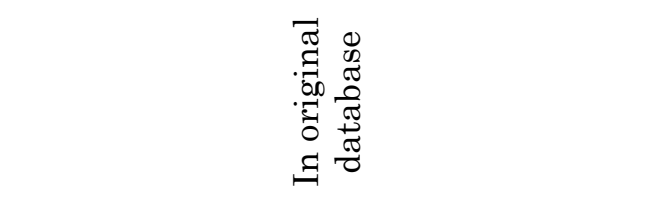 & 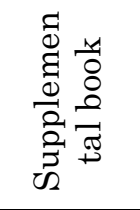 & 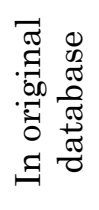 \\
\hline $\begin{array}{l}\vec{d} \\
\stackrel{a}{\sigma} \\
\vec{\sigma}\end{array}$ & 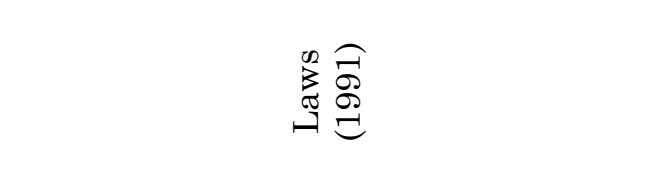 & 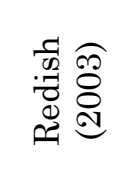 & 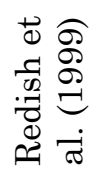 \\
\hline
\end{tabular}

155 


\begin{tabular}{|c|c|c|}
\hline 量 & 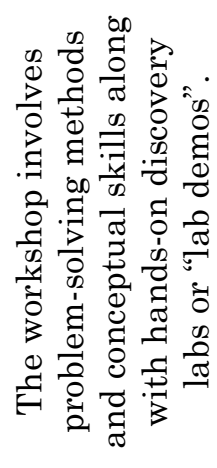 & 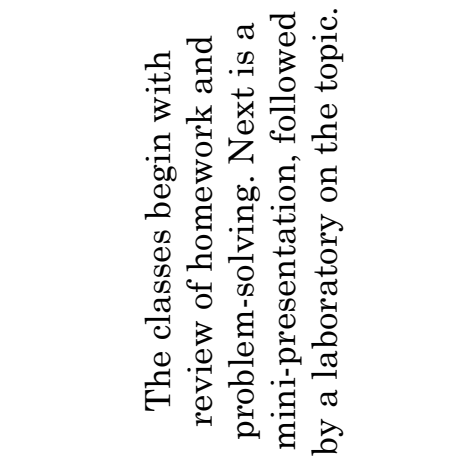 \\
\hline 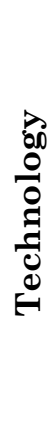 & 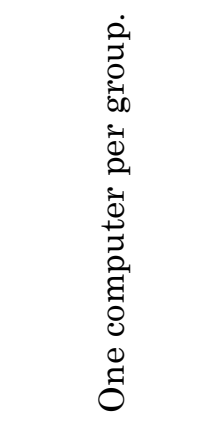 & 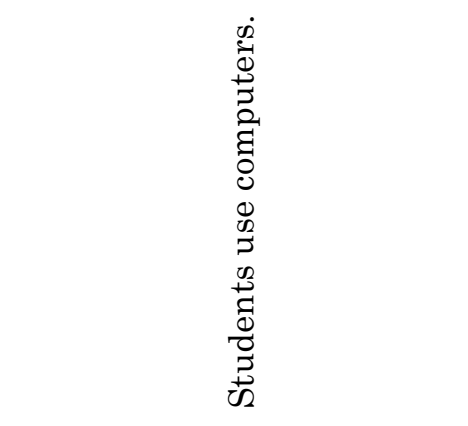 \\
\hline 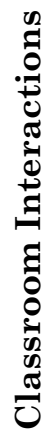 & 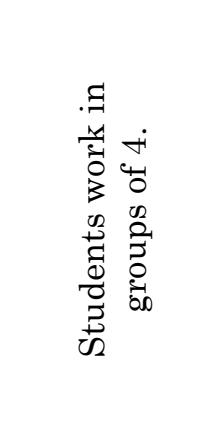 & 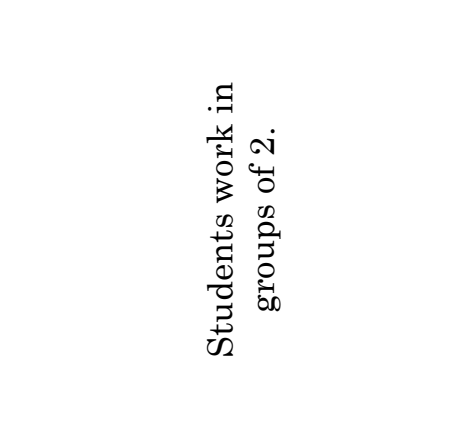 \\
\hline 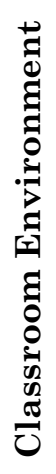 & 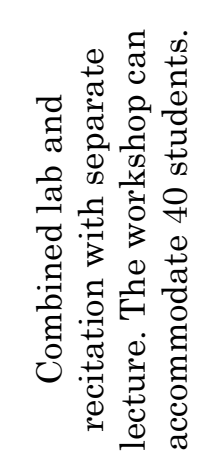 & 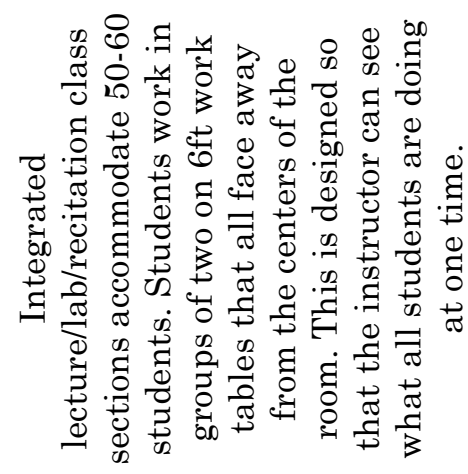 \\
\hline 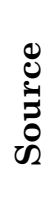 & 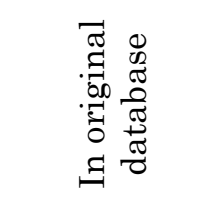 & 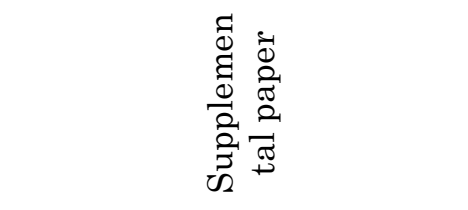 \\
\hline $\begin{array}{l}\dot{0} \\
\dot{0} \\
\dot{\sigma}\end{array}$ & 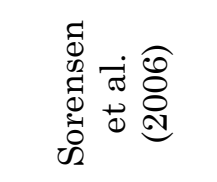 & 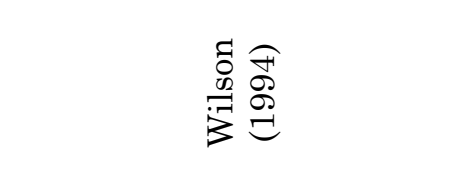 \\
\hline
\end{tabular}




\section{Confirming and Disconfirming Evidentiary Analysis}

The preceding analyses indicated that Workshop/Studio Physics is a highly effective innovation which consists of 5 critical characteristics. A question which follows is: Do other effective innovations contain these 5 critical characteristics, and along the same lines, are these 5 critical characteristics less common among less effective innovations? In order to investigate this question, all of the 23 methodologically similar studies from the meta-analysis were re-coded with respect to these 5 critical characteristics. The presence of each critical characteristic is shown in Table 24.

In Table 24 studies are sorted top to bottom according to increasing effect size. The presence of a critical characteristic is indicated by an "X" in the table; therefore, if the five critical characteristics of Workshop/Studio Physics are present in high effect size studies and absent in low effect size studies, the table would show more "X's" in the lower half. 


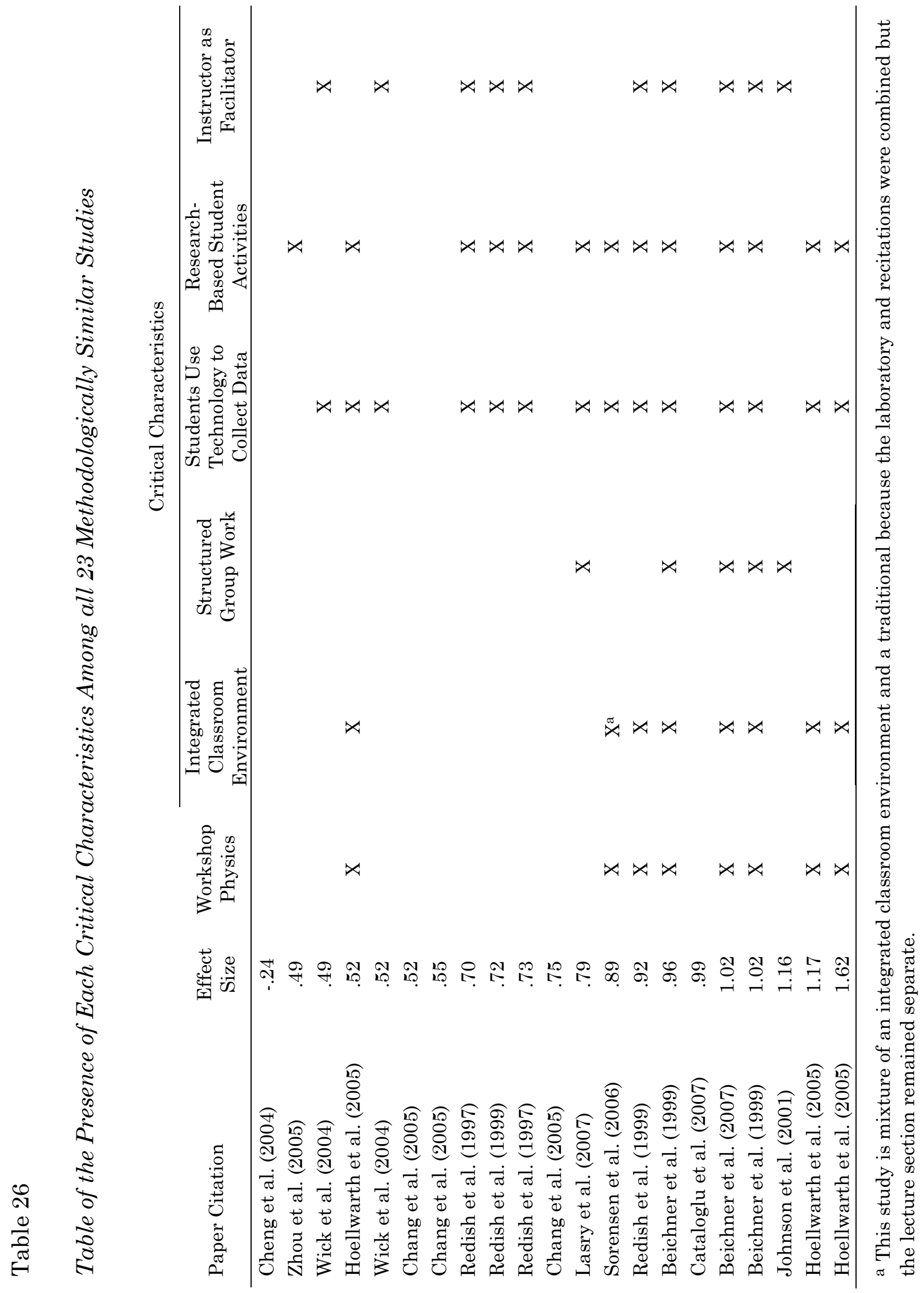


The table suggests that studies that have an integrated classroom environment and use structured group work tend to have higher effect sizes than studies that do not. However, the relationship is less clear for the other three characteristics. In addition, it is difficult to see visually whether the relationship between these variables and effect size holds for the non-Workshop/Studio Physics studies. Therefore in order to get a better feel for these relationships, I conducted a statistical analysis.

Mean effect sizes were computed for the groups of studies with and without each critical characteristic for the purpose of testing the relationship between these study characteristics and effect size. If the relationship between the characteristic and effect size exists, the mean effect size for studies with each characteristic will be higher than the mean effect size for studies in which the characteristic is absent. This data is shown in Table $25^{3}$.

In addition, I did these same computations for the studies which do not involve Workshop/Studio Physics. This was done in order to eliminate the impact that these studies may have had in the analysis. This data is also included in Table 25.

\footnotetext{
${ }^{3}$ Mean effect sizes are presented in this analysis; however the median effect sizes were also. Because the relationships described were the same when the median effect size statistics were used, only the mean effect size data is presented here for the sake of simplicity.
} 


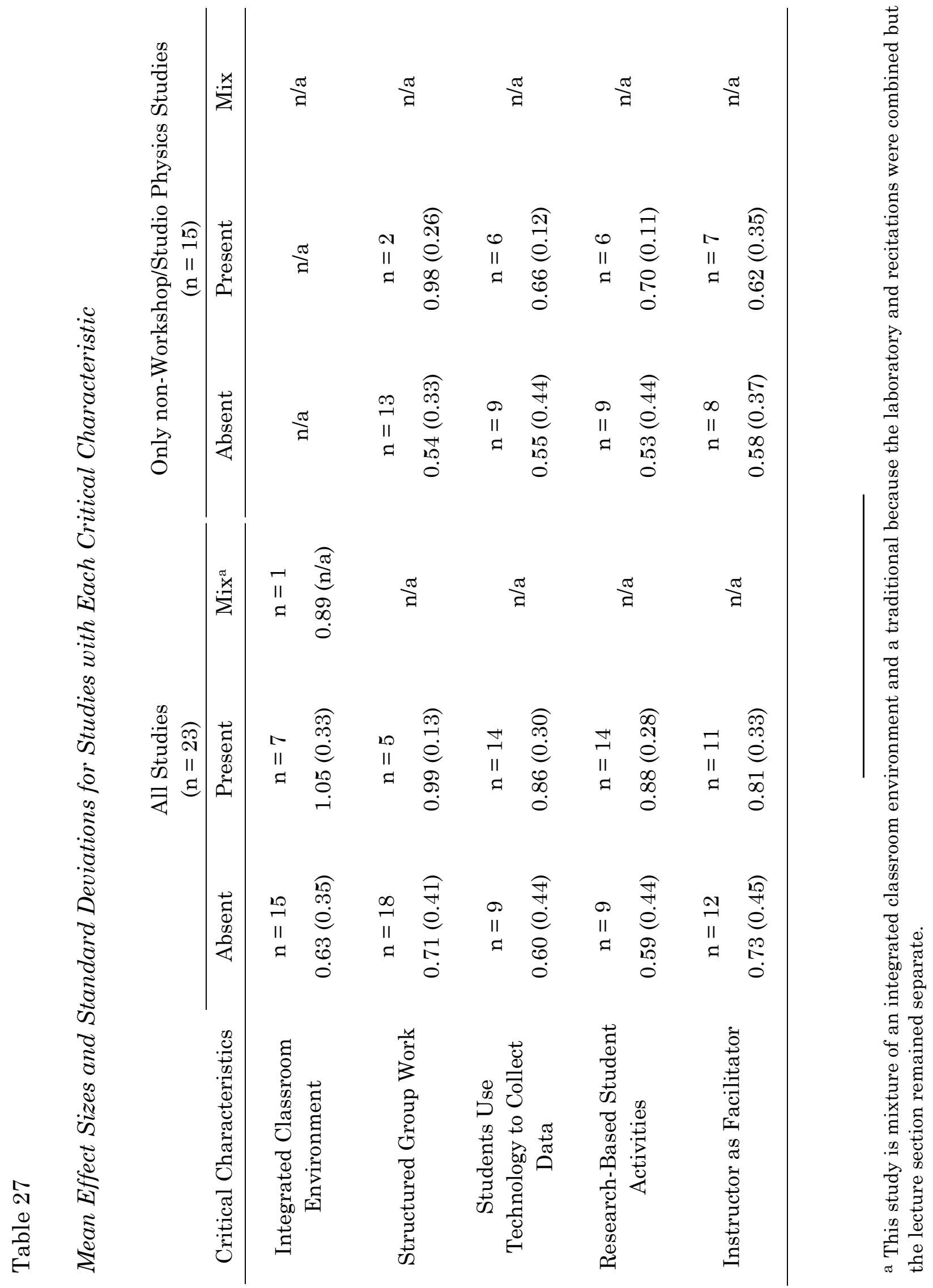


With respect to the first critical characteristic involving an integrated classroom environment, the statistical data seems to support the trend in the raw data: namely, that the presence of an integrated curriculum seems to be correlated with higher effect sizes. Studies which involve the integration of course components have a higher average effect size by 0.42 than those that do not. This represents a practically significant difference as it comparable to the overall effect size standard deviation for all 23 studies (overall $\mathrm{SD}=0.39$ ). However, this relationship could not be tested beyond Workshop/Studio Physics classes because there were no other studies that involved the integration of course components.

Similarly, the statistical data for the second critical characteristic involving structures group work also support the trend seen in the raw data. Overall, studies with structured group work have 0.28 higher effect sizes on average than those that do not. The studies that do not include structured group work include both studies with no group work and studies with unstructured group work (i.e. informal groups in which there are no organizational structures in place or group roles assigned). This relationship is even stronger among the studies which do not involve Workshop/Studio Physics. For these studies, those that involve structured group work have 0.44 higher effect sizes than those that don't. However, while the strength of this relationship is higher for this group of studies, the validity of the relationship is diminished because there are only 2 studies which involve structured group work. 
With respect to the third critical characteristic, that students use technology to collect and analyze data, the statistical analysis hints at a relationship that was not obvious from the raw data. For all studies the impact of this characteristic is a 0.26 increase in effect size on average. However, when the Workshop/Studio Physics studies are eliminated from the analysis, the impact of this characteristic practically decreases. For these studies, the impact of students using technology to collect and analyze data is only an increase of 0.11 in effect size on average.

The relationship for the fourth critical characteristic is similar to the third. For all studies the impact of research-based student activities on effect size is 0.29 on average. However, when the Workshop/Studio Physics studies are eliminated the impact on effect size drops to 0.17 on average.

Lastly, with respect to the fifth critical characteristic, the impact of the role of the instructor as a facilitator is a minimal increase of 0.08 in effect size on average. The impact of this characteristic on effect size decreases slightly to 0.04 after the Workshop/Studio Physics studies are eliminated. This relationship should be considered only tentatively due to the fact that none of the Workshop/Studio Physics papers described adequately the role of the instructor. If this trend holds across the majority of papers, the relationship between the role of the instructor and study effect size may not be accurate when only the written paper is used to code the study. 
Summary of Confirming and Disconfirming Evidentiary Analysis

The content of each of the 23 methodologically similar studies were re-coded with respect to the presence or absence of each of the identified 5 critical characteristics of Workshop/Studio Physics. The results of this analysis indicate that studies in which a characteristic is present have higher mean effect sizes than those that do not. This relationship holds across all characteristics. The relationship between the presence of characteristics and mean effect size was investigated for all studies, as well as for only non-Workshop/Studio Physics studies. This distinction was made in order to investigate the potential impact of the characteristics on effect size without masking or augmenting the relationship due to the presence of Workshop/Studio studies, which have already been identified as a high effect size group of studies.

Overall, the results are mixed. The impact of the integration of the course components could not be evaluated since there were no non-Workshop/Studio physics studies with this characteristic. Similarly, the impact of the role of the instructor as a facilitator could not be evaluated because it has been shown that this characteristic is not often described in published articles, at least for Workshop/Studio Physics studies. Along the same lines, the impact of structured group work appears to be modestly large; however, there are only 2 nonWorkshop/Studio Physics studies which does not allow for valid conclusions to be drawn. Lastly, the presence of two characteristics, students' use of technology and research-based activities, was shown to have a positive impact on effect size on 
average; however, the impact was minimal especially for the non-Workshop/Studio Physics studies. 


\section{CHAPER VII}

\section{DISCUSSION}

Before turning to the discussion of the preceding results, I would like to refer back to the two hypothetical students, Sofia and Elinor, whose experiences I described in the Preface. For undergraduate students - like Sofia - who are enrolled in traditional physics classes, education is a passive experience. Students take notes in lecture, copy practice problems in recitation, and follow cookbook-style experiments in laboratory. After experiencing this style of instruction, students are often able to solve computationally difficult problems; however, they rarely possess a deep conceptual understanding of the physics principles which underlie these problems.

Yet for some undergraduate students, like Elinor, physics education is a very different experience. In these reform-oriented classes, lecture may be purposefully interspersed with student discussion regarding conceptually-oriented questions, recitation may involve activities which elicit students' prior knowledge and foster collaborative learning, and laboratory may include activities in which students must develop the experimental procedures rather than follow instructions in a manual. In these reform-oriented course innovations, students take a more active role in their learning due to the decreased focus on lecturing and increased focus on collaborative learning and student-centered conceptual activities. 
A large number of studies have been conducted on the effectiveness of course innovations on student learning, especially over the last several decades. However, there have been very few syntheses on the types of innovations implemented and only one published synthesis on the effectiveness of course innovations on student learning. This thesis is the first synthesis, on the other hand, which has sought to investigate the relationship between different types of innovations and their relative impact on student learning.

In the sections that follow I present a brief description of the findings, organized by research question. In each section, I present some hypothesized explanations for these findings, limitations, and recommendations for future work. I will conclude with some overarching implications and conclusions of the research project.

\section{Research Question 1}

The first research question, What is the range of undergraduate physics course innovations that have been implemented and evaluated, was addressed through a descriptive analysis. Across all innovations, the large majority focused on the topic of mechanics in introductory physics classes. The majority of innovations took place in either the lecture, recitation, or laboratory sections of the course with a smaller number of innovations taking place in workshop sections or during homework. The known instructional innovations Tutorials and Workshop Physics were the most commonly studied known innovations. Similarly, the use of 
conceptually oriented tasks combined with collaborative learning and technology was the most commonly studied innovation type. In fact, conceptually oriented tasks, collaborative learning, and technology were by far the most commonly studied innovation types, either alone or in some combination with each other.

In contrast, the least commonly studied innovation by far was inquiry-based projects. These studies might include innovations where students are given more choice with respect to the experimental questions they ask, and the procedures and methods with which they investigate problems. The lack of inquiry-based projects in the reviewed studies is in line with the findings of previous qualitative synthesis of the field. For example, McDermott \& Redish (1999) highlight the lack of research in undergraduate physics education on the development and evaluation of innovations in which students are given more autonomy.

\section{Limitations and Future Work}

While inquiry-based projects have been studied extensively in K-12 science education the effect of inquiry-based projects on student learning has not yet been established for undergraduate students. However, meta-analyses conducted with these K-12 studies have found that a large number of studies do not provide the sufficient data needed to calculate an effect size (Minner, Levy, \& Century, 2010; Schroeder, Scott, Tolson, Huang, \& Lee, 2007) - a result which is very similar to that found in this thesis. Despite these limitations the results of studies from the K12 literature suggest that guided inquiry activities may be more effective at 
promoting student learning. However, this perspective on student inquiry has not been studied extensively with undergraduate students.

The effectiveness of Workshop Physics and its highly interactive environment provides a natural setting for which to explore the impact that inquiry-based projects may have on student learning. For example, future studies might investigate the effect of inquiry-based projects with varying degrees of guidance on student learning. Are adult learners similar to K-12 students with respect to the benefits of guided inquiry, or do adult learners benefit from more autonomy in the classroom? Additional studies might investigate the effect of inquiry-based projects on students' epistemological beliefs as well as conceptual learning. The organization of the Workshop/Studio class would be a natural setting for a study like this.

Another interesting phenomenon with the studies reviewed was their limited references to theoretical work. While almost half of the studies cite theoretical work, the description of these theories is very cursory. In contrast, references of previous empirical work, and explanations of this work, were much more prevalent among the studies reviewed. In fairness to undergraduate physics education researchers, there are two primary reasons for why theoretical work is not referenced more in undergraduate physics research education. The first is that journal publishers and editors may not always value references to educational and cognitive theory. Edward Redish described how this was the case at least in the years when research on innovations first started to be published (2007, UCI advisory board meeting). 
A related issue is that, at least within the sample of studies synthesized in this thesis, journal article length was positively correlated with whether educational and/or cognitive theory was cited in the article. There appears to be a sub-phenomenon occurring within this data for specific journals. For example, of the six most common journals in the sample, three publish exclusively on the topic of physics education (American Journal of Physics, Physics Review Special Topics, and European Journal of Physics) and three are less specific (Cognition and Instruction, International Journal of Science Education, and Journal of Research in Science Teaching). For the three physics specific journals the average article length was 9 pages. However, for the other three journals the average article length was 24 pages. This data seems to indicate that the journals catering to physics specific topics are dramatically shorter than those intended for a larger science education community. What is unclear is how this finding relates to the inclusion of information on the theoretical foundations of the innovation. For example, it is unclear whether the lack of theoretical references is keeping the page numbers down in these journals, or whether there are article length restrictions which are making it so that there is not enough room in the articles for theoretical elaborations.

A second, more speculative, explanation for this phenomenon is that researchers may not be developing innovations intentionally based on educational theories. However, it is not clear whether this is the case or not because this information is not readily available in published research. If this is the case it is 
more likely that innovations are being developed based on more implicit and informal ideas about students learn. However researchers might benefit from being more explicit about their working assumptions about how students learn and how the innovation they have developed is based on these assumptions. Since the current reform in undergraduate physics education has educational and cognitive theory as one of its foundations, it does not seem as though referencing this work would be antithetical to the culture and roots of this field of research.

Papers which provide a detailed description of the underlying theory of their innovation are certainly appreciated by researchers studying their work: and particularly appreciated by doctoral students doing their dissertation on this work. However, it is less clear whether this information is essential for other consumers of the work. For example, is a detailed description of theory necessary to a practitioner who is interested in enacting the innovation? If it is, why isn't this information provided more readily in publications on undergraduate physics course innovations? Theoretical discussions are cursory among the reviewed papers, at least those published in physics specific journals, which might indicate that the papers are intended to be more practitioner-oriented. If the physics articles on innovations are intended to be more practitioner-oriented, how might the inclusion of theory in the papers alter the focus on the field? Similarly, how might the increased use of theory in published work enrich the community-wide conversations about student learning? In addition, how might the explicit reference to theory create a more unified field of research that builds upon previous work in a systematic and 
scientific way? These are just some of the questions that arose for me as this thesis progressed.

\section{Research Question 2}

The second research question, What is the effect of innovations on student learning, was addressed through meta-analysis. Unfortunately, not all of the studies used in the previous descriptive analysis could be used in the meta-analysis: over half of the overall 170 studies had to be eliminated. Out of the 79 studies for which an effect size could be calculated, the overall mean effect size was 0.76. However, the distribution of effect sizes was highly variable. The large amount of variability in the observed effect size distribution is similar to that which was found in Hake (1998).

Of the 79 studies for which an effect size could be calculated, I grouped studies based on three methodological characteristics: methodological design, control group type, and outcome measure characteristics. These three methodological characteristics accounted for about $47 \%$ of the overall variability in effect size. The largest group of methodologically similar studies all had pretestposttest two group designs, a traditional control group, and an outcome measure which was externally developed with multiple-choice items.

These 23 methodologically similar studies were then investigated for possible relationships innovation type and effect size. The analysis indicated that innovations using the Workshop Physics model of instruction, which involves a 
combination of conceptually oriented tasks combined with collaborative learning and technology, have the largest positive effect on student learning on average out of any group of innovations.

\section{Limitations and Future Work}

One of the main limitations of this meta-analysis is that $54 \%$ of the gathered studies had to be eliminated because there was not enough information provided in the paper to calculate an effect size. Unfortunately this means that the results of the meta-analysis only account for half of the story. This missing information may have allowed for a more comprehensive analysis of the relationship between study features and effect size. Only a fraction of the total codes applied to each paper could be used in the meta-analysis because of the small sample sizes. Therefore it is unclear whether the inclusion of these studies would have changed the findings and conclusions or strengthened them.

In addition, almost half of the studies included in the meta-analysis required that the effect size be estimated rather than calculated by approximating effect size from average normalized gain scores, a common metric in undergraduate physics education research. Without this method of estimating the effect size, only 43 studies would have been included instead of 79. Although this method allowed me to include a larger number of studies, the limitation is that the exact effect size could not be calculated. 
An additional limitation to the meta-analysis was that a large majority of studies had at least one threat to the internal validity of the study. This calls into question the effect sizes for the studies. For example, there were only two studies out of the 79 studies for which an effect size could be calculated in which students were randomly assigned to treatment and control conditions. For studies in which students were not randomly assigned to treatment and control conditions, selection bias is possible threat to the validity of the study. In such instances when random assignment is not possible, pretest data should be collected in order to mitigate the possible threat of selection bias. However, a large number of the reviewed studies used a posttest only study design.

In addition to selection bias, half of the studies had at least one threat to the construct validity of the study. The primary threat was the inadequate explanation of the treatment and control conditions. In these studies it was difficult to accurately establish what occurred in the experiment. For example, when a paper states that it used "active learning methods" it is not clear exactly what occurred in the class. In order for the reader to be able to evaluate the study, authors should be more explicit about what happened in the treatment and control conditions. This information should include a detailed explanation of the activities used and the frequency with which they were used.

Lastly, the large majority of studies did not report information on the validity and reliability of the outcome measure used. This information is crucial because it pertains to the accuracy of the test instrument at measuring what it is intended to 
measure. Ironically, measurement accuracy is crucial within the discipline of physics. Instructors and research assistants spend hours making sure that laboratory equipment is set up properly so that accurate data can be collected. In addition, many physics classes involve activities which focus on the importance of accurate scientific measurement for students. However, the concept of measurement accuracy with respect to testing instruments is not considered among the very large majority of the studies reviewed. Just as measurement accuracy is of great importance in the practice of physics, the validity and reliability of test instruments used to evaluate the effect of an innovation are of great importance.

There are additional limitations pertaining to the meta-analytic approach itself. For example, there are a number of different equations available for calculating an effect size for a study and none are universally used. The results of a meta-analysis may differ depending on the effect size calculation used. As I illustrated in an earlier chapter, the use of two different equations resulted in two very different effect size calculations (1.00 and 0.49$)$. While ultimately I decided to use an effect size equation that mitigates the threat of selection bias in a study, this choice also made it so that I had to cut a number of studies that did not include pretest data. In every meta-analysis the researcher must decide which effect size calculation will be used. This is a non-trivial decision which may alter the results of the meta-analysis and there is no universally accepted approach.

An additional limitation of the meta-analytic approach is that there are often multiple studies within a single paper. For example, many researchers use multiple 
outcome measure to investigate the effect of an innovation. While this decision makes sense for the design of the study it poses problems for the meta-analyst. The use of multiple outcome measures and/or multiple control groups results in the inclusion of studies which are not independent. This means that the assumption of independence is violated and therefore the use of parametric statistics may not be warranted. Perhaps more importantly however, is the issue that multiple studies from one paper magnify the impact of this paper compared to other papers that might only have one study. In other words, the use of multiple studies produces a weighting system of studies - the more studies within a paper, the more weight it has in the overall pool of papers. There is no universally accepted meta-analytic approach for accommodating multiple studies within a single paper.

\section{Research Question 3}

The third research question, What are the critical features of more and less effective innovations, was addressed through a case study approach. Based on the results of the meta-analysis I identified Workshop/Studio Physics for case study analysis. This analysis indicated that the critical features of Workshop Physics are that: (1) it takes place in classroom environment in which the traditionally separate lecture, laboratory, and recitation sections are integrated into one section; (2) class time is dominated by activities involving a real-world connection which are based on findings from physics education research on common student difficulties in physics; (3) students work in structured collaborative groups on these activities; (4) these 
activities typically involve the use of technology; and (5) the instructor initiates summary discussions and continuously circulates the room assisting students and asking clarifying questions. In addition, these features are associated with higher effect sizes among other non-Workshop/Studio Physics innovations. In the following paragraphs I will speculate as to some possible explanations for the effectiveness of these 5 characteristics.

\section{Integrated Classroom Environment}

In most physics classes students attend separate lecture, recitation, and laboratory class sessions. These course components are separated in both space and time such that the students attend them each at different times and in different rooms throughout the week. These three components of a physics class each serve a specific purpose in the traditional instructional model. The lecture section of a course is typically where instructors describe scientific concepts, principles, and laws. Recitations are where students work on specific problems which require the application of information learned in lecture. The laboratory is where students engage in an experiment in which they collect data, make observations, model data, and make conclusions. Put together, the lecture is where generalized abstract scientific ideas are presented, the recitation is where scientific and mathematical principles are brought to bear on specific problems, and the laboratory is where concrete experiences take place. On paper the model looks comprehensive: all of the pieces are there. However, in traditional practice it falls short. Why? 
Although the methodology deployed in this thesis does not allow for me to make causal inferences, the effectiveness of the Workshop Physics model may lie in part with the integration of the traditionally separate lecture, recitation, and laboratory class sessions. In Workshop Physics students attend class in one room for 2-3 hours at a time in which they conduct experiments, practice problem-solving skills, and make connections to the scientific concepts, principles, and theories covered within the course content. In these classes concrete laboratory experiences are integrated with the abstract scientific concepts, principles, and laws which are typically only covered in lectures. It is possible that the design of the Workshop Physics course naturally makes explicit the connections between two types of concepts: abstract scientific ideas typically covered in formal lectures, and concrete concepts which are formed based on practical experiences which may form in laboratory sessions. This hypothesis is based on Lev Vygotsky's theory of concept formation which is described in his book Thought and Language (1986).

Vygotsky's theory of concept formation involves two types of concepts: (1) abstract concepts which are formal, "scientific" (p. 161), and generalized are generally the product of instruction; and (2) concrete concepts which are "spontaneous" (p. 148) and a product of "everyday" (p. 153) practical experiences. In order for robust concept formation to occur, Vygotsky's theory is that the learner must build connections between their concrete experiences and the generalized and abstract concepts they learn in school. Like stalactites, scientific concepts gradually move downward into concrete applications while practical experiences grow upward 
like stalagmites into generalized scientific concepts (Vygotsky, 1986). The importance of this idea necessitates a direct quote from Vygotsky:

We believe that our data warrant the assumption that from the very beginning, the child's scientific and his spontaneous concepts...starting far apart, they move to meet each other. This is the key point of our hypothesis.... One might say that the development of the child's spontaneous concepts proceeds upward, and the development of his scientific concepts downward, to a more elementary and concrete level (p. 152-153, emphasis in original).

The essence of this quote is that concepts are formed through the connections built between generalized scientific concepts and everyday ideas stemming from experience. The role of education is to facilitate students' efforts to make these connections: "scientific concepts evolve under the conditions of systematic cooperation between the child and the teacher" (Vygotsky, 1986, p. 148).

Vygotsky's theory of concept formation provides a possible explanation for how the integrated design of Workshop/Studio Physics seems to have a large impact on student learning. The Workshop/Studio Physics model naturally melds together physics content that is traditionally taught separately. In traditional classes, the connections between the abstract principles covered lecture, specific problems covered in recitations, and experiments covered in laboratory are left for the students to make, and instructors take for granted that students are making these connections outside of class. 
An additional explanation for the effectiveness of the integrated classroom environment of Workshop/Studio Physics has to do with the consistency of the educational experience. In order to illustrate this point, I will again make a comparison to traditional instruction. In traditional physics classes, what counts as participation changes depending on the class session the student is in. In lecture students are expected to sit quietly and independently take notes; in recitation students are expected to solve problems and ask questions; and in laboratory students are expected to work in a group and actively conduct experiments. Perhaps these disjointed experiences result in disjointed knowledge.

For example, students on an exam may be able to eloquently state Newton's $3^{\text {rd }}$ law but when asked a question about the forces acting on a large truck impacting a small car they are not able to apply the concept of Newton's $3^{\text {rd }}$ law correctly. This phenomenon is illustrated by the experience of Eric Mazur who was shocked when he discovered that his Harvard undergraduates were able to solve complex problem-solving tasks, like those covered in class, but were not able to correctly answer seemingly simplistic conceptual questions on the FCI (Mazur, 1999).

One possible explanation for the effectiveness of an integrated classroom environment is that it naturally makes explicit the connections between the types physics knowledge which are traditionally taught separately. The integrated classroom experience of Workshop/Studio Physics may benefit students due to the 
unifying approach with which students learn physics, rather than the disjointed approach of traditional instruction.

As an additional note, the separation of lecture, recitation, and laboratory is not unique to traditional physics classes. Workshop/Studio Physics was the only innovation within the reviewed studies that involved the integration of course components. All of the other innovations reviewed involve changes to the manner in which the lecture, recitation, or laboratory sessions are conducted, but these changes do not involve the integration of these components. Workshop/Studio Physics is unique in this respect among all other innovations.

\section{Research-Based Activities}

The use of research-based student activities is an additional critical characteristic of Workshop/Studio Physics. These activities are based on the large body of research that has accumulated on the most effective ways in which students learn physics (Goldberg, Otero, \& Robinson, 2010). This includes research on areas of physics where students commonly struggle. A large number of innovations involve research-based student activities besides Workshop/Studio Physics. These innovations include Tutorials, RealTime Physics, and Interactive Lecture Demonstrations.

Research-based student activities are based on the overarching concept of constructivist teaching; namely, that knowledge is built by the learner and is built within the framework of the learners' prior knowledge and ideas. Along these lines, 
research-based activities are often built so that the tasks involve eliciting students' prior knowledge by asking them to make a prediction. Next, the activity works to reinforce students' scientific ideas or confront any misapplied concepts. This activity may involve a task, or a discrepant event, where students conduct an experiment and/or make observations about a physical phenomenon. Lastly, students are prompted to resolve any discrepancy between their prediction and observations. This part of the activity often takes the form of a written of verbal explanation of what they have learned. This type of sequencing within activities is exemplified in the predict-observe-explain instructional strategy which was developed by White and Gunstone (1992) for younger students; however the general strategy has been adapted for undergraduates. For example, in Tutorials, this sequence involves elicitation, confrontation, and resolution.

One possible explanation for the observed effectiveness of research-based instructional activities is that they are rooted in a concrete theory of how learning occurs; namely, classic conceptual change theory which is exemplified in work by Posner, Strike, Hewson, and Gertzog, (1982) and Hewson \& Thorley (1989). This theory of conceptual development is based on the ideas of dissatisfaction, assimilation, and accommodation. The process of accommodation is possible when new ideas and concepts do not fit with the knowledge the learner has already accumulated. This misfit then creates the opportunity for the learner to accommodate new information and integrate it with already assimilated knowledge. 
Another possible explanation for the positive impact of research-based activities on student learning is that they have been tried and tested. Many activities are very similar across different innovations. For example, the task of matching graphs of student movement with position vs. time graphs followed by velocity vs. time graphs using a motion detector attached to a micro-computer is a very common activity among research-based curricula. The reason why is that it has been shown to work well with students.

\section{Student Work in Structured Groups}

The use of structured collaborative groups is a characteristic of effective enactments of Workshop/Studio Physics as well as other innovations. Structured group work differs from other group work in that students are assigned particular roles for the part that they will play in the group activity. These roles are rotated periodically so that each student benefits from each role.

The use of structured groups has been shown to alleviate issues of nonparticipation, power struggles, and other inter-personal issues that hinder the functionality of the group in studies of K-12 students (e.g. Cohen, 1994; Goldberg, et al., 2010; Johnson, \& Johnson, 1994). The alleviation of inter-group issues may allow students to focus more on the content of the activities. This effect may be amplified in Workshop/Studio Physics, where so much of the students time in class is spent working in group activities. 
Students Use Technology to Collect Data

The use of technology in student activities was a critical characteristic of Workshop/Studio Physics. In these activities students gather data on physical phenomena sometimes using everyday technologies such as stopwatches and yardsticks, and sometimes students use more sophisticated data-collection procedures which use probes affixed to computers.

One possible explanation for the effectiveness of this characteristic in innovations is that activities which require the collection of data have an experiential, or hands-on, aspect. The use of technology brings real-world physics problems readily available in physics classrooms (Bransford, Brown, \& Cocking, 2000). As Priscilla Laws states, "the majority of students enrolled in the introductory physics at both the high school and college level do not have sufficient concrete experiences with everyday phenomena to comprehend the mathematical representations of them traditionally presented in these courses" (1991, p. 25).

The benefit of these experiential activities within the Workshop/Studio Physics innovation is that students are able to immediately relate physical experiences and observations with the scientific concepts they are learning.

This idea relates back to Vygotsky's theory of concept formation which was described in an earlier section. When students use technology to gather data, the process of relating physical experiences to the generalized physics concepts are enhanced. For example, when students use motion detectors to gather data on their 
motion, the software immediately graphs the relationship between position vs. time. This allows students to visually make the connection between the experience of moving back and forth to the relationship between position vs. time as shown on the graph. Then when students notice the changes occurring in the position vs. time graph and they connect it to changes in their movement, like moving faster or slower, they can make an immediate connection between their physical experience and the mathematical representation of it. With respect to Vygotsky's theory of concept formation, the benefit of the technology is that it provides the student a way to directly relate his or her physical everyday experience of walking fast or slow to the scientific and mathematical representation of this motion. In this way the experience may result in increased learning for the student.

Teacher as Facilitator

In Workshop/Studio Physics the instructor is released from his or her role as sage at the front of the class and instead acts as facilitator, moving around the classroom asking questions and providing assistance. Instructors are freed from their obligations to prepare lectures and instead can focus their attention on understanding the content of the student activities, anticipating areas where student errors may occur, developing approaches to help students make connections and synthesize their ideas, and developing well-formulated questions that probe student understanding. During class the instructors' role is to circulate the room in order to help clarify students' ideas and resolve cognitive conflicts, motivate 
students, answer questions, and help students make connections to scientific principles. In addition, this increased time with students allows instructors to develop personal relationships and keep track of what students understand and what they are struggling with. This may allow instructors to adjust instruction in order to suit the needs and interests of the students. These are benefits of this approach to teaching which is not as easily accomplished in the traditional model of physics instruction.

One of the benefits of having an instructor as a facilitator is that students are able to ask questions of the instructor in a low-stakes manner during class time. In a traditional lecture class, students only have the opportunity to ask the instructor questions in front of the entire class which may include up to 500 other students. This may represent a high-stakes environment for students in which case they may not be comfortable asking a question. Additionally, some traditional instructors do not allow or provide opportunities for students to ask questions. An additional possible benefit of this instructional approach is that the instructor shifts their role as the ultimate knowledge source to one of many sources of learning. Students may benefit from seeing the instructor as a source of assistance rather than an untouchable perfect source of knowledge.

Additionally, the opportunity of increased interaction between the instructor and student may allow for opportunities of formative assessment to occur. In their seminal review and meta-analysis of research on the subject, Black and Wiliam (1998) broadly define formative assessment as “...encompassing all those activities 
undertaken by teachers, and/or by their students, which provide information to be used as feedback to modify the teaching and learning activities in which they are engaged" (p. 7). Sadler (1989) states: "[for an assessment to be formative]...the learner has to (a) possess a concept of the standard (or goal, or reference level) being aimed for, (b) compare the actual (or current) level of performance with the standard, and (c) engage in appropriate action which leads to some closure of the gap" (p. 121, emphasis in original). By allowing opportunities for instructors to gauge the level of students' thinking they can respond formatively either by immediately responding to the student, and/or altering future activities to suit the needs of the students. The increased interactions between the instructor and students in the Workshop/Studio Physics innovation may allow instructors to be able to better understanding student thinking and respond to it.

Future work might investigate more deeply the role of the instructor in Workshop/Studio Physics. For example, what is it that students do in effective enactments of Workshop/Studio Physics to facilitate student learning? Many of the reviewed studies do not describe the role of the instructor in their published work. However, the results of the case-study indicate that the role of the instructor may be essential for many of these innovations although it is not described in papers. The overall feel of the articles is that the role of the instructor is treated as a black box. Future work might unpack this black box in order to understand better the impact that instructors have on student learning. 
Overall Holistic Impact of Workshop/Studio Physics

While it is likely that each of the aforementioned aspects of Workshop/Studio Physics contribute to the effectiveness of the model, it is likely that the effectiveness of the model as a whole is greater than the sum of its parts (Pollock, 2005). One possible overarching explanation for the effectiveness of the Workshop/Studio Physics model is that the model requires an overhaul of every aspect of the traditional instructional model. It requires physical modifications such as a new classroom environment, modified curriculum, and additional technological materials. In addition it requires a major shift in the way instructors and students engage in physics instruction. These changes are not trivial, even with the most motivated instructors. The success of an educational overhaul which is necessary for the enactment of Workshop/Studio Physics rests on the support of institutional and departmental supports (Turpen, 2010). The fact that these institutional supports must be in place for the use of Workshop/Studio Physics may be a factor which adds to the effectiveness of the innovation. For example, if a Workshop/Studio Physics course is being used it is because there is tremendous support for its use including support for the instructor. This support may allow the instructor to feel more comfortable about placing an increased focus on their instruction - something which is not always supported within university physics departments.

The large majority of the innovations implemented in the reviewed literature focus on changes that can be accomplished within the overall model of traditional physics education. For example, Tutorials are used in place of traditional 
recitations. However, in many studies this is the only change to the course. In other words, the course retains the traditional lecture and laboratory format with the addition of the modified recitations. Similarly, some innovations only impact the lecture component of a course, or only the students' homework. Workshop/Studio Physics was the only innovation among the reviewed studies which involves a complete overhaul of the traditional model of physics instruction.

\section{Limitations of Case Study}

The primary limitation of this case study analysis is that it involved only reviews of published work and interviews with implementers. A more comprehensive description of the Workshop/Studio Physics innovation would have required observations of the course and even student interviews. This, however, would have posed an issue with choosing a particular instantiation because the model varies slightly across different schools and instructors.

An additional limitation is that this case study analysis is just a single analysis and it is not possible to generalize the findings beyond the scope of the sampled studies. For example, it is not possible to extrapolate the success of the Workshop/Studio Physics model to different universities of different educational settings. 


\section{Closing Thoughts}

There are three main conclusions of this dissertation research that I would like to highlight in this section. The first is that, within the reviewed studies, the overall impact of undergraduate physics course innovations on student learning is positive and compared to other educational innovations, very large (Haager, et al., 2008; Hattie \& Timperley, 2007). This is a finding that until now had not yet been established for the vast number of course innovations that have been implemented and evaluated. The changes that have been made to the traditional model of instruction over the last several decades have positively impacted student understanding. While the overall effect of course innovations had been positive, the effectiveness of innovations is highly variable. While almost half of this variability can be explained by differences in the methodological characteristics of the study, a good portion of the variability is likely the result of different innovations.

The second main conclusion of this dissertation research is that innovations which involve a model of instruction referred to as Workshop/Studio Physics have particularly high effect sizes. This model involves an overhaul of the traditional model of instruction in which students meet in an integrated classroom environment. In this instructional model lecture is minimized while collaborative group work with the use of technology is emphasized. Additionally the instructors' role shifts from lecturer in the traditional physics class to facilitator and guide within the Workshop/Studio Physics model. 
The third main conclusion of this dissertation research is more of a caveat. The results of the preceding analysis have been limited by the characteristics of the reviewed studies. More than half of the studies had to be eliminated from the metaanalysis because they did not provide the statistical data necessary for an effect size calculation. In addition, a large majority of studies suffer from the possibility of selection bias due to the non-random assignment of students to treatment and control and the lack of pretest data for students across treatment and control groups. Additionally, few studies provide information on the validity and reliability of the outcome measure used in the study. Future implementers of undergraduate physics course innovations are encouraged to consider providing this information in future reports. 


\section{References}

Adams, W.K., Perkins, K.K., Podolefsky, N.S., Dubson, M., Finkelstein, N.D., \& Wieman, C.E. (2006). New instrument for measuring student beliefs about physics and learning physics: The Colorado Learning Attitudes about Science Survey. Physical Review Special Topics Physics Education Research, 2, 010101.

Ambrose, B.S., Shaffer, P.S., Steinberg, R.N., \& McDermott, L.C. (1999). An investigation of student understanding of single-slit diffraction and doubleslit interference. American Journal of Physics, 67, 146-155.

Anderson, J.R. (1983). A spreading activation theory of memory. Journal of Verbal Learning and Verbal Behavior, 22, 261-295.

Arons, A.B. (1973). Toward Wider Public Understanding of Science. American Journal of Physics, 41(6), 769-782.

Arons, A.B. (1974). Addendum to "Toward Wider Public Understanding of Science". American Journal of Physics, 42(2), 157-158.

Atkin, M., \& Black, P. (2003). Inside Science Education Reform: A History of Curricular and Policy Change. Open University Press, Reading.

Austin, S.M., \& Gilbert, K.E. (1973). Student Performance in a Keller-Plan Course in Introductory Electricity and Magnetism. American Journal of Physics, 41(1), 12-18.

Ausubel, D. (1963). The Psychology of Meaningful Verbal Learning. New York: Grue \& Stratton. 
Baddeley, A.D. (1986). Working Memory. Oxford: Clarendon Press.

Bandura, A. (1977). Self-efficacy: Toward a unifying theory of behavior change. Psychological review, 84, 191-215.

Barak, M., Harward, J., Kocur, G., \& Lerman, S. (2007). Transforming an Introductory Programming Course: From Lectures to Active Learning via Wireless Laptops. Journal of Science Education and Technology, 16(4), p. 325-336.

Becker, B.J. (1988). Synthesizing standardized mean-change measures. British Journal of Mathematical and Statistical Psychology, 41(25), 257-278.

Beichner, R. J., Saul, J. M. , Abbott, D. S. , Morse, J. J. , Deardorff, D. L. , Allain, R. J., Bonham, S. W. , Dancy, M. H., \& Risley, J.S. (2007). The StudentCentered Activities for Large Enrollment Undergraduate Programs (SCALEUP) project, in Research-Based Reform of University Physics, edited by E. F. Redish and P. J. Cooney (American Association of Physics Teachers, College Park, MD, 2007), Reviews in PER Vol. 1, <http://www.percentral.org/document/ServeFile.cfm?ID=4517>.

Beichner, R., Bernold, L., Burniston, E., Dail, P., Felder, R., Gastineau, J., Gjertsen, M., \& Risley, J. (1999). Case study of the physics component of an integrated curriculum. American Journal of Physics, 67, S16.

Beichner, R.J. (1994). Testing student interpretation of kinematics graphs. American Journal of Physics, 62, 750-762. 
Beichner, R.J. (2009). An Introduction to Physics education Research. Reviews in PER Volume 2: Getting Started in Physics Education Research, 2(1).

Black, P., \& Wiliam, D. (1998). Assessment and classroom learning. Assessment in Education, 5(1), 7-74.

Bogdan, R.C., \& Biklen, S.K. (1998). Qualitative research for education: An introduction to theory and methods. Needham Heights, MA: Ally \& Bacon.

Bohlmeyer, E.M., \& Burke, J.P. (1987). Selecting Cooperative Learning Techniques: A Consultative Strategy Guide. School Psychology Review, 16(1), 36-49.

Bonham, S., Beichner, R., \& Deardorff, D. (2001). Online homework: Does it make a difference? The Physics Teacher, 39(5), p. 293-296.

Bonham, S.W., Deardorff, D.L., \& Beichner, R.J. (2003) Comparison of student performance using web and paper-based homework in college-level physics. Journal of Research in Science Teaching, 40(10), p. 1050-1071.

Bransford, J.D., Brown, A.L., \& Cocking, R.R. (Eds.). (2000). How people learn: brain, mind, experience, and school. Washington, DC: National Academy Press.

Briggs, D.C. (2005). Meta-Analysis: A Case Study. Evaluation Review, 29(2), 87-127.

Brown, A., \& Palincsar, A. (1989). Guided, cooperative learning and individual knowledge acquisition. In L.B. Resnick (Ed), Knowing, learning and instruction: Essays in honor of Robert Glaser (p. 393-451). Hillsdale, NJ: Lawence Erlbaum. 
Bybee, R.W. (1997). Achieving scientific literacy: From purposes to practices. Potsmouth. NH: Heineman.

Chandler, P., \& Sweller, J. (1991). Cognitive Load Theory and the Format of Instruction, Cognition and Instruction, 8(4), 293-332.

Chi, M.T.H., Feltovich, P.J., \& Glaser, R. (1981). Categorization and representation of physics problems by expert and novices. Cognitive science, 5, 121-152.

Clement, J. (1982). Students' preconceptions in introductory mechanics. American Journal of Physics, 50(1), 66-71.

Clement, J. (1993). Using bridging analogies and anchoring institutions to deal with students' preconceptions in physics. Journal of Research in Science Teaching, 30(10), 1241-1257.

Cohen, D.K. (1990). A Revolution in One Classroom: The Case of Mrs. Oublier, Educational Evaluation and Policy Analysis, 12(3), 311-329.

Cohen, R., Eylon, B., \& Ganiel, U. (1983). Potential difference and current in simple electric circuits: a study of student's concepts. American Journal of Physics, 51(5), 407-412.

Collins, A., Browm, J.S., \& Newman, S.E. (1989). Cognitive apprenticeship: Teaching the crafts of reading, writing, and mathematics. In L.B. Resnick (Ed.). Knowing, learning and instruction: Essays in honor of Robert Glaser, p. 453-494. Hillsdale, NJ: Lawrence Erlbaum Associates. 
Cooper, H., Hedger, L.V., \& Valentine, J.C. (2009). Handbook of Research Synthesis and Meta-Analysis $2^{\text {nd }}$ Edition. New York, New York: Russell Sage Foundation.

Cooper, M.A. (1993). An evaluation of the implementation of an integrated learning system for introductory college physics, Ph.D. thesis, Rutgers, The State University of NJ, 1993.

Crouch, C.H., \& Mazur, E. (2001). Peer Instruction: Ten Years of Experience and Results. American Journal of Physics, 69(9), 970-977.

Crouch, C.H., Watkins, J., Fagen, A.P., \& Mazur, E. (2007). Peer Instruction: Engaging Students One-on-One, All at Once, in Research-Based Reform of University Physics, edited by E. F. Redish and P. J. Cooney (American Association of Physics Teachers, College Park, MD, 2007), Reviews in PER Vol. 1, <http://www.per-central.org/document/ServeFile.cfm?ID=4990>.

Cummings, K., Marx, J., Thornton, R., \& Kuhl, D. (1999). Evaluating innovation on studio physics. American Journal of Physics, 67(S1), S38-S44.

Dancy, M., \& Henderson, C. (2007). Framework for articulating instructional practices and conceptions. Physics Review Special Topics Physics Education Research, 3(010103), 1-15.

DeBoer, G. (1991). A history of ideas in science education: Implications for practice. New York: Teachers College Press.

DeHaan, R. L. (2005). The impending revolution in undergraduate science education. J. Sci. Educ. Tech. 14, 253-269. 
Ding, L., Chabay, R., Sherwood, B., \& Beichner, R. (2006). Evaluating an electricity and magnetism assessment tool: Brief electricity and magnetism assessment. Physical Review Special Topics Physics Education Research, 2, 010105.

Dori, Y., \& Belcher, J. (2005). How does technology-enabled active learning affect undergraduate students' understanding or electromagnetism concepts? Journal of the Learning Sciences, 14(2), 243-279.

Dori, Y.J., Hult, E., Breslow, L., \& Belcher, J.W. (2007). How Much Have They Retained? Making Unseen Concepts Seen in a Freshman Electromagnetism Course at MIT. Journal of Science Education and Technology, 16(4), p. 299323.

Driver, R. (1989). Students' conceptions and the learning of science. International Journal of Science Education, 11(5), 481-490.

Driver, R., 7 Bell, B. (1986). Students' thinking and the learning of science: A constructivist view. School Science Review, 67, 443-456.

Elby, A., Frederiksen, J., Schwarz, C., \& White, B. (1997). Epistemological Beliefs Assessment for the Physical Sciences. Papers presented at the Annual Conference of the American Educational Research Association, Chicago.

Etkina, E., Murthy, S., \& Zou, X. (2006). Using introductory labs to engage students in experimental design. American Journal of Physics, 74, p. 979.

Fagen, A.P., Crouch, C.H., \& Mazur, E. (2002). Peer Instruction: Results from a Range of Classrooms. The Physics Teacher, 40, 206-209. 
Finkelstein, N.D., Adams, W.K., Keller, C.J., Kohl, P.B., Perkins, K.K., Podolefsky, N.S., Reid, S., \& LeMaster, R. (2005). When learning about the real world is better done virtually: A study of substituting computer simulations for laboratory equipment. Physical Review Special Topics Physics Education Research, 1, 010103.

Finn, J. D., \& Achilles, C.M. (1990). Answers and questions about class size: A statewide experiment. American Educational Research Journal, 27, 557-577.

Fredette, N., \& Lochhead, J. (1980). Student conceptions of simple circuits. Physics Teacher, 18, 194-198.

Fuller, Karplus, \& Lawson, A.E. (1977). Can physics develop reasoning? Physics Today, 23-28.

Gautreau, R., \& Novemsky, L. (1997). Concepts first - A small group approach to physics learning. American Journal of Physics, 65(5), p. 418-428.

Glaser, B.G. \& Strauss, A. (1967). Discovery of Grounded Theory: Strategies for Qualitative Research. New York, NY: Aldine Publishing Company.

Goldberg, F.M., \& Anderson, J.H. (1989). Student difficulties with graphical representations of negative values of velocity. Physics Teacher, 27, 254-260.

Goldberg, F., Otero, V., \& Robinson, S. (2010). Design principles for effective physics instruction: A case from physics and everyday thinking. American Journal of Physics, 78(12), 2010.

Green, B.A. (1971). Physics Teaching by the Keller Plan at MIT. American Journal of Physics, 39(7), 764-775. 
Haager, D., Heimbichner, C., Dhar, R., Moulton, M., \& McMillan, S. (2008). The California Reading First Year 6 Evaluation Report. Retrieved at: http://rtac.acoe.org/files/documents/Year6.pdf

Hake, R.R. (1992). Socratic Pedagogy in the Introductory Physics Lab. The Physics Teacher, 30, 546.

Hake, R.R. (1998). Interactive-Engagement Versus Traditional Methods: A SixThousand-Student Survey of Mechanics Test Data for Introductory Physics Courses. American Journal of Physics, 66(1), 64-74.

Halloun, I., \& Hestenes, D. (1996). Views About Science Survey. Paper presented at the Annual Meeting of the National Association for Research in Science Teaching, Saint Louis, Missouri.

Halloun, I.A., \& Hestenes, D. (1985)a. Common sense concepts about motion. American Journal of Physics, 53(11), 1056-1065.

Halloun, I.A., \& Hestenes, D. (1985)b. The Initial State of College Physics Students. American Journal of Physics, 53(11), 1043-1055.

Hammer, D. (1989). Two approaches to learning physics. Physics Teacher, 27, 664670.

Hammer, D. (1994). Epistemological beliefs in introductory physics. Cognition and Instruction, 12(2), 151-183.

Hansen, J.A., Barnett, M., MaKinster, J.G., \& Keating, T. (2004). The impact of three-dimensional computational modeling on student understanding of 
astronomical concepts: a quantitative analysis. International Journal of Science Education, 26(11), p. 0950-0693.

Hanushek, E.A. (1999). Some Findings From an Independent Investigation of the Tennessee STAR Experiment and From Other Investigations of Class Size Effects. Educational Evaluation and Policy Analysis, 21(2), 143-163.

Hardiman, P., Dufresne, R., \& Mestre, J. (1989). The relation between problem categorization and problem solving among experts and novices. Memory and Cognition, 17, 627-638.

Hattie, J. \& Timperley, H. (2007). The Power of Feedback. Review of Educational Research, 77(1), 81-112.

Heller, P., \& Hollabaugh M. (1992). Teaching problem solving through cooperative grouping. Part 2: Designing problems and structuring groups. American Journal of Physics, 60, $637-644$.

Heller, P., Keith, R., \& Anderson, S. (1992). Teaching problem solving through cooperative grouping. Part 1: Group versus individual problem solving. American Journal of Physics, 60(7), 627-636.

Heron, P.R., Loverude, M.E., Shaffer, P.S., \& McDermott L.C. (2003). Helping students develop an understanding of Archimedes' Principle Part II. Development of research-based instructional materials. American Journal of Physics, 71(11), 1188-1195. 
Heron, P.R.L., \& Meltzer, D.E. (2005). The future of physics education research: Intellectual challenges and practical concerns. American Journal of Physics, 73(5), 390-394.

Hestenes, D. \& Wells, M. (1992). A Mechanics Baseline Test. Physics Teacher, 30, 159-166.

Hestenes, D. (1979). Wherefore a science of teaching? The Physics Teacher, 17, 235242.

Hestenes, D., Wells, M., \& Swakhammer, G. (1992). Force concept Inventory. Physics Teacher, 30(3), 141-158.

Hewson, P.W., \& Hewson, M.G. (1984). The role of conceptual conflict in conceptual change and the decision of science instruction. Instructional Science, 13, 1-13. Hewson, P.W., Thorley, N.R. (1989). The conditions of conceptual change in the classroom. International Journal of Science Education, 11, 541-553.

Hoellwarth, C., Moelter, M.J., \& Knight, R.D. (2005). A direct comparison of conceptual learning and problem solving ability in traditional and studio style classrooms. American Journal of Physics, 73, p. 459.

Hubbard, L., Stein, M.K., \& Mehan, H. (2006). Reform as learning: When school reform collides with school culture and community practice. New York: Routledge.

Hung, W., \& Jonassen, D.H. (2006). Conceptual Understanding of Causal Reasoning in Physics. International Journal of Science Education, 28 (13), p. 0950-0693. 
Johnson, D.W., \& Johnson, R.T (1994). Learning Together and Alone. Cooperative, Competitive, and Individualistic Learning. Allyn and Bacon.

Johnson, I.D., Crawford, K., \& Fletcher, P.R. (1998). Student difficulties in learning quantum mechanics. International Journal of Science Education, 20, 427-446.

Johnstone, A.H., El-Banna, H. (1986). Capacities, demands and processes - a predictive model for science education. Education in Chemistry, 23, 80-84.

Keller, F.S. (1968). "Good-bye Teacher...” Journal of Applied Behavior Analysis, 1(1), 79-89.

King, A. (1994). Inquiry as a tool in critical thinking. In Halpern, D.F. (Ed.), Changing College Classrooms: New teaching and Learning Strategies for an Increasingly Complex World. Jossey-Bass, San Francisco, pp. 155-161.

Larkin, J.H., \& Reif, F. (1979). Understanding and teaching problem solving in physics. European Journal of Science Education, 1(2), 191-203.

Laws, P. (1991). Calculus-based physics without lectures. Physics Today, 44(12), 2431.

Laws, P. (1997). Millikan Lecture 1996: Promoting active learning based on physics education research in introductory physics courses. American Journal of Physics, 65(1), 13-21.

Laws, P.W. (1997). Workshop Physics Activity Guide. Wiley, New York.

Lenaerts, J., Wieme, W., \& Van Zele, E. (2003). Peer instruction: a case study for an introductory magnetism course. European Journal of Physics, 24(1), 7-14. 
Light, R.J., \& Pillemer, D.B. (1984). Summing Up: The Science of Reviewing Research. Cambridge, Massachusetts: Harvard University Press.

Lindsey, W.C. (1972). Synchronization systems in communication and control. Englewood cliffs, NJ: Prentice-Hall, p. 734.

Lipsey, M.W., \& Wilson, D.B. (2001). Practical Meta-Analysis. California: SAGE Publications, Inc.

Mazur, E. (1999). Peer Instruction: A User's Manual. American Journal of Physics, 67(4), 359-360.

McCloskey, M., Caramazza, A., \& Green, B. (1980). Curvilinear Motion in the Absence of External Forces: Naïve Beliefs About the Motion of Objects. Science, 210(4474), 1139-1141.

McDermott, L. (1991). Millikan Lecture 1990: What we teach and what is learned closing the gap. American Journal of Physics, 59, 301-315.

McDermott, L.C. \& Shaffer, P.S., \& Somers, M.D. (1994). Research as a guide for teaching introductory mechanics: An illustration in the context of the Atwood's machine. American Journal of Physics, 62, 46.

McDermott, L.C. (1984). Research on conceptual understanding in mechanics. Physics Today, 37(7), 24-32.

McDermott, L.C. (1993). Guest Comment: How we teach and how students learn - a mismatch?, American Journal of Physics, 61, 295-298.

McDermott, L.C. (1993). How we teach and how students learn - A Mismatch?, American Journal of Physics, 61(4). 
McDermott, L.C., \& Redish, E.F. (1999). Resource letter on Physics Education Research. American Journal of Physics, 67(9), 755-773.

McDermott, L.C., \& Shaffer, P.S. (1992). Research as a Guide for Curriculum Development: An Example from Introductory Electricity, Part I: Investigation of student Understanding. American Journal of Physics, 60(11), 994 - 1003.

McDermott, L.C., Rosenquist, M.L., Shaffer, P.S. (1996). Physics by Inquiry. New York: J. Wiley.

McKagan, S.B., Perkins, K.K., \& Wieman, C.E. (2010). Design and validation of the Quantum Mechanics Conceptual Survey. Physical Review Special Topics Physics Education Research, 6, 020121.

Meltzer, D., \& Manivannan, K. (2002). Transforming the lecture-hall environment: The fully interactive physics lecture. American Journal of Physics, 70(6), 639654.

Merriam, S.B. (1998). Qualitative research and case study applications in education. San Francisco, CA: Jossey-Bass.

Miller, G.A. (1956). The Magical Number Seven, Plus or Minus Two: Some Limits on our Capacity for Processing Information. Psychological Review, 63, 81-97.

Minner, D., Levy, A., \& Century, J. (2010). Inquiry-based science instruction- what is it and does it matter? Results from a research synthesis years 1984 to 2002. Journal of Research in Science Teaching, 47(4), 474-496.

Morris, S.B. (2008). Estimating Effect Sizes From Pretest-Posttest-Control Group Designs, Organizational Research Methods, 11(2), 364-386. 
National Commission on Excellence in Education (NCEE). (1983). A nation at risk: The imperative for educational reform. Washington, DC: U.S. Department of Education.

Novak, G.M., Patterson, E.T., Gavrin, A.D., \& Christian, W. (1999). Just-in-Time Teaching: Blending Active Learning with Web Technology. Prentice Hall.

Papert, S., \& Harel, I. (1991). Constructionism. Ablex Publishing Corporation. Pollock, S.J. (2005). No Single Cause: learning gains, student attitudes, and the impacts of multiple effective reforms. AIP Conference Proceedings, 790(1), 137-140.

Posner, G.J., Strike, K.A., Hewson, P.W., \& Gerzog, W.A. (1982). Accommodation of a scientific conception: Toward a theory of conceptual change. Science Education, 66(2), 211-227.

Reay, N.W., Bao, L., Li, P., Warnakulasooriya, R., \& Baugh, G. (2005). Toward the effective use of voting machines in physics lectures. American Journal of Physics, 73, p. 554 .

Redish, E. (1994). The implications of cognitive studies for teaching physics. American Journal of Physics, 62, 796-803.

Redish, E., Saul, J., \& Steinberg, R. (1997). On the effectiveness of activeengagement microcomputer-based laboratories. American Journal of Physics, 65(1), p. 45-54.

Redish, E.F. (1999). Millikan lecture 1998: Building a science of teaching physics. American Journal of Physics, 67(7), 562-573. 
Redish, E.F. (2003). Teaching Physics with the Physics Suite. John Wiley \& Sons, Inc.

Redish, E.F., Steinberg, R.N., \& Saul, J.M. (1998). Student Expectations in Introductory Physics. American Journal of Physics, 66, 212-224.

Reif, F. (1974). Educational Challenges for the University. Science, 184(4136), 537542.

Reif, F. (1986). Scientific approaches to science education. Physics Today, 39(11), 4854 .

Resnick, L.B. (1983). Mathematics and Science Learning: A New Conception. Science, 220(4596), 477-478.

Robinson, G.E., \& Wittebols, J.H. (1986). Class size research: A related cluster analysis for decision making. Arlington, VA: Educational Research Service.

Rudolph, J.L. (2002). Scientists in the classroom: The cold war reconstruction of American science education. New York: Palgrave.

Ruiz-Primo, M. A., Briggs, D., Shepard, L., Iverson, H., \& Huchton, M. (2008). Evaluating the impact of instructional innovations in engineering education. In M. Duque (Ed.). Engineering education for the XXI Century: Foundations, strategies and cases (pp. 241-274). Bogotá, Colombia: ACOFI Publications.

Ruiz-Primo, M.A., Briggs, D., \& Shepard, L. (2006). Undergraduate Science Course Innovations and Their Impact on Student Learning. Proposal funded by National Science Foundation, Award ID: DRL-0736423. 
Ruiz-Primo, M.A., Shavelson, R.J., Hamilton, L., \& Klein, S. (2002). On the evaluation of systemic science education reform: Searching for instructional sensitivity. Journal of Research in Science Teaching, 39(5), 369-393.

Sadler, D.R. (1989). Formative assessment and the design of instructional systems. Instructional Science, 18(2), 119-144.

Schroeder, C. M., Scott, T. P., Tolson, H., Huang, T.-Y., \& Lee, Y.-H. (2007). A MetaAnalysis of National Research: Effects of Teaching Strategies on Student Achievement in Science in the United States. Journal of Research in Science Teaching, 44(10), 1436-1460.

Scott, P., Asoko, H., Driver, R. (1992). Teaching for conceptual change: A review of strategies. In R. Duit, F. Goldberg, \& H. Niedderer, Eds., Research in physics learning: Theoretical issues and empirical studies. Kiel, Germany: Institute for Science Education at the University of Kiel.

Scott, P., Dyson, T., \& Gater, S. (1987). A constructivist view of learning and teaching in science. Leeds University, United Kingdom.

Shaffer, P.S., \& McDermott, L.C. (1992). Research as a guide for curriculum development: An example from introductory electricity. Part II: Design of instructional strategies. American Journal of Physics, 60(11), 1003-1013.

Singh, C. (2005). Impact of peer interaction on conceptual test performance. American Journal of Physics, 73, p. 446. 
Slavin, R.E. (1989). Achievement effects of substantial reductions in class size. In R.E. Slavin (Ed.), School and classroom organization (pp. 247-257). Hillsdale, NJ: Erlbaum.

Smith, M., and Glass, G. (1977). Meta-analysis of psychotherapy outcome studies. American Psychologist, 32,752-760.

Sokoloff, D. \& Thornton, R. (1997). Using Interactive Lecture Demonstrations to create an Active Learning Environment, Physics Teacher, 35(10), 340-347.

Sokoloff, D.R., Laws, P.W., Thornton, R.K. (2007). RealTime Physics: active learning labs transforming the introductory laboratory. European Journal of Physics, 28, S83 - S94.

Sokoloff, D.R., Thornton, R.K., Laws P. (1999). Real Time Physics. J Wiley, New York, NY.

Sorensen, C.M., Churukian, A.D., Maleki, S., \& Zollman, D.A. (2006). The New Studio format for instruction of introductory physics. American Journal of Physics, 74, p. 1077.

Sunal, D.W., Sunal, C.S., Sundberg, C., Mason, C., Lardy, C., \& Zollman, D. (2008). What so we know about undergraduate science course reform? Synthesizing Themes. Retrieved at (http://education.ua.edu/centers/ortd/backgroundresearch-papers/)

Suter L., \& Narayanan, H. (2006). A View of Physics Education Portfolio and Research from The National Science Foundation. Paper presented at the 
Annual Meeting of the American Educational Research Association, April, 2006, San Francisco, CA.

Sweller, J. (1994). Cognitive load Theory, learning difficulty, and instructional design. Learning and Instruction, 4(4), 295-312.

The Carnegie Commission on Higher Education (1972). The Fourth Revolution: Instructional Technology in Higher Education. New Jersey: McGraw-Hill Book Company.

Thornton, R., \& Sokoloff, D. (1990). Learning motion concepts using real-time microcomputer-based laboratory tools. American Journal of Physics, 58(9), p. 858-867.

Thornton, R., \& Sokoloff, D. (1998). Assessing student learning of Newton's laws: The Force and Motion Conceptual Evaluation and the evaluation of active learning laboratory and lecture curricula. American Journal of Physics, 66, 338-352.

Trowbridge, D.E., \& McDermott, L.C. (1980). Investigation of student understanding of the concept of velocity in one dimension. American Journal of Physics, 48(12), 1020-1028).

Turpen, C. (2010). Towards a Model of Educational Transformation: Documenting the changing educational practices of professors, institutions, and students in introductory physics, Ph.D. thesis, University of Colorado Boulder.

Van Heuvelen, A. (1991). Overview, Case Study Physics. American Journal of Physics, 59(10), p. 898-907. 
Van Heuvelen, A. (1996). Active Learning Problem Sheets (Mechanics Kit and Electricity \& Magnetism Kit), Hayden-McNeil Publishing, Inc.

Vokos S., Shaffer, P.S., Ambrose, B.S., McDermott, L.C. (2000). Student Understanding of the Wave Nature of Matter: Diffraction and Interference of Particles. American Journal of Physics, 68, S42-S51.

von Glaserfeld, E. (1983). Learning as Constructive Activity. In J.C. Bergeron \& N. Herscovics (eds.) Proceedings of the 5th Annual Meeting of the North American Group of Psychology in Mathematics education, Vol. 1. Montreal: PME-NA, 41-101.

von Glaserfeld, E. (1995). A constructivist approach to teaching. In L. Steffe \& J. Gale (eds.), Constructivism in education (p. 3-16). Hillsdale, NJ: Lawrence Erlbaum.

Vygotsky, L.S. (1978). Mind in Society. Cambridge, Massachusetts.

Vygotsky, L.S. (1986). Thought and Language. Cambridge, MA: The MIT Press.

White, R.T., \& Gunstone, R.F. (1992). Probing understanding. London: Falmer.

Wick, D.P., \& Ramsdell, M.W. (2004). Modeling the motion of a toy train powered with a time-dependent applied voltage: Educational implementation and analysis. American Journal of Physics, 72, p. 863.

Wilson, J. (1994). The CUPLE Physics Studio. The Physics Teacher, 32 (12), 518522.

Wittmann, M.C., Steinberg, R.N., \& Redish, E. (1999). Making sense of how students make sense of mechanical waves. Physics Teacher, 37(1), 15-21. 
Wosilait, K., Heron, P., Shaffer, P.S., McDermott, L.C. (1999). Addressing student Difficulties in Applying a Wave Model to the Interference and Diffraction of Light. American Journal of Physics, 67, S5 - S15.

Yin, Robert K. (1984). Case Study Research: Design and Methods. Beverly Hills, CA: Sage. 


\section{Appendix A}

\section{Letter to Key Researchers}

Subject: Undergraduate Science Course Innovations

Dear Professor

I am a graduate research assistant in the School of Education at the University of Colorado at Boulder working on an NSF funded study entitled "Undergraduate Science Course Innovations: Impact on Student Learning." I was referred to you by _ who is a member of our advisory panel.

A primary aim of our study is to synthesize what is known about the effectiveness of instructional innovations that have been implemented in undergraduate courses in physics. We have defined undergraduate science course innovations as those centered on an active student learning approach that involves: moving away from lecturing as the main or central instructional strategy, shifting the focus from the professor (instructor) towards the student, and supporting shared collaboration.

With this definition in mind, and after reviewing several studies and discussing a range of possibilities, we have identified five categories of course innovations in terms of a focus on (1) problem-solving, (2) collaborative learning, (3) technology use, (4) conceptually-oriented assessments, (5) formative assessments.

We are currently in the process of collecting seminal research publications in physics education research. Listed below you will find examples of some of the publications we have already gathered. We would greatly appreciate your input as to other publications (or researchers) that you feel should be included in this list.

Thank you very much for your time and assistance,

Heidi Iverson

PS If you would like more information about the details of our study, I would be happy to provide this as a separate attachment. 


\section{Appendix B}

\section{Reference List of Comparative Studies}

1. Abbott, D.S., Saul, J.M., Parker, G.W., \& Beichner, R.J. (2000). Can one lab make a difference? American Journal of Physics, 68(S1), S60-S61.

2. Bao, L., \& Redish, E.F. (2002). Understanding probabilistic interpretations of physical systems: A prerequisite to learning quantum physics. American Journal of Physics, 70, p. 210.

3. Barak, M., Harward, J., Kocur, G., \& Lerman, S. (2007). Transforming an Introductory Programming Course: From Lectures to Active Learning via Wireless Laptops. Journal of Science Education and Technology, 16(4), p. 325336.

4. Beichner, R., Bernold, L., Burniston, E., Dail, P., Felder, R., Gastineau, J., Gjertsen, M., \& Risley, J. (1999). Case study of the physics component of an integrated curriculum. American Journal of Physics, 67, S16.

5. Beichner, R.J. (1990). The effect of simultaneous motion presentation and graph generation in a kinematics lab. Journal of Research in Science Teaching, 27(8), p. 803-815.

6. Beichner, R.J. (1996). The impact of video motion analysis on kinematics graph interpretation skills. American Journal of Physics, 64, p. 1272.

7. Beichner, R. J., Saul, J. M. , Abbott, D. S. , Morse, J. J. , Deardorff, D. L. , Allain, R. J., Bonham, S. W. , Dancy, M. H., \& Risley, J.S. (2007). The Student-Centered Activities for Large Enrollment Undergraduate Programs (SCALE-UP) project, in Research-Based Reform of University Physics, edited by E. F. Redish and P. J. Cooney (American Association of Physics Teachers, College Park, MD, 2007), Reviews in PER Vol. 1, <http://www.percentral.org/document/ServeFile.cfm?ID $=4517>$.

8. Bonham, S., Beichner, R., \& Deardorff, D. (2001). Online homework: Does it make a difference? The Physics Teacher, 39(5), p. 293-296.

9. Bonham, S.W., Deardorff, D.L., \& Beichner, R.J. (2003) Comparison of student performance using web and paper-based homework in college-level physics. Journal of Research in Science Teaching, 40(10), p. 1050-1071. 
10. Cataloglu, E. (2007). Internet-mediated assessment portal as a pedagogical learning tool: a case study on understanding kinematics graphs. European Journal of Physics, 28(4), p. 767-776.

11. Chang, W. (2005). The rewards and challenges of teaching innovation in university physics: 4 years' reflection. International Journal of Science Education, 27(4), p. 0950-0693.

12. Cheng, K.K., Thacker, B.A., Cardenas, R.L., \& Crouch, C. (2004). Using an online homework system enhances students' learning of physics concepts in an introductory physics course. American Journal of Physics, 72, p. 1447.

13. Cochran, M.J., \& Heron, P.R.L. (2006). Development and assessment of research-based tutorials on heat engines and the second law of thermodynamics. American Journal of Physics, 74 (8), p. 734-741.

14. Crouch, C.H., Fagen, A.P., Callan, J.P., \& Mazur E. (2004). Classroom Demonstrations: Learning Tools or Entertainment? American Journal of Physics, 72, p. 835-838.

15. Cummings, K., Marx, J., Thornton, R., \& Kuhl, D. (1999). Evaluating innovation on studio physics. American Journal of Physics, 67(S1), S38-S44.

16. Dori, Y.J., Hult, E., Breslow, L., \& Belcher, J.W. (2007). How Much Have They Retained? Making Unseen Concepts Seen in a Freshman Electromagnetism Course at MIT. Journal of Science Education and Technology, 16(4), p. 299323.

17. Drane, D., Smith, H.D., Light, G., Pinto, L., \& Swarat, S. (2005). The Gateway Science Workshop Program: Enhancing Student Performance and Retention in the Sciences Through Peer-Facilitated Discussion. Journal of Science Education and Technology, 14(3), p.337-352.

18. Dufresne, R., Mestre, J., Hart, D.M., \& Rath, K.A. (2002). The effect of webbased homework on test performance in large enrollment introductory physics. Journal of Computers in Mathematics and Science Teaching, 21(3), p. 229-251.

19. Van Domelen, D., Van Heuvelen, A. (2000). American Journal of Physics, 70(7), 779-780.

20. Escalada, L.T., \& Zollman, D. (1997). An Investigation on the Effects of Using Interactive Digital Video in a Physics Classroom on Student Learning and Attitudes. Journal of Research in Science Teaching, 34(5), p. 467-489. 
21. Etkina, E., Gibbons, K., Holton, B.L., \& Horton, G.K. (1999). Lessons learned: A case study of an integrated way of teaching introductory physics to at-risk students at Rutgers University. American Journal of Physics, 67, p. 810.

22. Etkina, E., Murthy, S., \& Zou, X. (2006). Using introductory labs to engage students in experimental design. American Journal of Physics, 74, p. 979.

23. Etkina, E., Van Heuvelen, A., White-Brahmia, S., Brookes, D.T., Gentile, M., Murthy, S., Rosengrant, D., \& Warren, A. (2006). Scientific abilities and their assessment. Physical Review Special Topics Physics Education Research, 2, 020103.

24. Fencl, H., \& Scheel, K. Engaging students: an examination of the effects of teaching strategies on self-efficacy and course climate in a nonmajors physics course. Journal of College Science Teaching, 35(1), p.75.

25. Finkelstein, N., Adams, W., Keller, C., Perkins, K., Wieman, C. (2006). HighTech Tools for Teaching Physics: the Physics Education Technology Project. Journal of Online Learning and Teaching, 2(3).

26. Finkelstein, N.D., \& Pollock, S.J. (2005). Replicating and understanding successful innovations: Implementing tutorials in introductory physics. Physical Review Special Topics Physics Education Research, 1, 010101.

27. Finkelstein, N.D., Adams, W.K., Keller, C.J., Kohl, P.B., Perkins, K.K., Podolefsky, N.S., Reid, S., \& LeMaster, R. (2005). When learning about the real world is better done virtually: A study of substituting computer simulations for laboratory equipment. Physical Review Special Topics Physics Education Research, 1, 010103.

28. Gautreau, R., \& Novemsky, L. (1997). Concepts first - A small group approach to physics learning. American Journal of Physics, 65(5), p. 418-428.

29. Goldberg, F., \& Bendall, S. (1995). Making the invisible visible: A teaching/learning environment that builds on a new view of the physics learner. American Journal of Physics, 63, p. 978.

30. Gustafsson, P. (2005). Gender inclusive physics education-a distance case. European Journal of Physics, 26(5), p. 843-849.

31. Hansen, J.A., Barnett, M., MaKinster, J.G., \& Keating, T. (2004). The impact of three-dimensional computational modeling on student understanding of astronomical concepts: a quantitative analysis. International Journal of Science Education, 26(11), p. 0950-0693. 
32. Hegarty, M., Kriz, S., \& Cate, C. (2003). The Roles of Mental Animations and External Animations in Understanding Mechanical Systems. Cognition and Instruction, 21(4), p. 325-360.

33. Heller, P., Keith, R., \& Anderson, S. (1992). Teaching problem solving through cooperative grouping. Part 1: Group versus individual problem solving. American Journal of Physics, 60, p. 627.

34. Hoellwarth, C., Moelter, M.J., \& Knight, R.D. (2005). A direct comparison of conceptual learning and problem solving ability in traditional and studio style classrooms. American Journal of Physics, 73, p. 459.

35. Hulshof, C.D., \& de Jong, T. (2006). Using just-in-time information to support scientific discovery learning in a computer-based simulation. Interactive Learning Environments, 14(1), p. $79-94$.

36. Hung, W., \& Jonassen, D.H. (2006). Conceptual Understanding of Causal Reasoning in Physics. International Journal of Science Education, 28 (13), p. 0950-0693.

37. Johnson, M. (2001). Facilitating high quality student practice in introductory physics. American Journal of Physics, 69, S2.

38. Johnstone, A. H., Hogg, W. R., \& Ziane, M. (1993). A working memory model applied to physics problem solving. International Journal of Science Education, 15 (6), p. 0950-0693.

39. Kalman, C.S., Morris, S., Cottin, C., \& Gordon, R. (1999). Promoting conceptual change using collaborative groups in quantitative gateway courses. American Journal of Physics, 67, S45.

40. Kalman, C.S., Rohar, S., \& Wells, D. (2004). Enhancing conceptual change using argumentative essays. American Journal of Physics, 72, p. 715.

41. Kautz, C.H., Heron, P.R.L., Loverude, M.E., \& McDermott, L.C. (2005). Student understanding of the ideal gas law, Part I: A macroscopic perspective. American Journal of Physics, 73, p. 1055.

42. Koenig, K.M., Endorf, R.J., \& Braun, G.A. (2007). Effectiveness of different tutorial recitation teaching methods and its implications for TA training. Physical Review Special Topics Physics Education Research, 3, 010104.

43. Kohl, P.B., Rosengrant, D., \& Finkelstein, N.D. (2007). Strongly and weakly directed approaches to teaching multiple representation use in physics. Physical Review Special Topics Physics Education Research, 3, 010108. 
44. Kozhevnikov, M., \& Thornton, R. (2006). Real-Time Data Display, Spatial Visualization Ability, and Learning Force and Motion Concepts. Journal of Science Education and Technology, 15(1), p. 111-132.

45. Kozielska, M. (1996). Stimulation of students' investigative activeness in the computer-aided process of learning physics. European Journal of Physics, 17(4), p. 164-167.

46. Kung, R.L. (2005). Teaching the concepts of measurement: An example of a concept-based laboratory course. American Journal of Physics, 73, p. 771.

47.Larkin, T. L. (2005). Journal of STEM Education, 6(1-2).

48. Lasry, N., \& Aulls, M.W. (2007). The effect of multiple internal representations on context-rich instruction. American Journal of Physics, 75, p. 1030.

49. Lee, K.M., Nicoll, G., \& Brooks, D.W. (2004) A Comparison of Inquiry and Worked Example Web-Based Instruction Using Physlets. Journal of Science Education and Technology, 13(1).

50. Lenaerts, J., Wieme, W., \& Van Zele, E. (2003). Peer instruction: a case study for an introductory magnetism course. European Journal of Physics, 24(1), p. 7 14.

51. Leonard, W., Dufresne, R., \& Mestre, J. (1996). Using qualitative problemsolving strategies to highlight the role of conceptual knowledge in solving problems. American Journal of Physics, 64(12), p. 1495-1503.

52. Lorenzo, M., Crouch, C.H., \& Mazur, E. (2006). Reducing the gender gap in the physics classroom. American Journal of Physics, 74, p. 118.

53. Marr, M.J., Thomas, E.W., Benne, M.R., Thomas, A., \& Hume, R.M. (1999). Development of instructional systems for teaching an electricity and magnetism course for engineers. American Journal of Physics, 67, p. 789.

54. Mauk, H.V., \& Hingley, D. (2005). Student understanding of induced current: Using tutorials in introductory physics to teach electricity and magnetism. American Journal of Physics, 73, p. 1164.

55. Meltzer, D., Manivannan, K. (2002). Transforming the lecture-hall environment: The fully interactive physics lecture. Am. J. Phys. 70(6) 639-654.

56. Ortiz, L.G., Heron, P.R.L., \& Shaffer, P.S. (2005). Student understanding of static equilibrium: Predicting and accounting for balancing. American Journal of Physics, 73, 545. 
57. Picciarelli, V., Stella, R., Gennaro, M.D., \& Leonardis, L.D. (1990). An experimental study on the misunderstanding of velocity by university students and the effect of remedial activity based on the model of conceptual change. European Journal of Physics, 11, p. 268-274.

58. Podolefsky, N.S. \& Finkelstein, N.D. (2007). Analogical scaffolding and the learning of abstract ideas in physics: An example from electromagnetic waves. Physical Review Special Topics Physics Education Research, 3, 010109.

59. Pollock, S.J., Finkelstein, N.D., \& Kost, L.E. (2007). Reducing the gender gap in the physics classroom: How sufficient is interactive engagement? Physical Review Special Topics Physics Education Research, 3, 010107.

60. Reay, N.W., Bao, L., Li, P., Warnakulasooriya, R., \& Baugh, G. (2005). Toward the effective use of voting machines in physics lectures. American Journal of Physics, 73, p. 554.

61. Redish, E., Saul, J., \& Steinberg, R. (1997). On the effectiveness of activeengagement microcomputer-based laboratories. American Journal of Physics, 65(1), p. 45-54.

62. Redish, E.F. \& Steinberg, R.N. (1999). Physics Today, Vol. 52 Issue 1, p24.

63. Reif, F., \& Scott, L. (1998). Teaching scientific thinking skills: Students and computers coaching each other. American Journal of Physics, 67(9), p. 819-831.

64. Rosenthal, A.S., \& Henderson, C. (2006). Teaching about circuits at the introductory level: An emphasis on potential difference. American Journal of Physics, 74, p. 324.

65. Scherr, R.E., Shaffer, P.S., \& Vokos, S. (2002). The challenge of changing deeply held student beliefs about the relativity of simultaneity. American Journal of Physics, 70, p. 1238.

66. Shaffer, P.S., \& McDermott, L.C. (1992). Research as a guide for curriculum development: An example from introductory electricity, Part II: Design of instructional strategies. American Journal of Physics, 60(11), p. 1003.

67. Singh, C. (2005). Impact of peer interaction on conceptual test performance. American Journal of Physics, 73, p. 446.

68. Smith, T. I. \& Wittmann, M. C. (2007). Physical Review ST Phys. Educ. Res. 3, 020105. 
69. Sorensen, C.M., Churukian, A.D., Maleki, S., \& Zollman, D.A. (2006). The New Studio format for instruction of introductory physics. American Journal of Physics, 74, p. 1077.

70. Steinberg, R.N. (2000). Computers in teaching science: To simulate or not to simulate? American Journal of Physics, 68, S37.

71. Steinberg, R.N., Oberem, G.E., \& McDermott, L.C. (1996). Development of a computer-based tutorial on the photoelectric effect. American Journal of Physics, 64, p. 1370.

72. Thacker, B., Kim, E., Trefz, K., \& Lea, S.M. (1994). Comparing problem solving performance of physics students in inquiry-based and traditional introductory physics courses. American Journal of Physics. 62, p. 627.

73. Thornton, R., \& Sokoloff, D. (1990). Learning motion concepts using real-time microcomputer-based laboratory tools. American Journal of Physics, 58(9), p. 858-867.

74. Thornton, R., Sokoloff, D. (1996). Assessing students learning of Newton's Laws: The Force and Motion Conceptual Evaluation and the Evaluation of Active Learning Laboratory and Lecture Curricula. American Journal of Physics, 66(4), 338-352.

75. Van Heuvelen, A., Zou, X. (2000). Multiple representations of work-energy processes. American Journal of Physics, 69(2), p. 184-194.

76. Wick, D.P., \& Ramsdell, M.W. (2004). Modeling the motion of a toy train powered with a time-dependent applied voltage: Educational implementation and analysis. American Journal of Physics, 72, p. 863.

77. Wittmann, M.C., Morgan, J.T., \& Bao, L. (2005). Addressing student models of energy loss in quantum tunneling. European Journal Physics, 26(6), p. 939950.

78. Yu, F., \& Liu, Y. (2005). Potential Values of Incorporating a Multiple-Choice Question Construction in Physics Experimentation Instruction. International Journal of Science Education, 27(11), p. 0950-0693.

79. Zeilik, M., Schau, C., \& Mattern, N. (1999). Conceptual astronomy. II. Replicating conceptual gains, probing attitude changes across three semesters. American Journal of Physics, 67, p. 923.

80. Zeilik, M., Schau, C., Mattern, N., Hall, S., Teague, K.W., \& Bisard, W. (1997). Conceptual astronomy: A novel model for teaching postsecondary science courses. American Journal of Physics, 65, p. 987. 
81. Zieneddine, A., \& Abd-El-Khalick, F. (2001). Doing the right thing versus doing the right thing right: Concept mapping in a freshmen physics laboratory. European Journal of Physics, 22(5), p. 501-511.

82. Zollman, D. \& Larkin-Hein,T. (2000). Digital Video, Learning Styles, and Student Understanding of Kinematics Graphs. Journal of SMET Education, 1, 4-17.

83. Zhou,G.G., Brouwer, W., Nocente, N. \& Martin, B. Journal of Interactive Learning Research 16.1 (Spring 2005): p31(19). 


\section{Appendix C}

\section{UCI Coding Framework}

\begin{tabular}{|c|c|}
\hline Description & Codes \\
\hline \multicolumn{2}{|l|}{ Paper ID } \\
\hline Comparative or Not & $0=\mathrm{No}, 1=\mathrm{Yes}$ \\
\hline \multicolumn{2}{|l|}{ Comparative or something else } \\
\hline \multicolumn{2}{|l|}{ Study number } \\
\hline \multicolumn{2}{|l|}{ Experimental design number } \\
\hline \multicolumn{2}{|l|}{ Cognitive outcome number } \\
\hline \multicolumn{2}{|l|}{ Control group number } \\
\hline Were there systematic replications? & $1=\mathrm{Yes}, 2=\mathrm{No}$ \\
\hline $\begin{array}{l}\text { Were there modifications to the } \\
\text { treatment? }\end{array}$ & $1=\mathrm{Yes}, 2=\mathrm{No}$ \\
\hline Cognitive theory? & $0=$ No Cognitive Theory, $1=$ Cognitive Theory \\
\hline Empirical rationale? & $0=$ No Rationale, $1=$ Cited, $2=$ Discussed \\
\hline \multicolumn{2}{|l|}{ Number of pages } \\
\hline \multicolumn{2}{|l|}{ Comments } \\
\hline Primary innovation & $1=\mathrm{COT}, 2=\mathrm{CL}, 3=\mathrm{Tech}, 4=\mathrm{IBP}$ \\
\hline Additional innovations? & $1=$ Yes, $2=$ No \\
\hline Conceptually oriented tasks & $0=\mathrm{No}, 1=\mathrm{Yes}$ \\
\hline Collaborative learning & $0=\mathrm{No}, 1=\mathrm{Yes}$ \\
\hline Technology & $0=\mathrm{No}, 1=\mathrm{Yes}$ \\
\hline Inquiry based projects & $0=$ No, $1=$ Yes \\
\hline Intensity of innovation & $\begin{array}{l}1=\text { Less than or equal to one week, } 2=\text { More than } \\
\text { one week less than one semester, } 3=\text { Full semester } \\
\text { or more, } 4=\text { Not enough info }\end{array}$ \\
\hline \multicolumn{2}{|l|}{$\begin{array}{l}\text { Nothing should be here, absent from } \\
\text { access form. }\end{array}$} \\
\hline Class size & $1=$ No info, $2=$ Large $>30,3=$ Small $<30$ \\
\hline Locus of innovation & $1=$ Known, $2=$ Hard to Know \\
\hline In lecture? & $0=\mathrm{No}, 1=\mathrm{Yes}$ \\
\hline In recitation? & $0=\mathrm{No}, 1=\mathrm{Yes}$ \\
\hline In lab? & $0=\mathrm{No}, 1=\mathrm{Yes}$ \\
\hline In workshop-studio? & $0=\mathrm{No}, 1=\mathrm{Yes}$ \\
\hline With homework? & $0=$ No, $1=$ Yes \\
\hline
\end{tabular}




\begin{tabular}{|c|c|}
\hline Description & Codes \\
\hline Known instructional task & $1=$ Yes, $2=$ No \\
\hline Which instructional task & $\begin{array}{l}1=\text { Peer Instruction, } 2=\mathrm{ILD}, 3=\mathrm{JiTT}, 4= \\
\text { Overview Case Study, } 5=\text { Tutorials, } 6=\mathrm{ABP} \\
\text { Tutorials, } 7=\mathrm{CGPS}, 8=\text { Real Time Physics, } 9= \\
\text { Socratic Dialogue, } 10=\text { Problem Based Learning, } \\
11=\text { Simulation, } 12=\text { Other }\end{array}$ \\
\hline Describe known instruction task & $0=$ No, $1=$ Yes \\
\hline Problem Solving & $0=$ No, $1=$ Yes \\
\hline Inventory & $0=$ No, $1=$ Yes \\
\hline Concept-Maps & $0=$ No, $1=$ Yes \\
\hline POE & $0=\mathrm{No}, 1=\mathrm{Yes}$ \\
\hline Other & $0=$ No, $1=$ Yes \\
\hline \multicolumn{2}{|l|}{ Other describe } \\
\hline Problem Solving - Task verified & $1=$ No info, $2=$ Task known, $3=$ Example provided \\
\hline $\begin{array}{l}\text { Problem Solving - Based on student } \\
\text { misconceptions }\end{array}$ & $1=$ Yes, $2=$ No \\
\hline Concept Maps - Task Verified & $1=$ No info, $2=$ Example provided \\
\hline Concept Maps - Nature of & $\begin{array}{l}1=\text { Students construct from scratch, } 2=\text { Students } \\
\text { given concepts and/or linking words, } 3=\text { Maps are } \\
\text { discussed }\end{array}$ \\
\hline Inventory - task verified & $1=$ No info, $2=$ Task known, $3=$ Example provided \\
\hline $\begin{array}{l}\text { Inventory - Based on student } \\
\text { misconceptions }\end{array}$ & $0=\mathrm{No}, 1=\mathrm{Yes}$ \\
\hline $\begin{array}{l}\text { Inventory - Based on qualitative vs. } \\
\text { quantitative }\end{array}$ & $0=$ No, $1=$ Yes \\
\hline POE - Task verified & $1=$ No info, $2=$ Task known, $3=$ Example provided \\
\hline POE - Task conceptually rich & $1=$ Yes, $2=$ No \\
\hline Instructional process & $1=$ No information, $2=$ Information \\
\hline $\begin{array}{l}\text { Students discuss and/or make } \\
\text { conceptions explicit }\end{array}$ & $0=$ No, $1=$ Yes \\
\hline Students react & $0=$ No, $1=$ Yes \\
\hline Students revise & $0=$ No, $1=$ Yes \\
\hline Ways of grouping & $\begin{array}{l}1=\text { Not explained, } 2=\text { Gender, } 3=\text { Ability, } 4= \\
\text { Interest, } 6=\text { Random, } 8=\text { Combination }\end{array}$ \\
\hline
\end{tabular}




\begin{tabular}{|c|c|}
\hline Description & Codes \\
\hline How to group & $1=$ No info, $2=$ Student, $3=$ Teacher \\
\hline Group Stability & $\begin{array}{l}1=\text { No info, } 2=\text { Group changes, } 3=\text { Group stays the } \\
\text { same }\end{array}$ \\
\hline Group roles & $\begin{array}{l}1=\text { No info, } 2=\text { General info, } 3=\text { Roles mentioned, } \\
4=\text { Roles explained }\end{array}$ \\
\hline Rotation of roles within group & $0=$ No, $1=$ Yes \\
\hline $\begin{array}{l}\text { Evidence that students were aware of } \\
\text { group roles }\end{array}$ & $0=\mathrm{No}, 1=\mathrm{Yes}$ \\
\hline Group work monitored & $0=$ No, $1=$ Yes \\
\hline Group product & $1=$ None, $2=$ Individual, $3=$ Group, $4=$ Both \\
\hline Group accountability & $1=$ Not Specific, $2=$ Formal, $3=$ Informal, $4=$ Both \\
\hline Simulation & $0=\mathrm{No}, 1=\mathrm{Yes}$ \\
\hline Visualization & $0=\mathrm{No}, 1=\mathrm{Yes}$ \\
\hline Solve Problems & $0=\mathrm{No}, 1=\mathrm{Yes}$ \\
\hline Teacher uses to collect data & $0=\mathrm{No}, 1=\mathrm{Yes}$ \\
\hline Student uses to collect data & $0=$ No, $1=$ Yes \\
\hline No info & $0=\mathrm{No}, 1=\mathrm{Yes}$ \\
\hline Allows opportunity for feedback & $0=$ No, $1=$ Yes \\
\hline Feedback from program & $0=\mathrm{No}, 1=\mathrm{Yes}$ \\
\hline Feedback from instructor & $0=\mathrm{No}, 1=\mathrm{Yes}$ \\
\hline Feedback from others & $0=$ No, $1=$ Yes \\
\hline General info about IBP & $\begin{array}{l}1=\text { Independent, } 2=\text { Oriented around a goal, } 3= \\
\text { Developed over time }\end{array}$ \\
\hline Problem to be solved & $\begin{array}{l}1=\text { Provided, } 2=\text { Question guided, } 3=\text { Student } \\
\text { developed }\end{array}$ \\
\hline Procedure & $1=$ Provided, $2=$ Suggested, $3=$ Selected \\
\hline Follow a recipe type & $0=\mathrm{No}, 1=\mathrm{Yes}$ \\
\hline Analysis of data & $1=$ Provided, $2=$ Suggested, $3=$ Selected \\
\hline $\begin{array}{l}\text { Was evidence collected for assessment } \\
\text { purposes }\end{array}$ & $0=\mathrm{No}, 1=\mathrm{Yes}$ \\
\hline What type of assessment & $\begin{array}{l}1=\text { Grading, } 4=\text { Inform instruction, } 5=\text { Feedback, } \\
6=\text { Both }\end{array}$ \\
\hline Evidence of adjusted instruction & $0=\mathrm{No}, 1=\mathrm{Yes}$ \\
\hline Instruction adjusted how & $1=$ At least once, 2 = Continually \\
\hline What is the experimental design? & $\begin{array}{l}1=\text { Randomized Controlled Experiment, } 2=\text { Quasi- } \\
\text { Experiment }\end{array}$ \\
\hline
\end{tabular}




\begin{tabular}{|c|c|}
\hline Description & Codes \\
\hline How was the study design implemented? & $\begin{array}{l}1=\text { Post test only two groups, } 2=\text { Post test only } \\
\text { more than two groups, } 3=\text { Pre post test single } \\
\text { group, } 4=\text { Pre post test two groups, } 5=\text { Pre post } \\
\text { test more than two groups, } 6=\text { Multiple time points } \\
\text { single group, } 7=\text { Multiple time points two groups, } 8 \\
=\text { Multiple time points more than two groups }\end{array}$ \\
\hline \multicolumn{2}{|l|}{ Other implementation, enter } \\
\hline \multicolumn{2}{|l|}{ How were the students sampled? } \\
\hline \multicolumn{2}{|l|}{$\begin{array}{l}\text { Which type of probability sampling was } \\
\text { done? }\end{array}$} \\
\hline \multicolumn{2}{|l|}{ Other, enter } \\
\hline \multicolumn{2}{|l|}{$\begin{array}{l}\text { How were the units assigned to } \\
\text { treatment and control? }\end{array}$} \\
\hline \multicolumn{2}{|l|}{$\begin{array}{l}\text { What is the mechanism by which } \\
\text { assignment was done? }\end{array}$} \\
\hline Are the outcome items open-ended? & $0=$ No, $1=$ Yes \\
\hline Are the outcome items multiple choice? & $0=$ No, $1=$ Yes \\
\hline Are the outcome items short answer? & $0=\mathrm{No}, 1=\mathrm{Yes}$ \\
\hline $\begin{array}{l}\text { Are the outcome items performance } \\
\text { tasks? }\end{array}$ & $0=$ No, $1=$ Yes \\
\hline $\begin{array}{l}\text { Are the outcome items responses to an } \\
\text { interview protocol? }\end{array}$ & $0=$ No, $1=$ Yes \\
\hline $\begin{array}{l}\text { Are the outcome items from an } \\
\text { observation protocol? }\end{array}$ & $0=\mathrm{No}, 1=\mathrm{Yes}$ \\
\hline No information on item format & $0=\mathrm{No}, 1=\mathrm{Yes}$ \\
\hline How is the outcome developed? & $1=$ No information, $2=$ Externally, $3=$ Internally \\
\hline \multicolumn{2}{|l|}{$\begin{array}{l}\text { Description of internally developed } \\
\text { outcome }\end{array}$} \\
\hline $\begin{array}{l}\text { Which externally developed outcome } \\
\text { measure is used? }\end{array}$ & $\begin{array}{l}1=\text { FCI, } 2=\text { FMCE, } 3=\text { BEMA, } 4=\text { Lawson Test, } 5 \\
=\text { Mechanics Diagnostic Test, } 6=\text { Mechanics } \\
\text { Baseline Test, } 7=\text { Other }\end{array}$ \\
\hline $\begin{array}{l}\text { Is the outcome measure inconsistent with } \\
\text { the learning objectives? }\end{array}$ & $0=\mathrm{No}, 1=\mathrm{Yes}$ \\
\hline Are the outcome items made available? & $1=$ No, $2=$ All items, $3=$ One or more \\
\hline Reliability of outcome measure & $\begin{array}{l}1=\text { No info, } 2=\text { Information provided but } \\
\text { misunderstanding of concept, } 3=\text { Cronbachs alpha } \\
\text { based on previous, } 4=\text { Cronbachs alpha based on } \\
\text { current, } 5=\text { Estimate of inter-rater agreement, } 6= \\
\text { Estimate of inter-rater reliability }\end{array}$ \\
\hline Evidence of construct validity & $1=$ No info provided, $2=$ Info provided \\
\hline Evidence based on test content & $0=\mathrm{No}, 1=\mathrm{Yes}$ \\
\hline Evidence based on internal structure & $0=\mathrm{No}, 1=\mathrm{Yes}$ \\
\hline
\end{tabular}




\begin{tabular}{|c|c|}
\hline Description & Codes \\
\hline Evidence based on response process & $0=\mathrm{No}, 1=\mathrm{Yes}$ \\
\hline Evidence based on test consequences & $0=\mathrm{No}, 1=\mathrm{Yes}$ \\
\hline Contemporary or historical control? & $\begin{array}{l}1=\text { Contemporaneous, } 2=\text { Historical, } 3=\text { Not } \\
\text { enough info to tell }\end{array}$ \\
\hline $\begin{array}{l}\text { Instruction defined by absence of } \\
\text { innovation }\end{array}$ & $0=\mathrm{No}, 1=\mathrm{Yes}$ \\
\hline Traditional instruction & $0=\mathrm{No}, 1=\mathrm{Yes}$ \\
\hline Other control group & $0=\mathrm{No}, 1=\mathrm{Yes}$ \\
\hline \multicolumn{2}{|l|}{$\begin{array}{l}\text { Description of what happened in control } \\
\text { group }\end{array}$} \\
\hline Methods used to estimate effects & $\begin{array}{l}1=\text { Comparison of means, } 2=\text { Comparison of } \\
\text { normalized gains, } 3=\text { ANCOVA, } 4=\text { Logistic } \\
\text { Regression, } 5=\text { Other }\end{array}$ \\
\hline \multicolumn{2}{|l|}{ Treatment mean } \\
\hline \multicolumn{2}{|l|}{ Control mean } \\
\hline \multicolumn{2}{|l|}{ Treatment sample size } \\
\hline \multicolumn{2}{|l|}{ Control sample size } \\
\hline \multicolumn{2}{|l|}{ Treatment mean (numerical form) } \\
\hline \multicolumn{2}{|l|}{ Control mean (numerical form) } \\
\hline \multicolumn{2}{|l|}{ Treatment size (numerical form) } \\
\hline \multicolumn{2}{|l|}{ Control size (numerical form) } \\
\hline $\begin{array}{l}\text { Has the data been pooled for either } \\
\text { treatment or control? }\end{array}$ & $0=$ No, $1=$ Yes \\
\hline Are SDs available? & $1=$ Yes, $2=$ No \\
\hline Pooled SD & $0=$ No, $1=$ Yes \\
\hline \multicolumn{2}{|l|}{ Value of pooled SD } \\
\hline Control SD & $0=$ No, $1=$ Yes \\
\hline \multicolumn{2}{|l|}{ Value of control SD } \\
\hline Treatment SD & $0=$ No, $1=$ Yes \\
\hline \multicolumn{2}{|l|}{ Value of Treatment SD } \\
\hline Can an effect size be estimated? & $1=\mathrm{Yes}, 2=\mathrm{No}$ \\
\hline \multicolumn{2}{|l|}{ What is the effect size? } \\
\hline \multicolumn{2}{|l|}{ How was the effect size estimated? } \\
\hline \multicolumn{2}{|l|}{ Effect (for normalized gain) } \\
\hline $\begin{array}{l}\text { Was a test of statistical significance } \\
\text { conducted? }\end{array}$ & $1=\mathrm{Yes}, 2=\mathrm{No}$ \\
\hline Is a p-value reported? & $1=$ Yes, $2=$ No \\
\hline \multicolumn{2}{|l|}{ p-value } \\
\hline \multicolumn{2}{|l|}{ How was p-value estimated? } \\
\hline $\begin{array}{l}\text { Is there evidence to suggest that effect } \\
\text { not practically significant }\end{array}$ & $1=$ Yes, $2=$ No \\
\hline
\end{tabular}




\begin{tabular}{|c|c|}
\hline Description & Codes \\
\hline \multicolumn{2}{|l|}{$\begin{array}{l}\text { Description of how effect was not } \\
\text { practically significant }\end{array}$} \\
\hline $\begin{array}{l}\text { Internal validity - Ambiguous temporal } \\
\text { precedence }\end{array}$ & $0=\mathrm{No}, 1=\mathrm{Yes}$ \\
\hline Internal validity - Attrition & $0=\mathrm{No}, 1=\mathrm{Yes}$ \\
\hline Internal validity - Selection & $0=\mathrm{No}, 1=\mathrm{Yes}$ \\
\hline Internal validity - History & $0=$ No, $1=$ Yes \\
\hline Internal validity - Maturation & $0=\mathrm{No}, 1=\mathrm{Yes}$ \\
\hline Internal validity - Regression & $0=\mathrm{No}, 1=\mathrm{Yes}$ \\
\hline Internal validity - Testing & $0=\mathrm{No}, 1=\mathrm{Yes}$ \\
\hline Internal validity - Instrumentation & $0=\mathrm{No}, 1=\mathrm{Yes}$ \\
\hline $\begin{array}{l}\text { Internal validity - Additive or interactive } \\
\text { effects }\end{array}$ & $0=\mathrm{No}, 1=\mathrm{Yes}$ \\
\hline \multicolumn{2}{|l|}{ Internal validity - Comments } \\
\hline $\begin{array}{l}\text { Statistical conclusion validity - low } \\
\text { statistical power }\end{array}$ & $0=\mathrm{No}, 1=\mathrm{Yes}$ \\
\hline $\begin{array}{l}\text { Statistical conclusion validity - violated } \\
\text { assumptions }\end{array}$ & $0=\mathrm{No}, 1=\mathrm{Yes}$ \\
\hline $\begin{array}{l}\text { Statistical conclusion validity - fishing for } \\
\text { statistical significance }\end{array}$ & $0=\mathrm{No}, 1=\mathrm{Yes}$ \\
\hline $\begin{array}{l}\text { Statistical conclusion validity - } \\
\text { unreliability of measures }\end{array}$ & $0=\mathrm{No}, 1=\mathrm{Yes}$ \\
\hline $\begin{array}{l}\text { Statistical conclusion validity - } \\
\text { restriction of range }\end{array}$ & $0=\mathrm{No}, 1=\mathrm{Yes}$ \\
\hline \multicolumn{2}{|l|}{$\begin{array}{l}\text { Statistical conclusion validity - } \\
\text { Comments }\end{array}$} \\
\hline $\begin{array}{l}\text { Construct validity - Inadequate } \\
\text { explication }\end{array}$ & $0=\mathrm{No}, 1=\mathrm{Yes}$ \\
\hline $\begin{array}{l}\text { Construct validity - Theoretical definition } \\
\text { differs }\end{array}$ & $0=\mathrm{No}, 1=\mathrm{Yes}$ \\
\hline Construct validity - Hawthorne effect & $0=$ No, $1=$ Yes \\
\hline $\begin{array}{l}\text { Construct validity - Experimenter } \\
\text { expectancies }\end{array}$ & $0=\mathrm{No}, 1=\mathrm{Yes}$ \\
\hline $\begin{array}{l}\text { Construct validity - Compensatory } \\
\text { equalization }\end{array}$ & $0=\mathrm{No}, 1=\mathrm{Yes}$ \\
\hline $\begin{array}{l}\text { Construct validity - Compensatory } \\
\text { rivalry }\end{array}$ & $0=\mathrm{No}, 1=\mathrm{Yes}$ \\
\hline $\begin{array}{l}\text { Construct validity - Resentful } \\
\text { demoralization }\end{array}$ & $0=$ No, $1=$ Yes \\
\hline Construct validity - Treatment crossover & $0=$ No, $1=$ Yes \\
\hline Construct validity - Instructor effect & $0=$ No, $1=$ Yes \\
\hline \multicolumn{2}{|l|}{ Construct validity - Comments } \\
\hline \multicolumn{2}{|l|}{ Comments for paper } \\
\hline \multicolumn{2}{|l|}{ Exemplary paper } \\
\hline \multicolumn{2}{|l|}{ Poor paper } \\
\hline Coder & \\
\hline
\end{tabular}




\section{Appendix D}

\section{Interview Protocol}

Introductory statement:

I'm Heidi Iverson; I'm a graduate student at the University of Colorado Boulder. I'm working on my dissertation research project which is part of a larger project called Undergraduate course Innovations and their Impact on Student Learning. This project is overseen by Ayita Ruiz-Primo, Derek Briggs, and Lorrie Shepard. As part of my research I'm interested in understanding as much as possible about a select group of successful undergraduate course innovations. Our work on the subject to date has shown that the innovation you have developed/implemented, , is one which appears to have a strong positive effect on student learning, and one which I am particularly interested in understanding better. My goal is not only to understand the innovation itself, but also to understand better your motivation for developing/implementing the innovation, as well as the reasons why this innovation is effective. I am still developing my ideas and my hope is that my conversation with you today will help be learn more about (innovation) and why it is so successful. I hope to relay the results of this research back to the PER community in order to inform the implementation of innovations so that they are as beneficial as possible for students. In addition, I hope that these results may inform the development of future innovations. Do you have any questions so far about my purpose for this interview or anything else? Please don't hesitate to stop and ask me to clarify any questions.

1. Please describe for me the (innovation).

a. Tell me a little more about how it was developed.

b. Please describe your motivation for developing this innovation.

c. What were some of the key theories, principles, or empirical studies that you relied upon in developing this innovation?

2. What is it about this innovation that sets it apart from other undergraduate course innovations?

3. Of all of the components of this innovation, what is it that you think has the biggest effect on student learning? 
a. What are the key components that make this innovation successful?

b. Please tell me more about why you feel that these components are the most effective for students.

4. What (if any) additional instructors/teaching assistants have implemented this innovation (may or may not need this question)? Please describe how these instructors/teaching assistants have been trained.

a. How do you go about checking to be sure that the training and/or implementations of the innovation are done as you intended?

b. What do you think are the keys to the effective, and consistent, implementation of this innovation?

5. Please describe any curricular materials which supplement this innovation?

a. What are the most effective features of this curriculum in facilitating student learning?

6. We're reaching the end of the interview but lastly I would like to read back to you a description of the innovation from (a citation other than their own if possible). What, if anything, do you feel like is missing from this description?

7. Do you have anything else you would like to add? 


\section{Appendix E}

\section{Coding Example}

\section{Example Interview Notes:}

Priscilla Laws

0004 - students need to be actively engaged in learning, activities which are structured and sequenced when you take into account students' prior ideas. You need space and equipment and instructors that understanding the activities.

0111 - computers are an enabling factor but the innovating can be done without them, computers were the catalyst for the studio model. For example the idea of sensors and microcomputers.

0540 - first ideas was that the entire class should be taught in the laboratory with the technology that was coming up. Used Thornton and McDermott's activities and influenced the design of workshop studio physics. She believes the activities in WP came from a strong research base. For example in simple circuits.

1211 - experiments should be carefully set up and simple (but by that she means that there is not a lot of error with the materials). Students do not always carefully make sure that the measurements are working properly. Therefore some students in doing an experiment with N's $3^{\text {rd }}$ law, because the sensors were not working properly and therefore they would still firmly believe that the force was different. Which is why she believes that an ILD may be more effective because you can control conditions. Also at times when you do an ILD and then ask the students to replicate the experiment to be sure that it's all working correctly.

1700 - ask priscilla laws about whether an activity benefits student learning because it is rooted in their experience.

1825 - start with the sim (or the idealized situation) and then move to the actual experience.

1916 - we don't believe in a lecture, but do believe in the ILD, prefer to have nature rather than instructor is the expert. We don't tell them what they should be seeing.

"the instructor is the authority not nature"

Change counting down

2955- students make predictions, example of the steel ball vs. the clay ball. Use elicit confront resolve.

2300/2900 (counting up) - Jack Wilson first heard about it they were most interested in the use of computers. When an institution hears of an idea they take credit and call it something new if they perceive their status to be more than the others. Sociological phenomena "If an institution adopts an innovation that was developed at another institution, they give the other institution credit if they feel [that] they're lower status. If they feel that they are higher status they give it their own name and don't credit the originators. But to her that is just as well...because they are not always successful. 


\section{Example Paper Coding from Laws (1991):}

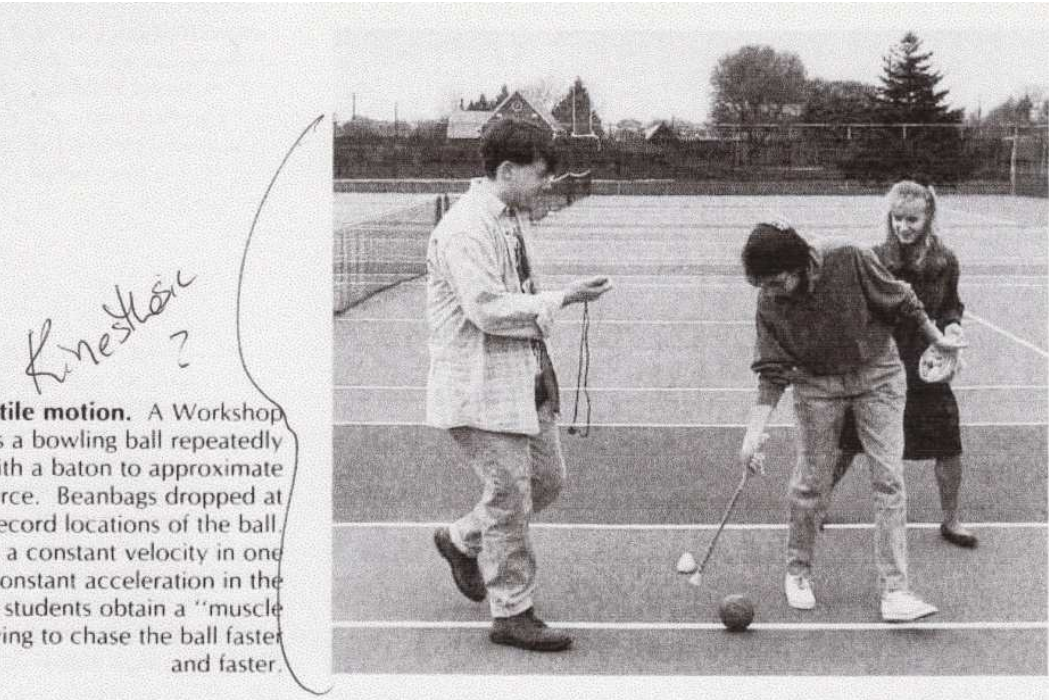

University of Oregon

The implicit goals in most traditional introductory physics courses center around teaching students to solve textbook problems. In developing Workshop Physics we assumed that acquiring transferable skills of scientific inquiry is a more important goal than either problem solving or the comprehensive transmission of descriptive knowledge about the enterprise of physics. Arnold Arons refers to this aim as the "development of enough? knowledge in an area of science to allow intelligent study and observation to lead to subsequent learning without formal instruction."

There were two major reasons for emphasizing transferable inquiry skills based on real experience. Pirst, the majority of students enrolled in introductory physics at both the high school and college level do not have sufficient concrete experience/ with/everyday phenomenal to comprehend the mathematical representations of them traditionally presented in these courses. The processes of observing phenomena, analyzing data and developing verbal and mathematical models to explain observations afford students an opportunity to relate concrete experience to scientific explanation The second reason for focusing on the development of transferable skills is that when one is confronted with the task of acquiring an overwhelming body of knowledge, the only viable strategy is to learn some things thoroughly while acquiring methods for independently investigating other things) as peeded. This approach follows the adage "Less is more."

We incorporated three new elements into our planning: We took findings from science education research into account; we designed and adapted integrated computer tools for the introductory classroom; and we developed devices that allow students to experience motions and forces with their own bodies (kinesthesic apparatus).

We used several criteria in choosing topies to be covered in the Workshop Physics courses. To help students prepare for further study in physics and engineering, we decided to select topics normally covered in the introductory course sequence. Most of these topics involve phenomena that are amenable to direct observation, and the mathematical and reasoning skills needed to analyze observations and experiments in these topics are applicable to many other areas of inquiry. We did not add topics, such as relativity and quantum mechanics, that require levels of abstract reasoning we believe to be

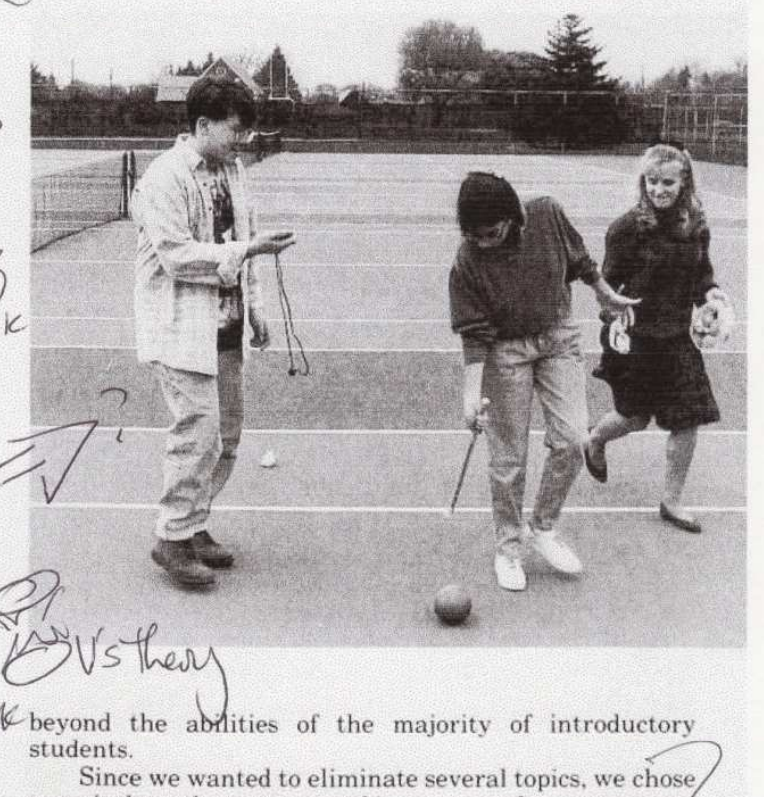
to omit those that are covered in our second-year program. such as waves, ac circuits, and geometric and physical optics. We did develop two new units on contemporary topics for the introductory program, one on chaos and the other on radon monitoring. Thus we found ourselves eliminating about $25 \%$ of the material we used to cover in our traditional introductory calculus-based physics sequence. There is nothing sacrosanct about our choices. Indeed, several other institutions that have adopted our program have chosen to delete different material, opting for a sequence of topics tailored to the particular needs of their students and the special interests of their faculties.

To allow students the time to make observations, do experiments and discuss their findings, we decided to efiminate formal lectures and teach the courses-in - a classroom-laboratory environment outfitted with computers and scientific apparatus. Although lectures and demenstions are useful alternatives to reading for

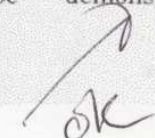


Example Memo:

Summary for ID 60 - Beichner et al. (1999) "It's all integrated or Everything but the kitchen sink"

\section{Summary Memo}

Their stated goals were to limit attrition while improving student understanding and attitudes towards the subject. They sought to address the historical issue of student underperformance by combining many different research-based instructional innovations within the classroom. Their goal was also to learn more about the nature of the student-to-student and student-to-teacher interactions in order to determine the aspects of "classroom layout and usage" contributed to the success of these innovations (p. S16). The courses were all taught in a single room (with the exception of the chemistry $\mathrm{lab}$ ) and students were assigned to three person teams for which they worked on homework and lab assignments. These groups were designed to be as heterogeneous as possible with respect to GPA, academic background, race, and gender and they were kept throughout the length of the course. Each member of the group was explicitly taught about the three rotating within the group: recorded, checker, and coordinator. In addition, course grades were "devised to ensure both individual accountability and positive interdependence" (p. S16). The classroom included seating such as benches and round tables for the purpose of facilitating group work. The need for lecturing was minimized through the use of activities that "keep students interested" (p. S16). These activities involved tasks in which students make predictions, develop some model of physical phenomena, collect and analyze data using technology, and work on design projects. Outside of class students were responsible for homework assignments, readings, and preparing questions to discuss in class when they arose. Students took quizzes about the selected reading material and were often assigned end-of-chapter problems for homework. The number of hours for the combined course was equivalent to the total sum number of hours for the regular courses. Specific classes included a workshop of differential equations, "jigsaw" projects, and semesterlong design projects, metacognitive activities including personal learning styles inventory, workshops on how to work in teams, effective ways to communicate orally and in written work, and time management (however the last three were only within the engineering course). Computers were provided for students and included MBL equipment. The activities included were adapted from existing curricula including workshop physics, physics by inquiry, concept tests, and alps worksheets. Students frequently modeled physical phenomena with "Interactive Physics". Instructors circulated within the classroom and employed Socratic dialogs. Students had access to the Web and accessing information related to the material became a constant practice. The authors give two examples of how activities played out in the classroom. In these activities students made predictions and designed their own experiments and verified their results using a computer simulation. Different "types" ( $p$. S19-S20) were employed in the classroom along with more extensive "wait times", both of which tended to facilitate student engagement. Round tables were found to be better suited for group work than the long rectangular tables, with larger size tables preferred over smaller ones. The ration of 2 computers for 3 people wasn't good (students would not use one or would look over the shoulders of the two that did). Student satisfaction was very high with the course. The student-to-student social interactions seemed to be a positive result for the students. Computer related tasks semed to keep students on task. These classes were composed of 30-35 students but in similar work they are working on employing these same techniques to a large-enrollment $(n=100)$ courses (SCALEUP). 